\title{
FINAL REPORT - High-Order Homogenization Method in Diffusion Theory for Reactor Core Simulation and Design Calculation
}

\author{
DOE Contract \# DE-FG0-001D13960; B\&R Code AF40
}

\author{
Principal Investigator: Farzad Rahnema, Georgia Institute of Technology
}

Report Period: July 1, 2000 - June 30, 2003

\begin{abstract}
Summary
Most modern nodal methods in use by the reactor vendors and utilities are based on the generalized equivalence theory (GET) that uses homogenized cross sections and flux discontinuity factors. These homogenized parameters, referred to as infinite medium parameters, are precomputed by performing single bundle fine-mesh calculations with zero current boundary conditions. It is known that for configurations in which the nodeto-node leakage (e.g., surface current-to-flux ratio) is large the use of the infinite medium parameters could lead to large errors in the nodal solution. This would be the case for highly heterogeneous core configurations, typical of modern reactor core designs.
\end{abstract}

The main objective of this project was to develop a new high-order cross section homogenization method based on the boundary condition perturbation theory to improve the accuracy of nodal diffusion methods within the context of the GET. The new homogenization method corrects the homogenized parameters and discontinuity factors for the effect of the core environment (node-to-node leakage), to an arbitrary order of accuracy, by expanding them in terms of the node surface current-to-flux ratios. The method utilizes two adjoint functions to determine the expansion coefficients. Since these adjoint functions are solutions to the infinite medium problem (zero current-to-flux ratio), the expansion coefficients can be precomputed and included with the standard homogenization parameters for use by a nodal code. As a result, the nodal method has the capability of achieving an arbitrarily accurate solution by efficiently updating (correcting) the homogenized parameters, including the discontinuity factor, as it computes the node interface current-to-flux ratio. The level of accuracy for the highorder corrected reactor flux solution is close to that of the fine-mesh calculation, which would be computationally expensive and impractical to determine directly at the core level.

The numerical implementation of the homogenization method required the development of a fine-mesh lattice code capable of providing, along with the standard homogenized parameters, the two adjoint functions (the adjoint flux and an adjoint Green's function) as additional homogenization parameters. When going from one-group to multigroup, the forms of the equations to be solved and of the expressions to be evaluated become more complex, due to energy coupling between groups. The method was first tested and implemented for simple problems (one-group, 1-D geometry). The work was then extended to more complex (two-group 1-D and then 2-D geometry) problems. The main 
difficulty requiring a substantial effort was the numerical implementation of the solution method for precomputing the Green's function. A fine-mesh lattice code with the capability mentioned above was developed for each of the three sets of problems: onespeed 1-D, two-group 1-D and two-group 2-D.

In this project, it was shown that the perturbation expansion series for the homogenized cross sections and discontinuity factors converge in a multigroup case. This is new in that it has not been shown before in the literature. The benchmark configurations consisted of two types of BWR assemblies in slab geometry for the one-dimensional case and different types of assemblies in the HAFAS core for the two-dimensional case. The benchmark configurations were analyzed for various magnitudes of the perturbation in the boundary condition. It was shown that the perturbation method achieves an excellent accuracy: the reference homogenized cross sections and discontinuity factors are almost exactly reproduced.

The new homogenization method was numerically implemented at the nodal level, in the context of the GET, for one-speed 1-D, as well as for two-group 1-D configurations. For each of these two types of configurations, a finite-difference coarse-mesh code with a bilinear intra-nodal flux shape was developed. As compared to a standard nodal code for solving the nodal diffusion equations, which has two levels of calculation (source iteration and flux iteration), this code has an additional level (iteration) in which the the homogenized parameters are corrected. Nodal equations were developed for implementing the homogenization method at the nodal level for two-group 2-D problems, and their numerical implementation is in progress. The code for solving the nodal equations in this case is based on a transverse integrated method with a nodal expansion used for solving the transverse-integrated equations. The associated system of equations is solved by employing a non-linear iterative strategy. For the 2-D case some difficulty might arise in determining a surface-dependent boundary condition (current-to-flux ratio) from node-averaged quantities. Note that the Green's function is not constant at the node interface. As a first approximation, the expansion parameter in the 2-D case would be taken as an average over the node surface, which is consistent with the GET assumption.

The testing of the new homogenization method at the nodal level (for one- and two-group one-dimensional problems) was performed on five benchmark configurations typical of a BWR, from mildly to highly heterogeneous. Three of these five benchmarks, in which each assembly is of the GE-9 bundle design, were newly developed because of the need for more realistic benchmark configurations. It is anticipated that the technical community in reactor physics and math and computations will benefit from the new benchmarks developed in this study. It was shown that the homogenization method provides excellent results. For all of the analyzed configurations, the node-integrated flux is within $1.2 \%$ of the assembly reference (fine-mesh) flux in all nodes for each group. There is a significant improvement from the zeroth order case (standard GET), in which the node-averaged flux has a large error (e.g., up to $8 \%$ in group 1 and up to $14 \%$ in group 2 for some of the analyzed configurations). It was also shown that the reconstructed fine-mesh flux (or equivalently the power distribution) in the core approximates the reference value very well. The reference flux distribution is almost 
reproduced by the third order correction.

The funding of this project enabled Georgia Tech to maintain a productive research program in an area with substantial experience. It also helped Georgia Tech to attract and educate talented students in reactor physics, a fundamental area in nuclear engineering. The investigations for this project provided research topics for two Ph.D. theses. A third Ph.D. student, Scott Mosher, was also partially supported on this project. Journal publications and ANS Transactions papers resulted from the research performed for this project. The titles are shown below:

1. M.S. McKinley, "Higher-Order Boundary Condition Perturbation Methods in Transport and Diffusion Theory", Ph.D. Thesis (2001)

2. G. Ilas, "A Monte Carlo based Nodal Diffusion Model for Criticality Analysis and Application of High-Order Homogenization Method to Two-Group Nodal Diffusion", Ph.D. Thesis (2002)

3. M.S. McKinley and F. Rahnema, "High-Order Boundary Condition Perturbation Theory for the Diffusion Approximation," Nuclear Science and Engineering, 135, 15$33(2000)$.

4. M.S. McKinley and F. Rahnema, "High-Order Cross Section Homogenization Method," Annals of Nuclear Energy, 29, 875-899 (2002).

5. M.S. McKinley and F. Rahnema, "High-Order Boundary Condition Perturbation Theory for the Neutron Transport Equation," Nuclear Science and Engineering, 140, 285-204 (2002).

6. M.S. McKinley and F. Rahnema, "Complete First-Order Boundary Condition Theory for the Neutron Transport Equation," Proceedings of ANS International Meeting on Mathematical Methods for Nuclear Applications, September 2001, Salt Lake City, Utah, USA (2001).

7. F. Rahnema and M.S. McKinley, "Coarse-Mesh Nodal Methods Corrected by Boundary Condition Perturbation Theory", ANS Transactions, 84, 93 (June 2001).

8. G. Ilas and F. Rahnema, "Application of High-Order Boundary Condition Perturbation Theory to Two-Group Diffusion Problems", ANS Transactions, 86, p.200 (2002)

9. G. Ilas and F. Rahnema, F., "Application of the High Order Cross-Section Homogenization Method to BWR Core Analysis", ANS Transactions, Accepted (June 2003)

10. G. Ilas and F. Rahnema, "Numerical Implementation of High-Order Cross Section Rehomogenization," to be submitted to Nuclear Science and Engineering 
September 30, 2003

\title{
High-Order Homogenization Method in Diffusion Theory for \\ Reactor Core Simulation and Design Calculation
}

\author{
FINAL REPORT
}

PERIOD OF PERFORMANCE: JULY 1, 2000 - JUNE 30, 2003

DOE Contract \# DE-FG0-001D13960; B\&R Code AF40

Farzad Rahnema, PI

Germina Ilas

Georgia Institute of Technology

Nuclear and Radiological Engineering Program

George W. Woodruff School of Mechanical Engineering

Atlanta, GA 30332-0405 USA 


\section{Table of contents}

List of tables $\quad$ iii

List of figures $\quad \mathrm{V}$

I. Introduction 1

II. Method 2

2.1. Basic equations 2

2.2. Method for the Green's function in two-group 5

2.3. High-order correction of the homogenized parameters 10

$\begin{array}{ll}\text { 2.3.1. One-dimensional configurations } & 10\end{array}$

2.3.1. Two-dimensional configurations 13

III. Description of the benchmark configurations 17

3.1. One-dimensional configurations 17

3.1.1. Development of new benchmarks 21

3.1. Two-dimensional configurations 31

IV. Results 33

4.1. Convergence of the expansion series in the multigroup case 33

4.1.1. One-group one-dimensional problems 33

4.1.2. Two-group one-dimensional problems 36

Results for assembly \#1 36

Results for assembly \#3 44

4.1.3. Two-group two-dimensional problems 49

4.2. Implementation of the high-order cross section homogenization to nodal diffusion $\quad 57$

Results for configurations 1 and $2 \quad 57$

Results for the newly developed benchmark configurations (A, B and C) 67

V. Summary and conclusion $\quad 80$

$\begin{array}{ll}\text { References } & 82\end{array}$

Appendix A. Discretization of the equations for the Green's function 83

Appendix B. Nodal equations for 1-D 86 


\section{List of tables}

3-1 Material properties for assemblies in configurations 1 and 2 (one-group) 17

3-2 Material properties for assemblies in configurations 1 and 2 (two-group) 17

3-3 $\mathrm{K}_{\propto}$ for assemblies in configurations 1 and 2 (two-group) 18

3-4 $\mathrm{K}_{\propto}$ for assemblies in cores A, B and C 23

3-5 Cross section data for assembly $1 \quad 24$

3-6 Cross section data for assembly 2

3-7 Cross section data for assembly $3 \quad 25$

3-8 Cross section data for assembly $4 \quad 25$

3-9 Cross section data for assembly 5

3-10 Cross section data for assembly 6

3-11 Material map for HAFAS assemblies 31

3-12 Material properties for HAFAS core 32

4-1 Flux and eigenvalue results for assembly \#1 34

4-2 Homogenized cross sections for assembly \#1 34

4-3 Flux and eigenvalue results for assembly \#3 35

4-4 Homogenized cross sections for assembly \#1 34

4-5 Flux and eigenvalue results for assembly \#1 37

4-6 Fast group cross sections for assembly \#1 39

4-7 Thermal group cross sections for assembly \#1 40

4-8 Flux and eigenvalue results for assembly \#3 44

4-9 Fast group cross sections for assembly \#1 46

4-10 Thermal group cross sections for assembly \#1 47

4-11 Homogenized cross sections for assembly A (reference 1) 51

4-12 Homogenized cross sections for assembly A (reference 2) 52

4-13 Flux comparison for assembly A 52

4-14 Homogenized cross sections for assembly A70 (reference 2) 53

4-15 Flux comparison for assembly A70 54

4-16 Homogenized cross sections for assembly A+ (reference 1) 54

4-17 Homogenized cross sections for assembly A+ (reference 2) 55 
4-18 Flux comparison for assembly A70 56

4-19 Assembly integrated flux for configuration 2

4-20 Assembly fast flux in core 2

4-21 Assembly thermal flux in core 2

4-22 $\mathrm{K}_{\text {eff }}$ for cores A, B and C 67

4-23 Assembly fast flux in core A $\quad 74$

4-24 Assembly thermal flux in core A $\quad 75$

4-25 Assembly fast flux in core B $\quad 76$

4-26 Assembly thermal flux in core B $\quad 77$

$\begin{array}{lll}\text { 4-27 Assembly fast flux in core C } & 78\end{array}$

4-28 Assembly thermal flux in core C 79 


\section{List of figures}

3-1 Assemblies and configurations layouts for cores 1 and $2 \quad 18$

3-2 Flux distribution in configuration $1 \quad 19$

3-3 Flux distribution in configuration $2 \quad 20$

3-4 Layouts for assemblies in configurations A, B, and C 22

3-5 Layouts for configurations A, B and C 23

3-6 Flux distribution in configuration A 27

3-7 Flux distribution in configuration B 28

3-8 Flux distribution in configuration $\mathrm{C} \quad 29$

3-9 HELIOS Model of the GE-9 Fuel Assembly 30

3-10 HAFAS core 31

3-11 Configuration and mesh layout for each assembly in HAFAS core 32

4-1 Flux distribution in case $3 \quad 38$

4-2 Flux distribution in case 1

4-3 Flux distribution in case 2

4-4 Flux distribution in case 4

4-5 Flux distribution in case 5

4-6 Flux distribution in case 6

4-7 Pin flux comparison for assembly A (reference 2) 53

4-8 Pin flux comparison for assembly A70 (reference 2) 55

4-9 Pin flux comparison for assembly A+ (reference 2) 56

4-10 Pin flux comparison for assembly A+ (reference 1) 57

4-11 Nodal fast flux distribution in core 2

4-12 Nodal thermal flux distribution in core 2

4-13 High-order reconstructed flux in group 1 in core $2 \quad 61$

4-14 High-order reconstructed flux in group 2 in core $2 \quad 62$

4-15 Zeroth-order reconstructed flux in group 1 in core 2

4-16 Zeroth-order reconstructed flux in group 2 in core 2

4-17 Reconstructed fast flux in core A $\quad 67$

4-18 Reconstructed thermal flux in core A 68 
4-19 Reconstructed fast flux in core B

4-20 Reconstructed thermal flux in core B

4-21 Reconstructed fast flux in core C

4-22 Reconstructed thermal flux in core C 


\section{INTRODUCTION}

Nodal methods based on equivalence theory ${ }^{1}$ use for each node (fuel assembly) homogenized cross sections and discontinuity factors that are determined by performing single bundle fine-mesh calculations with no net neutron leakage (zero current or currentto-flux ratio boundary condition). These are referred to as infinite medium homogenized parameters. It is known that for configurations in which the node-to-node neutron leakage is large, the use of infinite medium parameters, especially the discontinuity factor, could lead to large errors in the nodal solution ${ }^{2}$. This would be the case for highly heterogeneous core configurations of modern reactor designs as well as small reactor cores (in terms of mean free path).

The main objective of this project is to develop a new homogenization technique with a high-order of accuracy to account for the node-to-node leakage effect in the context of generalized equivalence theory (GET) and substantially improve the accuracy of nodal methods. This improvement is achieved through the application of a high-order boundary condition perturbation method in diffusion theory to expand the homogenized parameters as a function of the boundary (node interface) current-to-flux ratio. The perturbation method utilizes two adjoint functions to determine the expansion coefficients up to an arbitrary $\left(\mathrm{n}^{\text {th }}\right)$ order of accuracy. Since the adjoint functions are solutions to the infinite medium problem (zero current-to-flux ratio), the expansion coefficients can be precomputed and included with the standard homogenization parameters for use by the nodal code. The method allows for the reconstruction of the fuel pin flux and power distributions without requiring a priori knowledge of any core parameters such as $\mathrm{k}_{\mathrm{eff}}$. As a result, the nodal method has the capability of achieving an arbitrarily accurate solution by efficiently updating (correcting) the homogenized parameters, including the discontinuity factor, as it computes the node interface current-to-flux ratio.

The new boundary condition perturbation method developed in this work is presented in chapter II. Also included in this chapter is a discussion of the approaches used in solving the problems encountered with the numerical implemention of the method. Due to the energy coupling when going from one-group to multigroup, the equations whose solutions are required to evaluate the expansion coefficients have a more complicated form than for the one-group case. The numerical solution method for the required multigroup Green's function becomes substantially more complicated. The benchmark configurations used to test the method are presented in chapter III. Particular attention is given to the description of the new benchmark problems developed in this project because of the need for more realistic test configurations. The results for the benchmark problems are shown and discussed in chapter IV. The summary and conclusions are presented in chapter V. 


\section{METHOD}

\subsection{Basic Equations}

The high-order boundary condition perturbation method ${ }^{3}$ estimates the change in the solution of a reactive system due to a change in the boundary condition to an arbitrary order, in the diffusion approximation. The formalism, which was derived for a general case, is presented here in its multigroup form. It starts from the steady-state diffusion eigenvalue equation for an initial (unperturbed) state of the system:

$H_{g} \bar{\varphi}_{0, g}(\vec{x})=\lambda_{0} F_{g} \bar{\varphi}_{0, g}(\vec{x}), \quad \vec{x} \in V, \quad g=1 \ldots, G$

where $H_{g}$ is the diffusion operator (accounting for leakage, absorption and in-scattering), $\mathrm{F}$ is the production operator, $\lambda_{0}$ is the eigenvalue, and $\bar{\varphi}_{0}$ is the initial flux. The unperturbed (initial) flux is normalized such that its integral over $(\vec{x})$ is unity. The boundary condition associated with Eq. (2-1) is:

$a_{0, g}(\vec{x}) \hat{n} \cdot \nabla \bar{\varphi}_{0, g}(\vec{x})+b_{0, g}(\vec{x}) \bar{\varphi}_{0, g}(\vec{x})=0, \quad \vec{x} \in \partial V \quad g=1 \ldots, G$

with $\vec{x}$ the spatial variable, and $\hat{n}$ the outward unit normal. The parameter $b_{0, g}$ becomes the current-to-flux ratio in group $g$ at the boundary when $a_{0, g}$ is taken as the diffusion coefficient in that group.

The operators $H_{g}$ and $F_{g}$ are defined by:

$$
\begin{aligned}
& H_{g}=-\nabla D_{g}(\vec{x}) \nabla+\sigma_{g}(\vec{x})-\sum_{g^{\prime}=1}^{2} \sigma_{s g^{\prime} g}(\vec{x}) \\
& F_{g}=\chi_{g}(\vec{x}) \sum_{g^{\prime}=1}^{2} v \sigma_{f g^{\prime}}(\vec{x})
\end{aligned}
$$

where $D_{g}, \sigma_{g}$, and $\chi_{g}$ are the diffusion coefficient, the total cross section, and the fission spectrum in group $\mathrm{g} ; \sigma_{s g^{\prime} g}$ is the scattering cross section from group g' to group $\mathrm{g}$, and $v \sigma_{f g}$ is the product of the number of neutrons per fission and the fission cross section in group $\mathrm{g}$.

The adjoint flux for the unperturbed state is given by:

$$
H_{g}^{*} \bar{\varphi}_{0, g}^{*}(\vec{x})=\lambda_{0}^{*} F_{g}^{*} \bar{\varphi}_{0, g}^{*}(\vec{x}), \quad \vec{x} \in V \quad g=1 \ldots, G
$$


with the corresponding boundary condition:

$$
a_{0, g}(\vec{x}) \hat{n} \cdot \nabla \bar{\varphi}_{0, g}^{*}(\vec{x})+b_{0, g}(\vec{x}) \bar{\varphi}_{0, g}^{*}(\vec{x})=0, \quad \vec{x} \in \partial V \quad g=1 \ldots, G
$$

The adjoint operators $H_{g}^{*}$ and $F_{g}^{*}$ are defined by:

$$
\begin{aligned}
& H_{g}^{*}=-\nabla D_{g}(\vec{x}) \nabla+\sigma_{g}(\vec{x})-\sum_{g^{\prime}=1}^{2} \sigma_{s g g^{\prime}}(\vec{x}) \\
& F_{g}^{*}=v \sigma_{f g}(\vec{x}) \sum_{g^{\prime}=1}^{2} \chi_{g^{\prime}}(\vec{x})
\end{aligned}
$$

For a perturbation in the boundary condition of the form:

$$
a_{0, g}(\vec{x}) \hat{n} \cdot \nabla \bar{\varphi}_{0, g}(\vec{x})+\left(b_{0, g}(\vec{x})+\varepsilon b_{1, g}(\vec{x})\right) \bar{\varphi}_{0, g}(\vec{x})=0, \quad \vec{x} \in \partial V
$$

the eigenvalue equation (2-1) is written as:

$$
H_{g} \bar{\varphi}_{g}(\vec{x})=\lambda F_{g} \bar{\varphi}_{g}(\vec{x}), \quad \vec{x} \in V, \quad g=1 \ldots, G
$$

where $\lambda$ is the perturbed eigenvalue and $\bar{\varphi}$ is the perturbed flux normalized to unity. It is assumed that the perturbed flux and eigenvalue can be expanded in terms of a smallness parameter $\varepsilon$ as:

$$
\begin{aligned}
& \lambda=\lambda_{0}+\varepsilon \lambda_{1}+\varepsilon^{2} \lambda_{2} \cdots+\varepsilon^{n} \lambda_{n}+o\left(\varepsilon^{n+1}\right) \\
& \bar{\varphi}=\bar{\varphi}_{0}+\varepsilon \bar{\varphi}_{1}+\varepsilon^{2} \bar{\varphi}_{2} \cdots \varepsilon^{n} \bar{\varphi}_{n}+o\left(\varepsilon^{n+1}\right)
\end{aligned}
$$

These expansions are used in equation (2-10) and the expansion coefficients are obtained, by equating the terms with the same power of $\varepsilon$, as functionals of the flux. The highorder corrections for eigenvalue and flux in Eqs. (2-11) and (2-12) are calculated based on the solutions for the forward and adjoint flux of the initial (unperturbed) state, and a Green's function defined by the equation:

$$
\left(H_{g}^{*}-\lambda_{0} F_{g}^{*}\right) \Psi_{g h}\left(\vec{x}, \vec{x}_{0}\right)=\delta\left(\vec{x}-\vec{x}_{0}\right) \delta_{g h}-\bar{\varphi}_{0, h}\left(\vec{x}_{0}\right), \quad \vec{x} \in V \quad g, h=1,2
$$

with the boundary condition

$$
a_{0, g}(\vec{x}) \hat{n} \cdot \nabla \Psi_{g h}\left(\vec{x}, \vec{x}_{0}\right)+b_{0, g}(\vec{x}) \Psi_{g h}\left(\vec{x}, \vec{x}_{0}\right)=0, \quad \vec{x} \in \partial V \quad g, h=1,2
$$


The symbol $\delta_{\text {gh }}$ in (2-9) is the Kronecker function defined by:

$\delta_{g h}=\left\{\begin{array}{l}1, h=g \\ 0, h \neq g\end{array}\right.$

The Green's function is required to satisfy the following uniqueness condition:

$$
\left\langle\Psi\left(\vec{x}, \vec{x}_{0}, E\right) F \varphi_{0}(\vec{x}, E)\right\rangle=0, \quad \vec{x}, \vec{x}_{0} \in V
$$

The brackets in Eq. (2-16) stand for scalar product over the phase-space $(\vec{x}, E)$.

The expressions of the high-order corrections for flux and eigenvalue are:

$$
\left.\begin{array}{l}
\lambda_{1}=\frac{\sum_{g=1}^{2}\left\langle\bar{\varphi}_{0, g}^{*} \gamma_{g} \bar{\varphi}_{0, g}\right\rangle}{\sum_{g=1}^{2}\left\langle\bar{\varphi}_{0, g}^{*} F_{g} \bar{\varphi}_{0, g}\right\rangle} \\
\lambda_{2}=\frac{\sum_{g=1}^{2}\left\langle\left\langle\bar{\varphi}_{0, g}^{*} \gamma_{g} \bar{\varphi}_{1, g}\right\rangle_{s}-\lambda_{1}\left\langle\bar{\varphi}_{0, g}^{*} F_{g} \bar{\varphi}_{1, g}\right\rangle\right)}{\sum_{g=1}^{2}\left\langle\bar{\varphi}_{0, g}^{*} F_{g} \bar{\varphi}_{0, g}\right\rangle} \\
\lambda_{n}=\frac{\sum_{g=1}^{2}\left(\left\langle\bar{\varphi}_{0, g}^{*} \gamma_{g} \bar{\varphi}_{n-1, g}\right\rangle_{s}-\lambda_{1}\left\langle\bar{\varphi}_{0, g}^{*} F_{g} \bar{\varphi}_{n-1, g}\right\rangle-\lambda_{2}\left\langle\bar{\varphi}_{0, g}^{*} F_{g} \bar{\varphi}_{n-2, g}\right\rangle \cdots-\lambda_{n-1}\left\langle\bar{\varphi}_{0, g}^{*} F_{g} \bar{\varphi}_{1, g}\right\rangle\right)}{\sum_{g=1}^{2}\left\langle\bar{\varphi}_{0, g}^{*} F_{g} \bar{\varphi}_{0, g}\right\rangle} \\
+\lambda_{n-1} \sum_{g=1}^{2}\left\langle\Psi_{g h}\left(\vec{x}, \vec{x}_{0}\right) F_{g} \bar{\varphi}_{1, h}(\vec{x})\right\rangle-\sum_{g=1}^{2}\left\langle\Psi_{g h}\left(\vec{x}, \vec{x}_{0}\right) \gamma_{g} \bar{\varphi}_{n-1, h}(\vec{x})\right\rangle_{s}, \quad h=1,2 \\
\bar{\varphi}_{1, h}\left(\vec{x}_{0}\right)=-\sum_{g=1}^{2}\left\langle\Psi_{g h}\left(\vec{x}, \vec{x}_{0}\right) \gamma_{g} \bar{\varphi}_{0, h}(\vec{x})\right\rangle, \\
\bar{\varphi}_{2, h}\left(\vec{x}_{0}\right)=\lambda_{1} \sum_{g=1}^{2}\left\langle\Psi_{g h}\left(\vec{x}, \vec{x}_{0}\right) F_{g} \bar{\varphi}_{1, h}(\vec{x})\right\rangle-\sum_{g=1}^{2}\left\langle\Psi_{g h}\left(\vec{x}, \vec{x}_{0}\right) \gamma_{g} \bar{\varphi}_{1, h}(\vec{x})\right\rangle_{s}, \quad h=1,2 \\
\left.\bar{\varphi}_{n}\right)=\lambda_{1} \sum_{g=1}^{2}\left\langle\Psi_{g h}\left(\vec{x}, \vec{x}_{0}\right) F_{g} \bar{\varphi}_{n-1, h}(\vec{x})\right\rangle+\lambda_{2} \sum_{g=1}^{2}\left\langle\Psi_{g h}\left(\vec{x}, \vec{x}_{0}\right) F_{g} \bar{\varphi}_{n-2, h}(\vec{x})\right\rangle \cdots
\end{array}\right]
$$

The brackets in the above expressions stand for scalar products over the volume, the subscript $\mathrm{s}$ outside the brackets indicating that the integration is over the boundary region of the volume. The parameter $\gamma_{\mathrm{g}}$ is the perturbation of the boundary current-to-flux ratio 
for group $\mathrm{g}, \bar{\varphi}_{0, g}^{*}(\mathrm{x})$ is the adjoint flux in group $\mathrm{g}$ for the initial state, and $\bar{\varphi}_{k, g}(\mathrm{x})$ is the $\mathrm{k}^{\text {th }}$-order flux in group $\mathrm{g}$.

In reference 3 it is shown that ratios of arbitrary functionals of the flux solution can be expanded in terms of the smallness parameter, similar to the expansions for the eigenvalue and flux Eqs. (2-11) and (2-12), respectively. This result was used to homogenize phase-space parameters such as a cross section, which can be defined as:

$$
\sigma_{g}=\sigma_{0, g}+\varepsilon \sigma_{1, g}+\varepsilon^{2} \sigma_{2, g} \cdots+\varepsilon^{n} \sigma_{n, g}+o\left(\varepsilon^{n+1}\right)
$$

with the expansion coefficients given by:

$$
\begin{aligned}
\sigma_{0, g}= & \frac{\left\langle\sigma(\vec{x}, E) \bar{\varphi}_{0}(\vec{x}, E)\right\rangle_{\vec{x}, g}}{\left\langle\bar{\varphi}_{0}(\vec{x}, E)\right\rangle_{\vec{x}, g}} \\
\sigma_{1, g}= & \frac{\left\langle\sigma(\vec{x}, E) \bar{\varphi}_{1}(\vec{x}, E)\right\rangle_{\vec{x}, g}-\sigma_{0, g}\left\langle\bar{\varphi}_{1}(\vec{x}, E)\right\rangle_{\vec{x}, g}}{\left\langle\bar{\varphi}_{0}(\vec{x}, E)\right\rangle_{\vec{x}, g}} \\
\sigma_{2, g}= & \frac{\left\langle\sigma(\vec{x}, E) \bar{\varphi}_{2}(\vec{x}, E)\right\rangle_{\vec{x}, g}-\sigma_{0, g}\left\langle\bar{\varphi}_{2}(\vec{x}, E)\right\rangle_{\vec{x}, g}-\sigma_{1, g}\left\langle\overline{\varphi_{1}}(\vec{x}, E)\right\rangle_{\vec{x}, g}}{\left\langle\bar{\varphi}_{0}(\vec{x}, E)\right\rangle_{\vec{x}, g}} \\
\sigma_{n, g}= & \frac{\left\langle\sigma(\vec{x}, E) \bar{\varphi}_{n}(\vec{x}, E)\right\rangle_{\vec{x}, g}-\sigma_{0, g}\left\langle\overline{\varphi_{n}}(\vec{x}, E)\right\rangle_{\vec{x}, g}-\cdots \sigma_{n-1, g}\left\langle\bar{\varphi}_{1}(\vec{x}, E)\right\rangle_{\vec{x}, g}}{\left\langle\bar{\varphi}_{0}(\vec{x}, E)\right\rangle_{\vec{x}, g}}
\end{aligned}
$$

The subscript $\vec{x}$ outside the brackets in the above equations stands for integration over all space, and the subscript $g$ means integration over energy from $E_{g-1}$ to $E_{g}$.

In the multigroup case, the three equations (for the forward flux, the adjoint flux, and Green's function of the unperturbed state of the system) whose solutions are required to evaluate the expansion coefficients for flux, eigenvalue, and homogenized cross-section have a more complicated form than for the one-group case, due to energy coupling between groups. The numerical solution method for the multigroup Green's function becomes substantially more complicated then in the one-group case. The method for the Green's function for the two-group case is presented below.

\subsection{Method for the Green's function in two-group}

The main difficulty when extending the method to two-group is in obtaining the solution for the Green's function $\Psi_{g h}\left(\vec{x}, \vec{x}_{0}\right)$, which in two-group 1-D becomes a vectorial function, whereas in one-group 1-D is a scalar function. For fixed values of the spatial 
variables $\vec{x}$ and $\vec{x}_{0}$, there are four components (equal to the square of the number of groups) of the function $\Psi_{g h}\left(\vec{x}, \vec{x}_{0}\right)$ which need to be determined, and therefore four coupled equations, compared to only one equation in the one-group case. By writing Eq. (2-13) for the two-group $(\mathrm{g}, \mathrm{h}=1,2)$ case, one gets the following four, two by two coupled, equations:

$$
\begin{aligned}
& \begin{array}{l}
\left.L-\nabla D_{1}(\vec{x}) \nabla+\sigma_{r 1}(\vec{x})-\lambda_{0} v \sigma_{f 1}(\vec{x}) \chi_{1}(\vec{x})\right] \Psi_{11}\left(\vec{x}, \vec{x}_{0}\right)- \\
{\left[\sigma_{s 12}(\vec{x})+\lambda_{0} v \sigma_{f 1}(\vec{x}) \chi_{2}(\vec{x})\right] \Psi_{21}\left(\vec{x}, \vec{x}_{0}\right)=\delta\left(\vec{x}-\vec{x}_{0}\right)-\bar{\varphi}_{0,1}\left(\vec{x}_{0}\right)}
\end{array} \\
& \begin{array}{c}
\left.L-\nabla D_{2}(\vec{x}) \nabla+\sigma_{r 2}(\vec{x})-\lambda_{0} v \sigma_{f 2}(\vec{x}) \chi_{2}(\vec{x})\right] \Psi_{21}\left(\vec{x}, \vec{x}_{0}\right)- \\
{\left[\sigma_{s 21}(\vec{x})+\lambda_{0} v \sigma_{f 2}(\vec{x}) \chi_{1}(\vec{x})\right] \Psi_{11}\left(\vec{x}, \vec{x}_{0}\right)=-\bar{\varphi}_{0,1}\left(\vec{x}_{0}\right)}
\end{array} \\
& \begin{array}{c}
\left.L-\nabla D_{1}(\vec{x}) \nabla+\sigma_{r 1}(\vec{x})-\lambda_{0} v \sigma_{f 1}(\vec{x}) \chi_{1}(\vec{x})\right] \Psi_{12}\left(\vec{x}, \vec{x}_{0}\right)- \\
{\left[\sigma_{s 12}(\vec{x})+\lambda_{0} v \sigma_{f 1}(\vec{x}) \chi_{2}(\vec{x})\right] \Psi_{22}\left(\vec{x}, \vec{x}_{0}\right)=-\bar{\varphi}_{0,2}\left(\vec{x}_{0}\right)} \\
\left.L-\nabla D_{2}(\vec{x}) \nabla+\sigma_{r 2}(\vec{x})-\lambda_{0} v \sigma_{f 2}(\vec{x}) \chi_{2}(\vec{x})\right] \Psi_{22}\left(\vec{x}, \vec{x}_{0}\right)- \\
{\left[\sigma_{s 21}(\vec{x})+\lambda_{0} v \sigma_{f 2}(\vec{x}) \chi_{1}(\vec{x})\right] \Psi_{12}\left(\vec{x}, \vec{x}_{0}\right)=\delta\left(\vec{x}-\vec{x}_{0}\right)-\bar{\varphi}_{0,2}\left(\vec{x}_{0}\right)}
\end{array}
\end{aligned}
$$

where $\sigma_{r}$ is the removal cross section. Equations (2-21-a) and (2-21-b) constitute a linear system for the unknowns $\Psi_{11}\left(\vec{x}, \vec{x}_{0}\right)$ and $\Psi_{21}\left(\vec{x}, \vec{x}_{0}\right)$, whereas Eqs. (2-21-c) and (221-d) constitute a similar system for $\Psi_{12}\left(\vec{x}, \vec{x}_{0}\right)$ and $\Psi_{22}\left(\vec{x}, \vec{x}_{0}\right)$. By discretizing the equations in slab geometry (integrating over the $\mathrm{x}$ variable), one gets two systems of matrix equations with unknowns $\mathrm{X}_{1}, \mathrm{X}_{2}, \mathrm{Y}_{1}$, and $\mathrm{Y}_{2}$, as shown below:

$$
\begin{gathered}
\left\{\begin{array}{c}
A_{1} X_{1}(j)-B_{1} X_{2}(j)=D(j)-c_{1}(j) C \\
A_{2} X_{2}(j)-B_{2} X_{1}(j)=-c_{1}(j) C
\end{array}\right. \\
\left\{\begin{array}{c}
A_{1} Y_{1}(j)-B_{1} Y_{2}(j)=D(j)-c_{2}(j) C \\
A_{2} Y_{2}(j)-B_{2} Y_{1}(j)=c_{2}(j) C
\end{array}\right.
\end{gathered}
$$

The system (2-22) corresponds to Eqs. (2-20-a) and (2-20-b), whereas the system (2-23) corresponds to Eqs. (2-21-c) and (2-21-d). $\mathrm{A}_{1}$ and $\mathrm{A}_{2}$ are $\mathrm{NxN}$ tridiagonal matrices, $\mathrm{B}_{1}$ and $\mathrm{B}_{2}$ are $\mathrm{NxN}$ diagonal matrices, $\mathrm{D}, \mathrm{C}, \mathrm{X}_{1}, \mathrm{X}_{2}, \mathrm{Y}_{1}$, and $\mathrm{Y}_{2}$ are $\mathrm{N}$ - component vectors, and $c_{1}(j)$ and $c_{2}(j)$ are constants, with $j$ as a mesh index for $x_{0}(j=1, . ., N)$.

$$
\begin{aligned}
& X_{1}^{T}(j)=\left[\Psi_{11}(1, j), \Psi_{11}(2, j) \cdots \Psi_{11}(i, j) \cdots \Psi_{11}(N, j)\right] \\
& X_{2}^{T}(j)=\left[\Psi_{21}(1, j), \Psi_{21}(2, j) \cdots \Psi_{21}(i, j) \cdots \Psi_{21}(N, j)\right] \\
& Y_{1}^{T}(j)=\left[\Psi_{12}(1, j), \Psi_{12}(2, j) \cdots \Psi_{12}(i, j) \cdots \Psi_{12}(N, j)\right]
\end{aligned}
$$




$$
\begin{aligned}
& Y_{2}^{T}(j)=\left[\Psi_{22}(1, j), \Psi_{22}(2, j) \cdots \Psi_{22}(i, j) \cdots \Psi_{22}(N, j)\right] \\
& D^{T}(j)=\left[\delta_{1 j}, \delta_{2 j} \cdots \delta_{i j} \cdots \delta_{N j}\right] \\
& C^{T}(j)=\left[\Delta x_{1}, \Delta x_{2} \cdots \Delta x_{i} \cdots \Delta x_{N}\right]
\end{aligned}
$$

The components of the vector $\mathrm{C}$ are the mesh lengths, and those of the vector $\mathrm{D}$ are Kronecker functions (see Eqs. (2-15)). The diagonal coefficients for matrices $\mathrm{B}_{1}$ and $\mathrm{B}_{2}$ are given by:

$$
\begin{array}{ll}
b_{i i}^{1}=\lambda_{0} v \sigma_{f 1}^{i} \chi_{2}^{i}+\sigma_{s 12}^{i} & , i=1, \cdots N \\
b_{i i}^{2}=\lambda_{0} v \sigma_{f 2}^{i} \chi_{1}^{i}+\sigma_{s 21}^{i} & , i=1, \cdots N
\end{array}
$$

The nonzero coefficients of matrices $A_{1}$ and $A_{2}$ are defined by:

$$
\begin{array}{ll}
a_{i-1, i}^{1}=-\frac{2\left(D_{1}^{i} / \Delta_{i}\right)\left(D_{1}^{i-1} / \Delta_{i-1}\right)}{\left(D_{1}^{i} / \Delta_{i}\right)+\left(D_{1}^{i-1} / \Delta_{i-1}\right)} \quad, i=2 \cdots N \\
a_{i, i+1}^{1}=-\frac{2\left(D_{1}^{i} / \Delta_{i}\right)\left(D_{1}^{i+1} / \Delta_{i+1}\right)}{\left(D_{1}^{i} / \Delta_{i}\right)+\left(D_{1}^{i+1} / \Delta_{i+1}\right)} \quad, i=1 \cdots N-1 \\
a_{i, i}^{1}=a_{i-1, i}^{1}+a_{i, i+1}^{1}+\Delta_{i}\left(\sigma_{r 1}^{i}-\lambda_{0} v \sigma_{f 1}^{i} \chi_{1}\right) \quad, i=2 \cdots N-1 \\
a_{i-1, i}^{2}=-\frac{2\left(D_{2}^{i} / \Delta_{i}\right)\left(D_{2}^{i-1} / \Delta_{i-1}\right)}{\left(D_{2}^{i} / \Delta_{i}\right)+\left(D_{2}^{i-1} / \Delta_{i-1}\right)} \quad, i=2 \cdots N \\
a_{i, i+1}^{2}=-\frac{2\left(D_{2}^{i} / \Delta_{i}\right)\left(D_{2}^{i+1} / \Delta_{i+1}\right)}{\left(D_{2}^{i} / \Delta_{i}\right)+\left(D_{2}^{i+1} / \Delta_{i+1}\right)} \quad, i=1 \cdots N-1 \\
a_{i, i}^{2}=a_{i-1, i}^{2}+a_{i, i+1}^{2}+\Delta_{i}\left(\sigma_{r 2}^{i}-\lambda_{0} v \sigma_{f 2}^{i} \chi_{2}\right) \quad, i=2 \cdots N-1
\end{array}
$$

The constants $c_{1}$ and $c_{2}$ are given by:

$$
\begin{aligned}
& c_{1}(j)=\bar{\varphi}_{0,1}(j) \\
& c_{2}(j)=\bar{\varphi}_{0,2}(j)
\end{aligned}
$$

The coefficients for which the expressions are not shown in the above equations are those that correspond to boundary meshes $(i=1, N)$. These expressions cannot be written for a general case unless the boundary condition is specified. The discretization of Eqs. (2-21) is presented in more detail in Appendix A.

The systems (2-22) and (2-23) need to be solved for each $j=1,2, \ldots N$. In order to do this, they are written in a compact form, as shown below: 


$$
\begin{gathered}
{\left[\begin{array}{cc}
A_{1} & -B_{1} \\
-B_{2} & A_{2}
\end{array}\right]\left(\begin{array}{l}
X_{1}(j) \\
X_{2}(j)
\end{array}\right)=\left(\begin{array}{c}
D(j) \\
0
\end{array}\right)-c_{1}(j)\left(\begin{array}{l}
C \\
C
\end{array}\right)} \\
{\left[\begin{array}{cc}
A_{1} & -B_{1} \\
-B_{2} & A_{2}
\end{array}\right]\left(\begin{array}{l}
Y_{1}(j) \\
Y_{2}(j)
\end{array}\right)=\left(\begin{array}{c}
D(j) \\
0
\end{array}\right)-c_{2}(j)\left(\begin{array}{l}
C \\
C
\end{array}\right)}
\end{gathered}
$$

or equivalently as:

$$
\begin{aligned}
& A X(j)=V_{1}(j)-c_{1}(j) V_{2} \\
& A Y(j)=V_{1}(j)-c_{2}(j) V_{2}
\end{aligned}
$$

In the above equations $\mathrm{A}$ is a $2 \mathrm{~N} \times 2 \mathrm{~N}$ band matrix, and $\mathrm{X}, \mathrm{Y}, \mathrm{V}_{1}$ and $\mathrm{V}_{2}$ are $2 \mathrm{~N}$ component vectors. In solving Eqs. (2-34) and (2-35) one must account for the uniqueness condition (2-16), which in two-group is expressed by the two following equations:

$$
\begin{aligned}
& \left\langle\Psi_{11}\left(\vec{x}, \vec{x}_{0}\right) \chi_{1}(\vec{x}) \sum_{g^{\prime}=1}^{2} v \sigma_{f g^{\prime}}(\vec{x}) \varphi_{0, g^{\prime}}(\vec{x})+\Psi_{21}\left(\vec{x}, \vec{x}_{0}\right) \chi_{2}(\vec{x}) \sum_{g^{\prime}=1}^{2} v \sigma_{f g^{\prime}}(\vec{x}) \varphi_{0, g^{\prime}}(\vec{x})\right\rangle_{\vec{x}}=0 \\
& \left\langle\Psi_{12}\left(\vec{x}, \vec{x}_{0}\right) \chi_{1}(\vec{x}) \sum_{g^{\prime}=1}^{2} v \sigma_{f g^{\prime}}(\vec{x}) \varphi_{0, g^{\prime}}(\vec{x})+\Psi_{22}\left(\vec{x}, \vec{x}_{0}\right) \chi_{2}(\vec{x}) \sum_{g^{\prime}=1}^{2} v \sigma_{f g^{\prime}}(\vec{x}) \varphi_{0, g^{\prime}}(\vec{x})\right\rangle_{\vec{x}}=0
\end{aligned}
$$

By discretizing the Eqs. (2-38) and (2-39) in slab geometry one gets:

$$
\begin{aligned}
& \sum_{i=1}^{N}\left(\Psi_{11}(i, j) \chi_{1}(i) \sum_{g^{\prime}=1}^{2} v \sigma_{f g^{\prime}}(i) \varphi_{0, g^{\prime}}(i)+\Psi_{21}(i, j) \chi_{2}(i) \sum_{g^{\prime}=1}^{2} v \sigma_{f g^{\prime}}(i) \varphi_{0, g^{\prime}}(i)\right) \Delta_{i}=0, j=1, \ldots N \\
& \sum_{i=1}^{N}\left(\Psi_{21}(i, j) \chi_{1}(i) \sum_{g^{\prime}=1}^{2} v \sigma_{f g^{\prime}}(i) \varphi_{0, g^{\prime}}(i)+\Psi_{22}(i, j) \chi_{2}(i) \sum_{g^{\prime}=1}^{2} v \sigma_{f g^{\prime}}(i) \varphi_{0, g^{\prime}}(i)\right) \Delta_{i}=0, j=1, \ldots N
\end{aligned}
$$

The subscripts $\mathrm{i}$ and $\mathrm{j}$ are mesh indices for $x$ and $x_{0}, \Delta_{i}$ is the length of mesh $\mathrm{i}$, and $\mathrm{N}$ is the total number of meshes. Equation (2-40) and the system (2-34) have as unknowns the components of the adjoint Green's function $\Psi_{g h}(i, j)$ for which $\mathrm{g}=1,2$ and $\mathrm{h}=1$. Equation (2-41) and the system (2-35) have as unknown the components of the adjoint Green's function $\Psi_{g h}(i, j)$ for which $\mathrm{g}=1,2$ and $\mathrm{h}=2$.

Two approaches have been followed to solve for Green's function. Let's consider the system (2-34) with the corresponding Eq. (2-40) expressing the uniqueness condition. The first approach was to consider Eq. (2-40) as an additional equation of the system (234). The resulting system is overdetermined: 


$$
A_{3} x_{3}=b_{3}
$$

where $A_{3}$ is a $(2 \mathrm{~N}+1)$ by $2 \mathrm{~N}$ matrix, and $x_{3}$ and $b_{3}$ are $(2 \mathrm{~N}+1)$-length vectors. The system (2-42) can be solved by using a least square method, which consists of minimizing the square Euclidian norm:

$$
\|r\|_{2}^{2}=r^{T} r, \quad r=b_{3}-A_{3} x_{3}
$$

The procedures used to minimize (2-43) involve the reduction of the matrix $A_{3}$ to various canonical forms via orthogonal transformations ${ }^{4}$ Here a $\mathrm{QR}$ factorization of $A_{3}$ method has been used, which consists of seeking a $(2 \mathrm{~N}+1)$ by $(2 \mathrm{~N}+1)$ orthogonal matrix $\mathrm{Q}$ such that

$$
A_{3}=Q\left[\begin{array}{l}
R \\
0
\end{array}\right]
$$

where $R$ is a $2 \mathrm{~N}$ by $2 \mathrm{~N}$ upper triangular matrix. The factorization was performed by using a routine from the IMSL MATH/LIBRARY ${ }^{5}$. The solution obtained for Eq. (2-42) was not accurate enough for the purpose of the present work. The residuals (components of $r=b_{3}-A_{3} x_{3}$ ) were not very small compared to the components of the right term $b_{3}$.

The second approach used to solve for Green's function is the following: for each $x_{0}(\mathrm{j}$ from 1 to $\mathrm{N}$ ), the system (2-34) is solved by replacing the $\mathrm{j}^{\text {th }}$ line with Eq. (2-40) for the same $\mathrm{j}$ (expressing the uniqueness condition for that particular $x_{0}$ ). The system (2-35) is solved in a similar manner, but in conjunction with Eq. (2-41). Since the resulting systems of equations are ill-conditioned, standard methods cannot be used for solving them. The condition number is of the order $10^{3}-10^{4}$. Here a singular value decomposition method (SVD) ${ }^{4}$ is used for obtaining the solution. The SVD method for solving a linear system $(A x=b)$, with $A$ a $2 \mathrm{~N}$ by $2 \mathrm{~N}$ real nonsingular matrix, is based on the decomposition:

$$
A=U \Sigma V^{T}
$$

where $U$ and $V$ are orthogonal matrices, and $\Sigma$ is a diagonal matrix. The elements on the diagonal of $\Sigma$ are called singular values of the matrix A:

$$
\sigma_{1} \geq \sigma_{2} \geq \ldots \geq \sigma_{2 N} \geq 0
$$

They can be used to get an estimation of the condition number, as a ratio of the largest to the smallest of the components. 


\subsection{High-order correction of the homogenized parameters}

Based on the high-order boundary condition perturbation theory (equations in section 2.1), the high-order cross section homogenization method expands the nodal parameters in terms of the node surface current-to flux ratio. The procedure of correcting the homogenized parameters in a nodal calculation is as follows:

- The nodal calculation is performed by using the infinite medium homogenized parameters (zero current boundary condition), and the solution is used to calculate the current-to-flux ratio $(\gamma)$ at each node interface

- This ratio is used as a perturbation of the boundary condition in the high-order boundary condition formalism that evaluates the high-order correction for the homogenized parameters in each node (see Eqs 2-12.)

- The nodal calculation is redone with the corrected homogenized parameters, and new $\gamma$ 's are determined

- The iteration continues until convergence is achieved

The calculation of the corrections for the homogenized parameters is decoupled from the nodal calculation. The corrections for a particular node are evaluated based on precomputed data for each assembly type: the forward and ajoint flux distribution of the infinite-medium calculation for that assembly, and the solution of the corresponding Green's function defined by Eq. 2-7. The only data provided by the nodal calculation is the updated value of the current-to-flux ration at the node interface.

\subsubsection{One-dimensional configurations}

A nodal diffusion code with a bilinear intra-nodal flux shape and discontinuous flux across the node interface was developed in conjunction with the high-order cross section homogenization method, for each of the one-group and two-group problems. The discretization of the nodal equations is presented in Appendix B.

The initial (zeroth order) nodal parameters are the standard GET homogenized cross sections and discontinuity factors, determined from infinite medium single node calculations for each assembly type. The standard discontinuity factor on each side of a nodal interface is defined as the ratio of the heterogeneous flux (that is continuous at the interface) to the homogeneous flux on each side of the interface. It is calculated as:

$$
f^{k}=\frac{\bar{\varphi}_{i m}^{k}}{\bar{\varphi}_{i m}}
$$

where $\chi^{k}$ is the standard discontinuity factor for face $\mathrm{k}$ of the node, $\bar{\varphi}_{i m}^{k}$ and $\bar{\varphi}_{i m}$ are the surface-averaged flux on face $\mathrm{k}$ and the node-averaged flux from infinite medium calculations, respectively. 
For the nodal calculations, the discontinuity factor in group $\mathrm{g}$ on face $\mathrm{k}$ of the node can be written in terms of its infinite medium approximation $\chi_{\mathrm{g}}{ }^{\mathrm{k}}$ as ${ }^{2}$ :

$f_{g}^{k}=\chi_{g}^{k} \frac{\bar{\phi}_{g}}{\bar{\phi}_{g}^{k}}$

where $\bar{\phi}_{g}$ and $\bar{\phi}_{g}^{k}$ represent the node-averaged flux in group g and the average flux on face $\mathrm{k}$ in group $\mathrm{g}$ from the nodal calculations, respectively. The so-called heterogeneous discontinuity factor $\chi_{\mathrm{g}}{ }^{\mathrm{k}}$ is calculated as:

$\chi_{g}^{k}=\frac{\int_{S_{k}} d^{2} x \bar{\varphi}_{g}(\vec{x})}{\int_{V} d^{3} x \bar{\varphi}_{g}(\vec{x})}=\frac{\left\langle\bar{\varphi}_{0, g}\right\rangle_{s}+\gamma_{g}\left\langle\bar{\varphi}_{1, g}\right\rangle_{s}+\gamma_{g}^{2}\left\langle\bar{\varphi}_{2, g}\right\rangle_{s}+\cdots+\gamma_{g}^{n}\left\langle\bar{\varphi}_{n, g}\right\rangle_{s}+o\left(\varepsilon^{n+1}\right)}{\left\langle\bar{\varphi}_{0, g}\right\rangle+\gamma_{g}\left\langle\bar{\varphi}_{1, g}\right\rangle+\gamma_{g}^{2}\left\langle\bar{\varphi}_{2, g}\right\rangle+\cdots+\gamma_{g}^{2}\left\langle\bar{\varphi}_{n, g}\right\rangle+o\left(\varepsilon^{n+1}\right)}$

where $\gamma_{g}$ is the current-to-flux ratio in group $\mathrm{g}$ for interface $\mathrm{k}$ of the node. $\gamma_{g}$ is calculated as ${ }^{2}$ :

$\gamma_{g}^{k}=\frac{\bar{J}_{g}^{k}}{f_{g}^{k} \bar{\varphi}_{g}^{k}}$

where $\bar{J}_{g}^{k}$ is the average current for group $\mathrm{g}$ on face $\mathrm{k}$, determined from the nodal calculation.

The convergence criteria used for the iterative nodal calculations are the following:

- The change in the average flux in each node (mesh) and for each group in two consecutive cross sections updating iterations is less than $1 \%$

$$
\frac{\left|\varphi_{g, i}^{a v g}(k)-\varphi_{g, i}^{a v g}(k-1)\right|}{\varphi_{g, i}^{a v g}(k)} \leq 1 \% \quad i=1, . . N, \quad g=1,2
$$

- The change in the eigenvalue in two consecutive iterations is less than $10^{-3}$

$$
|\lambda(k)-\lambda(k-1)| \leq 10^{-3}
$$

The reconstructed fine-mesh flux is a byproduct of the method. For each node, it is obtained by modulating the detailed flux distribution, which is obtained at each updating of the cross section through the high-order perturbation formalism (see Eqs (2-15)), with the nodal flux: 
$\varphi_{r, g}^{n}(i)=\varphi_{p, g}^{n}(i) \frac{\int_{\text {node }} d x \sum_{g^{\prime}=1}^{2} \varphi_{g^{\prime}}^{\text {node }}(x)}{\sum_{i=1}^{N} \sum_{g^{\prime}=1}^{2} \Delta_{i} \varphi_{p, g^{\prime}}^{n}(i)}$

where $\varphi_{r, g}^{n}(i)$ is the reconstructed flux for group $\mathrm{g}$ and mesh $\mathrm{i}$ in node $\mathrm{n}$, and $\varphi_{p, g}^{n}(i)$ is the fine-mesh flux for group $\mathrm{g}$ and mesh $\mathrm{i}$ in node $\mathrm{n}$ obtained using the perturbation formalism. The denominator of the ratio in Eq. (2-53) represents the integral of the nodal flux over the node $n$, and the numerator is the integral of the fine-mesh flux, obtained from the perturbation formalism, over the assembly corresponding to node $n$.

The reconstructed flux at a different order of the correction is compared to the $0^{\text {th }}$ order (standard GET) reconstructed flux. The reconstruction of the $0^{\text {th }}$ order flux here is performed by modulating the infinite-medium assembly flux with the nodal flux obtained by using the standard (uncorrected) cross sections in the nodal calculations. The form of the $0^{\text {th }}$ order reconstructed flux in a node is expressed as:

$\varphi_{r}^{i}(x)=c_{i} \varphi_{n}^{i}(x) \varphi_{i m}^{i}(x), \quad i=1, N$

where $\mathrm{N}$ is the number of nodes, $\mathrm{i}$ is the node index, $\varphi_{r}$ is the $0^{\text {th }}$ order reconstructed flux, $\varphi_{n}$ is the nodal flux, $\varphi_{i m}$ is the infinite-medium flux, and $\mathrm{c}_{\mathrm{i}}$ is a constant. The constant $\mathrm{c}_{\mathrm{i}}$ is determined by requiring the $0^{\text {th }}$ order reconstructed flux to be continuous at the node interface:

$c_{i} \varphi_{n}^{i}\left(x_{i, i+1}\right) \varphi_{i m}^{i}\left(x_{i, i+1}\right)=c_{i+1} \varphi_{n}^{i+1}\left(x_{i, i+1}\right) \varphi_{i m}^{i+1}\left(x_{i, i+1}\right), \quad i=1, N-1$

where $\mathrm{x}_{\mathrm{i}, \mathrm{i}+1}$ is the coordinate corresponding to the interface between nodes $\mathrm{i}$ and $\mathrm{i}+1$. If $\mathrm{c}_{1}$ is fixed $\left(c_{1}=c\right)$, all the others constants $c_{i}(i=2, \ldots N-1)$ are determined from $(2-51)$. $c$ is determined by equating the core-integrated nodal flux with the core-integrated $0^{\text {th }}$ order reconstructed flux. 


\subsubsection{Two-dimensional configurations}

For one-dimensional configurations, the use of both bilinear and flat intranodal shape of the nodal flux when solving the nodal equations lead to very good results with respect to the implementation of the high-order cross section homogenization method ${ }^{7}$. For a twodimensional configuration however, the use of a flat flux approximation to solve the nodal equations is too crude. Therefore, the high-order homogenization method would need to be implemented into a nodal code with a better approximation for the intra -nodal flux shape.

For the present project, a transverse integrated approach is considered to solve the nodal equations, with a nodal expansion method (NEM) $)^{8}$ employed to determine the solutions for the transverse-integrated equations in Cartesian geometry. The basic formalism is presented below. The integration of the multigroup diffusion equation over a node $\mathrm{k}$ (see figure below) leads to:

$\frac{1}{\Delta x}\left[J_{g x+}^{k}-J_{g x-}^{k}\right]+\frac{1}{\Delta y}\left[J_{g y+}^{k}-J_{g y-}^{k}\right]+\sum_{r g}^{k} \bar{\Phi}_{g}^{k}=Q_{g}^{k}$

where $J_{g d \pm}^{k}$ and $\bar{\Phi}_{g}^{k}$ are the component of net current averaged over the d-directed face of the node and the node- averaged flux. Their expressions are:

$$
\begin{aligned}
& J_{g x \pm}^{k}=\frac{1}{\Delta y} \int_{-\Delta y / 2}^{\Delta y / 2}-\left.D_{g}^{k} \frac{\partial}{\partial x} \Phi_{g}^{k}(x, y)\right|_{x= \pm \Delta x / 2} d y \\
& \bar{\Phi}_{g}^{k}=\frac{1}{\Delta x \Delta y} \int_{-\Delta x / 2}^{\Delta x / 2} d x \int_{-\Delta y / 2}^{\Delta y / 2} d y \Phi_{g}^{k}(x, y)
\end{aligned}
$$

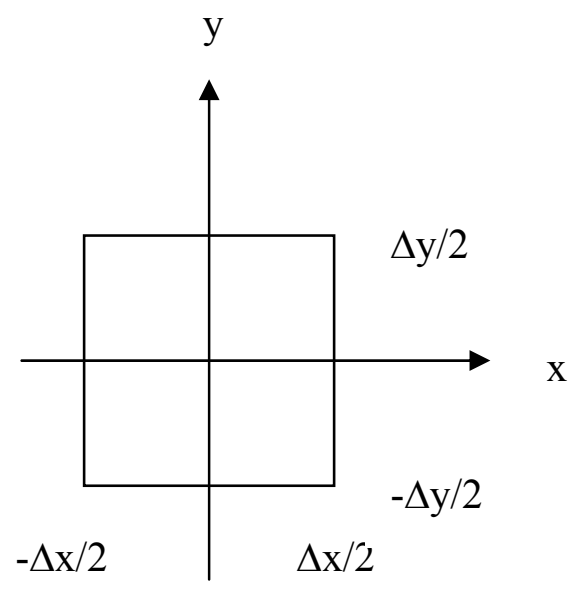

$D_{g}^{k}, \Sigma_{r g}^{k}$, and $Q_{g}^{k}$ are the diffusion coefficient, removal cross section and source term for group $\mathrm{g}$ in node $\mathrm{k}$, respectively. The expression for the source term is: 


$$
Q_{g}^{k}=\frac{1}{\lambda} \sum_{g^{\prime}=1}^{G} \chi_{g}^{k} \nu \sum_{f g^{\prime}}^{k} \Phi_{g^{\prime}}^{k}+\sum_{\substack{g^{\prime}=1 \\ g^{\prime} \neq g}}^{G} \sum_{g g^{\prime}}^{k} \Phi_{g^{\prime}}^{k}
$$

By integrating Eq. 2-56 over each direction $\mathrm{x}$ and $\mathrm{y}$, one gets the second-order form of the transverse-integrated equations:

$$
\begin{aligned}
& -\frac{d}{d x} D_{g}^{k} \frac{d}{d x} \bar{\Phi}_{g x}^{k}(x)+\sum_{r g}^{k} \bar{\Phi}_{g x}^{k}(x)=\bar{Q}_{g x}^{k}(x)-\frac{1}{\Delta y} L_{g y}^{k}(x) \\
& -\frac{d}{d y} D_{g}^{k} \frac{d}{d y} \bar{\Phi}_{g y}^{k}(y)+\sum_{r g}^{k} \bar{\Phi}_{g y}^{k}(y)=\bar{Q}_{g y}^{k}(y)-\frac{1}{\Delta x} L_{g x}^{k}(y)
\end{aligned}
$$

These one-dimensional equations are solved by using a fourth-order polynomial $\operatorname{expansion}^{8}$ :

$$
\bar{\Phi}_{g x}^{k}(x) \simeq \bar{\Phi}_{g}^{k} f_{0}(x)+\sum_{n=1}^{4} a_{g x n}^{k} f_{n}(x)
$$

with the basis functions given by:

$$
\begin{aligned}
& f_{0}(x) \equiv 1 \\
& f_{1}(x) \equiv \frac{x}{\Delta x}=\xi \\
& f_{2}(x) \equiv 3 \xi^{2}-\frac{1}{4} \\
& f_{3}(x) \equiv \xi\left(\xi-\frac{1}{2}\right)\left(\xi+\frac{1}{2}\right) \\
& f_{4}(x) \equiv\left(\xi^{2}-\frac{1}{20}\right)\left(\xi-\frac{1}{2}\right)\left(\xi+\frac{1}{2}\right)
\end{aligned}
$$

The one-dimensional fluxes are determined by using a weighted residual procedure applied to Eqs. 2-60 (see references 8 and 9 for details). The calculation of the transverse leakage moments requires additional approximations for the transverse leakage terms $L_{g x}^{k}(y)$ and $L_{g y}^{k}(x)$ in Eqs. 2-60. Here a quadratic polynomial approximation is used:

$$
L_{g y}^{k}(x) \cong \bar{L}_{g y}^{k}+\rho_{g y 1}^{k} f_{1}(x)+\rho_{g y 2}^{k} f_{2}(x)
$$

where $\bar{L}_{g y}^{k}$ is the average transverse integrated leakage. The expansion coefficients $\rho_{g y 1}^{k}$ and $\rho_{g y 2}^{k}$ are determined by requiring that: 


$$
\begin{aligned}
& \frac{1}{\Delta x_{k-1}} \int_{-\Delta x_{k} / 2-\Delta x_{k-1}}^{-\Delta x_{k} / 2} d x L_{g y}^{k}(x)=\bar{L}_{g y}^{k-1} \\
& \frac{1}{\Delta x_{k+1}} \int_{\Delta x_{k} / 2}^{\Delta x_{k} / 2+\Delta x_{k+1}} d x L_{g y}^{k}(x)=\bar{L}_{g y}^{k+1}
\end{aligned}
$$

The NEM equations are commonly solved by using a response matrix formulation. The implementation of NEM for this project utilizes a nonlinear matrix formulation ${ }^{9}$ of the nodal equations, which makes use of equivalence theory to force the coarse-mesh finite difference equations to match the results of a high order nodal method. This nonlinear scheme was originally introduced by Smith ${ }^{10}$. The advantage of this scheme relies in having the node averaged fluxes as the only unknowns and in its requiring less computation time than a response matrix formulation.

The strategy of this nonlinear scheme ${ }^{10}$ is summarized here. The expression of the interface current in the usual finite-difference nodal method used to eliminate the current term

$$
\bar{J}_{g u+}^{k}=\frac{2\left(D_{g}^{k} / h_{u}^{k}\right)\left(D_{g}^{k_{u+}} / h_{u}^{k_{u+}}\right)}{\left(D_{g}^{k} / h_{u}^{k}\right)+\left(D_{g}^{k_{u+}} / h_{u}^{k_{u+}}\right)}\left[\Phi_{g}^{k}-\Phi_{g}^{k_{u+}}\right]
$$

is modified in the non-linear scheme to:

$$
\bar{J}_{g u+}^{k}=\frac{2\left(D_{g}^{k} / h_{u}^{k}\right)\left(D_{g}^{k_{u+}} / h_{u}^{k_{u+}}\right)}{\left(D_{g}^{k} / h_{u}^{k}\right)+\left(D_{g}^{k_{u+}} / h_{u}^{k_{u+}}\right)}\left[\Phi_{g}^{k}-\Phi_{g}^{k_{u+}}+C_{g u+}^{k}\left(\Phi_{g}^{k}+\Phi_{g}^{k_{u+}}\right)\right]
$$

$u$ stands for direction, $\mathrm{h}$ for node length, and $C_{g u_{+}}^{k}$ is a coupling correction factor for the interface between nodes $k$ and $k_{u+}$. The correction factor is obtained as:

$$
C_{g u+}^{k}=\left[\bar{J}_{g u+}^{k} \frac{\left(D_{g}^{k} / h_{u}^{k}\right)+\left(D_{g}^{k_{u+}} / h_{u}^{k_{u+}}\right)}{2\left(D_{g}^{k} / h_{u}^{k}\right)\left(D_{g}^{k_{u+}} / h_{u}^{k_{u+}}\right)}-\Phi_{g}^{k}+\Phi_{g}^{k_{u+}}\right] /\left(\Phi_{g}^{k}+\Phi_{g}^{k_{u+}}\right)
$$

where $\bar{J}_{g u+}^{k}$ is replaced by the value corresponding to the NEM formulation:

$$
\bar{J}_{g u+}^{k}=-\left.\frac{D_{g}^{k}}{h_{u}^{k}} \frac{d}{d x} \bar{\Phi}_{g u}^{k}(u)\right|_{u+}
$$

The steps of the nodal calculation are: 
- solve the finite difference (FD) equations (null coupling correction factors) and get the flux in each node

- use this flux solution to solve the two-node problems for each node and interface for obtaining the NEM currents (2-68) and the corresponding coupling factors (267)

- calculate the new FD coefficients using (2-66) and solve the FD nodal equations

- repeat all previous steps until convergence is achieved.

Note that the above mentioned procedure is only for the calculation of the nodal flux. The correction of the homogenized parameters, as explained in 2-3, is a different level of the calculation (the correction uses the current-to-flux ratio) as given from the solution of the nodal equations). 


\section{DESCRIPTION OF THE BENCHMARK CONFIGURATIONS}

\subsection{One-dimensional configurations}

The layouts for the two seven-assemblies configurations used for the testing of the method for one- and two-group one-dimensional problems are shown in Figure 3-1 [5]. Each configuration is a core typical of a BWR in slab geometry, with a total length of $106.68 \mathrm{~cm}$. Each core is made-up of two unique alternating assemblies lined-up in a onedimensional array with a zero-current external boundary condition. The first configuration is a very simple case with relatively small changes across the core (see Figure 3-2). The second configuration is designed to be a relatively difficult benchmark problem for coarse-mesh methods (see Figure 3-2).

The three types of assemblies have the same geometry, but a different fuel composition. Each assembly consists of four fuel regions each $3.231 \mathrm{~cm}$ thick surrounded by water. The water gap is $1.158 \mathrm{~cm}$ thick, and the assembly length is $15.24 \mathrm{~cm}$. The type 1 assembly contains two enrichment zones whereas the type 2 assembly has one enrichment zone with slightly smaller average enrichment. The type 3 assembly is the same as type 1 except that it contains gadolinium in two of the four fuel regions $\left(\left(\mathrm{k}_{\propto}=\right.\right.$ 0.6677). The gadolinium content is purposely increased to create a highly heterogeneous configuration. The one-group cross sections ${ }^{7}$ are given in Table 3-1, and the two-group cross sections [5] in Table 3-2. The infinite medium multiplication constant for each assembly type is given in Table 3-3 for the two-group case.

Table 3-1. Material properties for assemblies in configurations 1 and 2 (one-group)

\begin{tabular}{|c|c|c|c|c|}
\hline Cross Section $^{*}$ & Water & Fuel I & Fuel II & $\begin{array}{c}\text { Fuel III } \\
\text { (with Gd) }\end{array}$ \\
\hline $\mathrm{D}$ & 1.44 & 1.24 & 1.22 & 1.30 \\
\hline$\sigma_{\mathrm{a}}$ & 0.00205 & 0.0238 & 0.0284 & 0.075 \\
\hline$\gamma \sigma_{\mathrm{f}}$ & 0.0 & 0.0314 & 0.0416 & 0.00844 \\
\hline
\end{tabular}

* The diffusion coefficients are in $\mathrm{cm}$, and the cross sections in $\mathrm{cm}^{-1}$

Table 3-2. Material properties for assemblies in configurations 1 and 2 (two-group)

\begin{tabular}{|c|c|c|c|c|}
\hline Cross Section $^{*}$ & Water & Fuel I & Fuel II & $\begin{array}{c}\text { Fuel III } \\
\text { (with Gd) }\end{array}$ \\
\hline $\mathrm{D}_{1}$ & 1.7639 & 1.4730 & 1.4804 & 1.5432 \\
\hline$\sigma_{\mathrm{a} 1}$ & 0.0003 & 0.0096 & 0.0101 & 0.0135 \\
\hline$\gamma \sigma_{\mathrm{f} 1}$ & 0 & 0.0067 & 0.0078 & 0.0056 \\
\hline$\sigma_{\mathrm{s} 12}$ & 0.0380 & 0.0161 & 0.0156 & 0.0136 \\
\hline $\mathrm{D}_{2}$ & 0.2278 & 0.3294 & 0.3362 & 0.3143 \\
\hline$\sigma_{\mathrm{a} 2}$ & 0.0097 & 0.0764 & 0.0901 & 0.4873 \\
\hline$\gamma \sigma_{\mathrm{f} 2}$ & 0 & 0.1241 & 0.1542 & 0.0187 \\
\hline$\sigma_{\mathrm{s} 21}$ & 0 & 0 & 0 & 0 \\
\hline
\end{tabular}


* The diffusion coefficients are in $\mathrm{cm}$, and the cross sections in $\mathrm{cm}^{-1}$

Table 3-2. $K_{\infty}{ }^{*}$ for assemblies in configurations 1 and 2 (two-group)

\begin{tabular}{|c|c|}
\hline Assembly Type & $\mathbf{K}_{\propto}$ \\
\hline 1 & 1.33267 \\
\hline 2 & 1.30188 \\
\hline 3 & 0.66768 \\
\hline
\end{tabular}

*Calculated with 6 meshes/each material region

Assembly 1
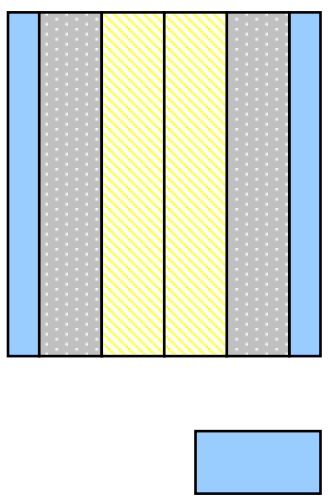

Water
Assembly 2
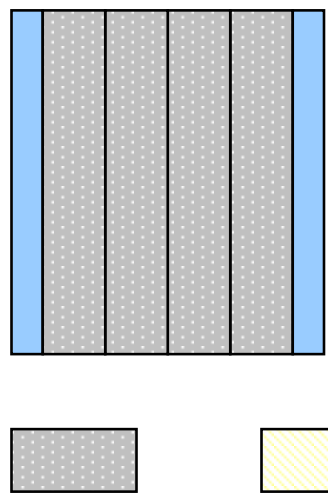

Fuel I
Assembly 3
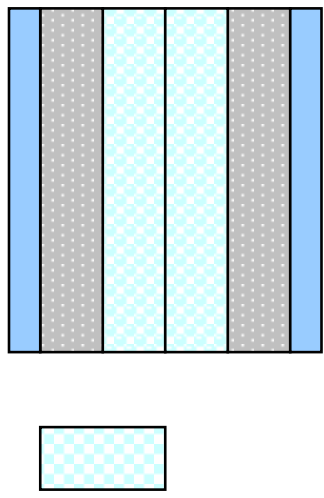

Fuel III (with Gd)

Configuration 1

\begin{tabular}{|l|l|l|l|l|l|l|}
\hline 1 & 2 & 1 & 2 & 1 & 2 & 1 \\
\hline
\end{tabular}

Configuration 2

\begin{tabular}{|l|l|l|l|l|l|l|}
\hline 1 & 3 & 1 & 3 & 1 & 3 & 1 \\
\hline
\end{tabular}

Figure 3-1. Assemblies and Configurations Layouts for Cores 1 and 2 


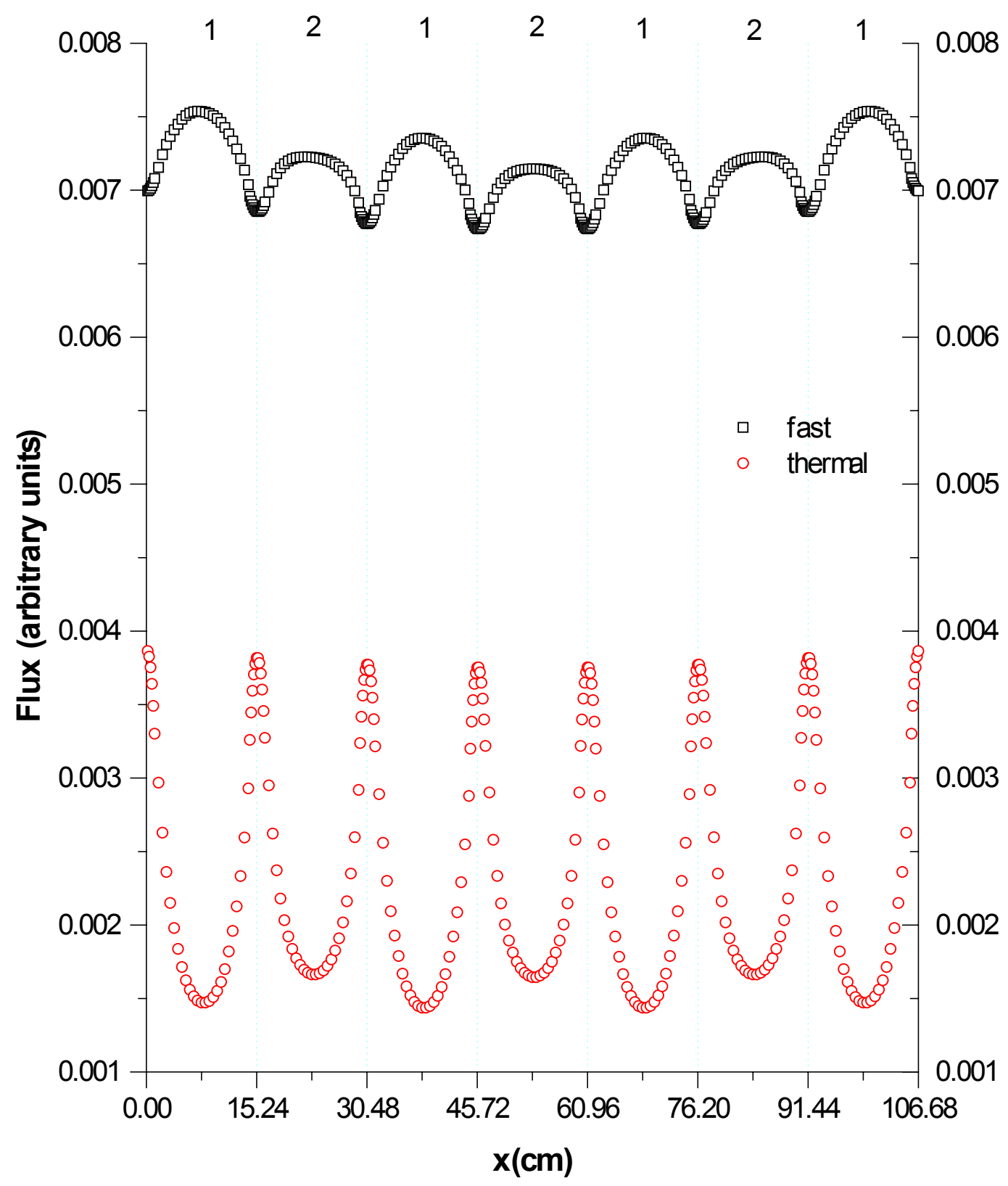

Figure 3-2. Flux Distribution in Configuration 1 


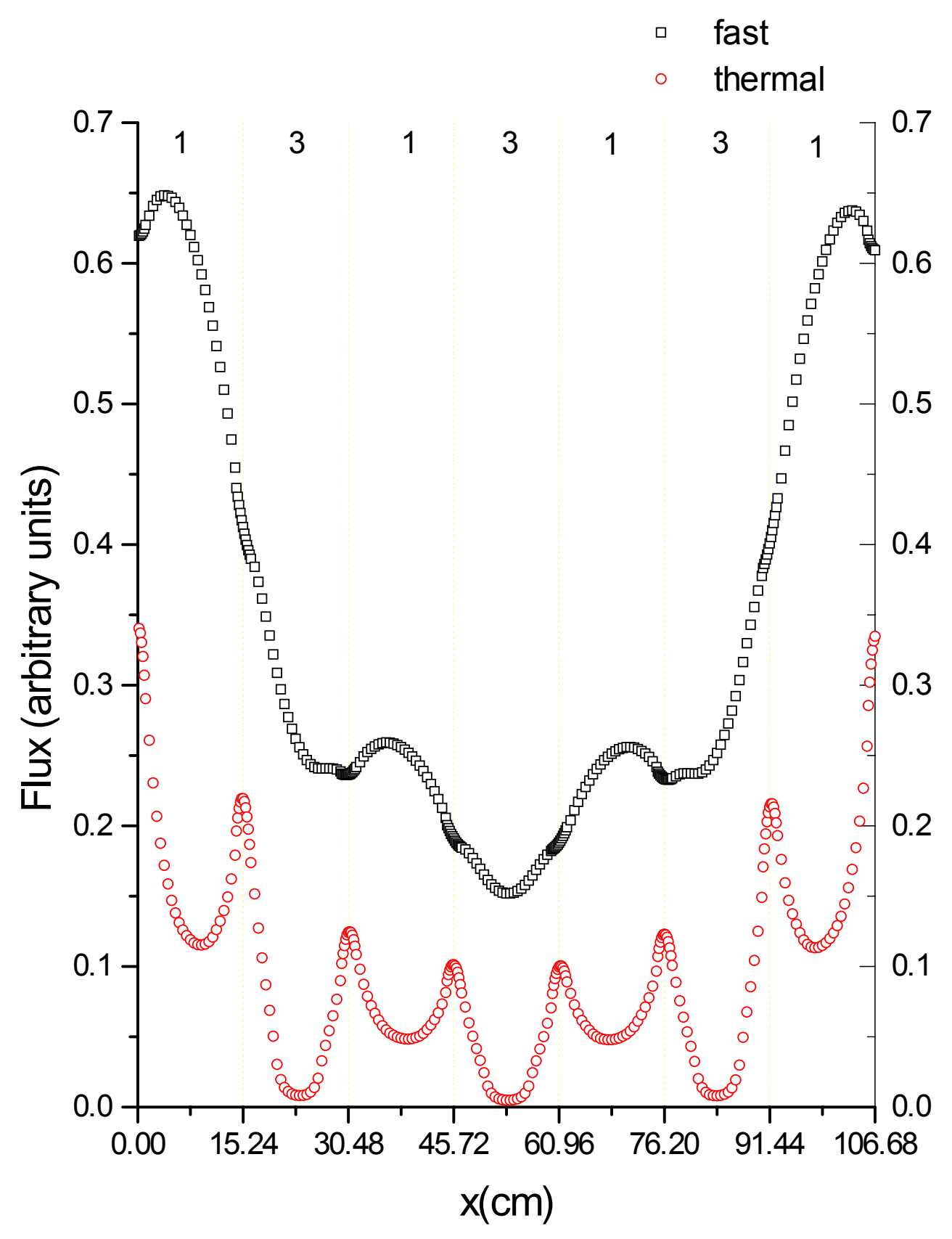

Figure 3-3. Flux Distribution in Configuration 2 


\subsubsection{Development of new benchmarks}

Three new more realistic benchmark configurations typical of a BWR in slab geometry were developed. Each core configuration has 16 fuel assemblies, and a total length of $243.84 \mathrm{~cm}$. There are six different assembly types. Each assembly, of the GE-9 bundle design, consists of eight fuel regions with water gaps at each side. The assembly and core layouts are shown in Figures 3-4 and 3-5, respectively. The assembly types are labeled from 1 to 6 , and the core types are labeled A, B, and C. The cross sections for each assembly type are given in Tables 3-3 to 3-8, and the infinite-medium multiplication constant is given in Table 3-9. The fine-mesh flux distributions from in core configurations A, B and $\mathrm{C}$ are shown in Figures 3-6, 3-7 and 3-8, respectively. Because of the symmetry, only the distribution for the left half of the configuration is shown. It can be observed that core $\mathrm{C}$ is the most heterogeneous one, with large variations of the flux across the core.

The two-group cross sections for the one-dimensional assemblies in Figure 3-4 were generated from the infinite-medium solution of a fine-mesh two-dimensional model of the $8 \times 8$ GE9 fuel assembly [3] with eight burnable gadolinium absorber rods. The infinite-medium solution was computed using the collision-probability code HELIOS [2] version 1.6 [7] with a 45-group neutron cross section library. A plot of the HELIOS computational mesh is shown in Figure 3-9. Note that only half of the assembly was modeled due to the diagonal symmetry of the system. The fuel was depleted to a burnup of 50,000 MWd/tU through 52 time steps. Six burnup levels were selected for use in the 1-D slab problem: fresh fuel with equilibrium Xenon and Samarium concentrations; 12,$000 ; 27,500 ; 30,000 ; 35,000$; and 50,000 MWd/tU. The fine-group cross sections for these assembly states were then homogenized in ten regions and collapsed to the classic two-group structure $(0.625 \mathrm{eV}$ fast/thermal boundary). The regions correspond to vertical slices of the assembly. With the assembly oriented with the wide gap on the left (as in Figure 3-9), the first region includes everything to the left of the first column of pin cells. The next eight regions correspond to the eight columns of pin cells. Note that the central two columns do not have straight vertical boundaries in the HELIOS model. Consequently, the average width of each of these two regions was used in the 1-D slab model. The tenth and final region corresponds to everything to the right of the last column of pin cells. Finally, assemblies were arranged in the 1-D core so that the wide and narrow gaps of neighboring assemblies were adjacent, as in actual BWR cores. 

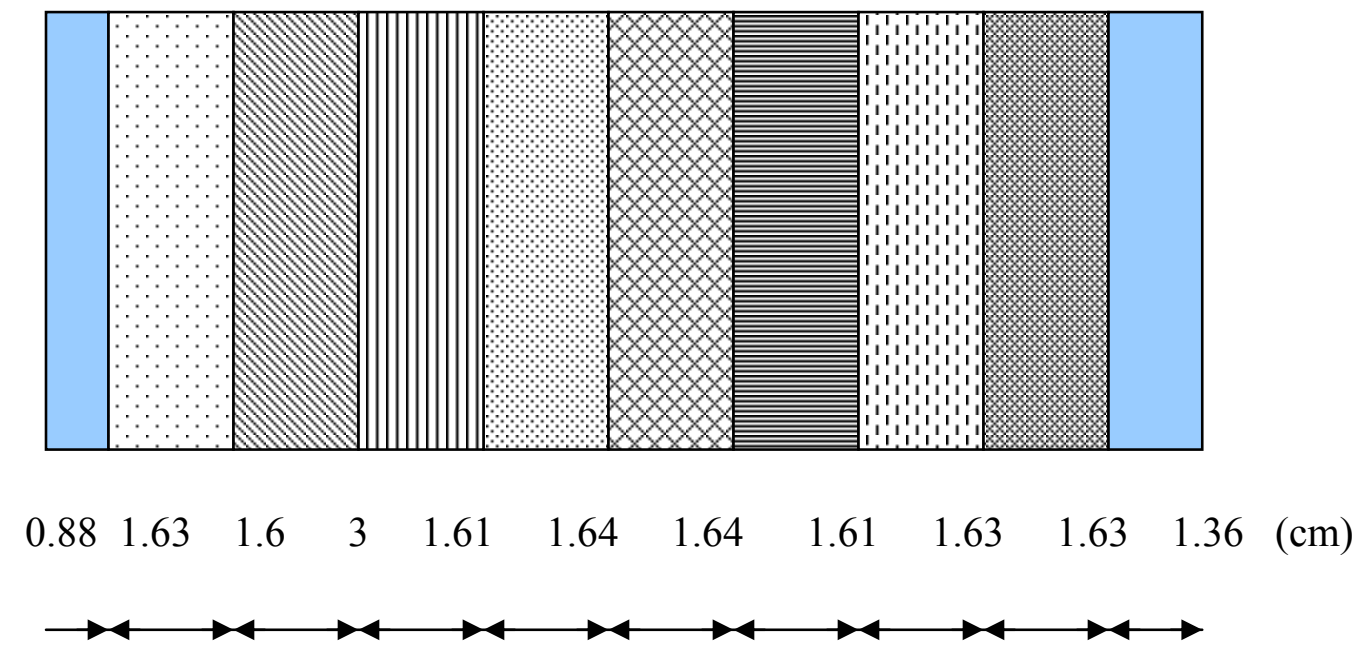

Geometry for assembly type 1, 3 and 5

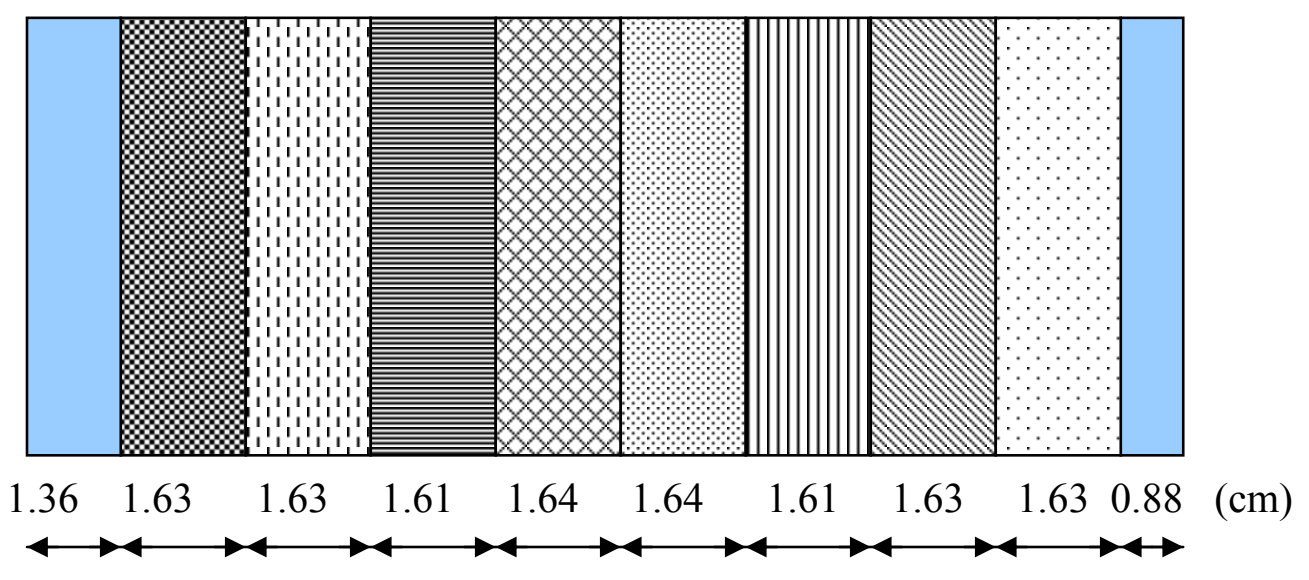

Geometry for assembly type 2, 4 and 6

Figure 3-4. Layouts for Assemblies in Configurations A, B, and C 


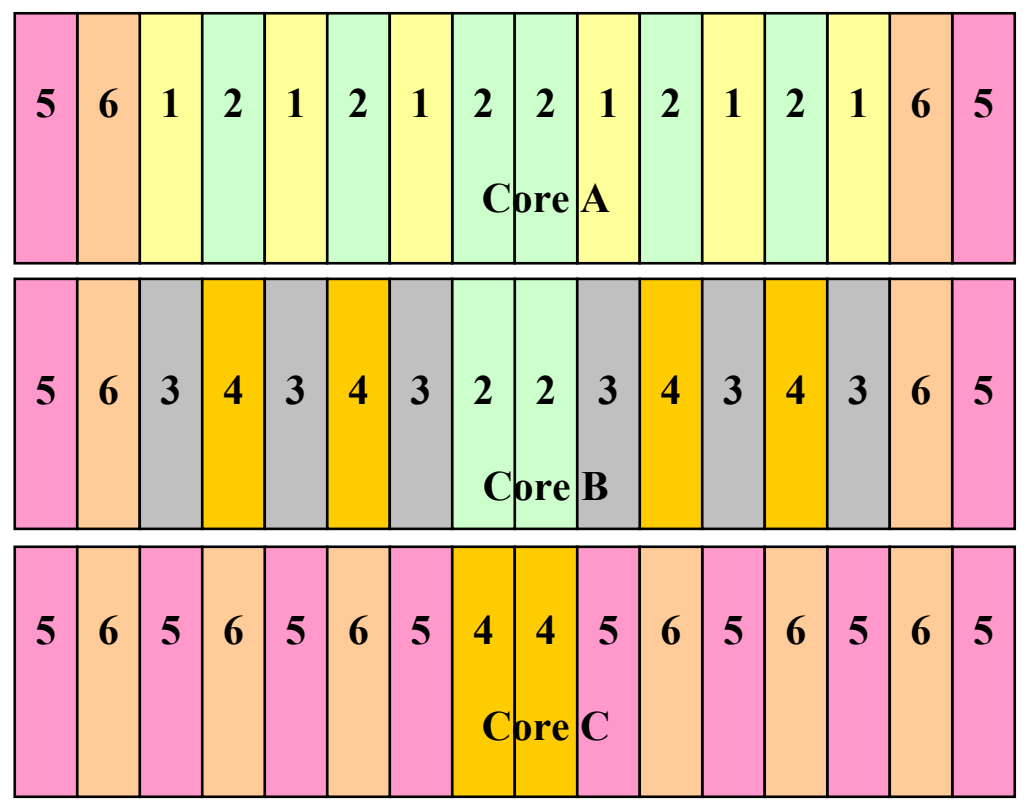

Figure 3-5. Layouts for Configurations A, B and C

Table 3-3. $K_{\propto}{ }^{*}$ for Assemblies in Cores A, B and C

\begin{tabular}{|c|c|c|}
\hline Assembly & $\begin{array}{c}\text { Burnup } \\
(\mathbf{M W d} / \mathbf{t U})\end{array}$ & $\mathbf{K}_{\propto}{ }^{*}$ \\
\hline 1 & 30,000 & 0.99787 \\
\hline 2 & 27,500 & 1.02104 \\
\hline 3 & 35,000 & 0.95309 \\
\hline 4 & $0+\mathrm{Xe} / \mathrm{Sm}$ & 1.05206 \\
\hline 5 & 50,000 & 0.83781 \\
\hline 6 & 12,000 & 1.16238 \\
\hline
\end{tabular}

Fine-mesh calculations with 6 meshes per material region 
Table 3-4. Cross Section* Data for Assembly 1

\begin{tabular}{|c|c|c|c|c|c|c|c|}
\hline Material \# $^{* * *}$ & $\mathbf{D}_{1}$ & $v \sigma_{f 1}$ & $\sigma_{\mathrm{a} 1}$ & $\sigma_{12}$ & $\mathbf{D}_{2}$ & $v \sigma_{f 2}$ & $\sigma_{\mathrm{a} 2}$ \\
\hline 1 & $.123606 \mathrm{E}+01$ & $.000000 \mathrm{E}+00$ & $.502126 \mathrm{E}-03$ & $.294667 \mathrm{E}-01$ & $.275967 \mathrm{E}+00$ & $.000000 \mathrm{E}+00$ & $.824310 \mathrm{E}-02$ \\
\hline 2 & $.132711 \mathrm{E}+01$ & $.357186 \mathrm{E}-02$ & $.912890 \mathrm{E}-02$ & $.134793 \mathrm{E}-01$ & $.418860 \mathrm{E}+00$ & $.673313 \mathrm{E}-01$ & $.575315 \mathrm{E}-01$ \\
\hline 3 & $.134518 \mathrm{E}+01$ & $.418529 \mathrm{E}-02$ & $.871413 \mathrm{E}-02$ & $.122726 \mathrm{E}-01$ & $.414601 \mathrm{E}+00$ & $.845764 \mathrm{E}-01$ & $.659061 \mathrm{E}-01$ \\
\hline 4 & $.134056 \mathrm{E}+01$ & $.450485 \mathrm{E}-02$ & $.904711 \mathrm{E}-02$ & $.116912 \mathrm{E}-01$ & $.414376 \mathrm{E}+00$ & $.959859 \mathrm{E}-01$ & $.721948 \mathrm{E}-01$ \\
\hline 5 & $.133044 \mathrm{E}+01$ & $.339868 \mathrm{E}-02$ & $.686882 \mathrm{E}-02$ & $.149655 \mathrm{E}-01$ & $.363271 \mathrm{E}+00$ & $.683769 \mathrm{E}-01$ & $.534524 \mathrm{E}-01$ \\
\hline 6 & $.133026 \mathrm{E}+01$ & $.348024 \mathrm{E}-02$ & $.677523 \mathrm{E}-02$ & $.152843 \mathrm{E}-01$ & $.363114 \mathrm{E}+00$ & $.701716 \mathrm{E}-01$ & $.539338 \mathrm{E}-01$ \\
\hline 7 & $.133903 \mathrm{E}+01$ & $.477865 \mathrm{E}-02$ & $.911480 \mathrm{E}-02$ & $.111977 \mathrm{E}-01$ & $.413490 \mathrm{E}+00$ & $.104183 \mathrm{E}+00$ & $.760959 \mathrm{E}-01$ \\
\hline 8 & $.134394 \mathrm{E}+01$ & $.467405 \mathrm{E}-02$ & $.894015 \mathrm{E}-02$ & $.113039 \mathrm{E}-01$ & $.412236 \mathrm{E}+00$ & $.994829 \mathrm{E}-01$ & $.733380 \mathrm{E}-01$ \\
\hline 9 & $.132979 \mathrm{E}+01$ & $.436352 \mathrm{E}-02$ & $.927441 \mathrm{E}-02$ & $.120595 \mathrm{E}-01$ & $.413988 \mathrm{E}+00$ & $.908413 \mathrm{E}-01$ & $.692121 \mathrm{E}-01$ \\
\hline 10 & $.128959 \mathrm{E}+01$ & $.000000 \mathrm{E}+00$ & $.594152 \mathrm{E}-03$ & $.230344 \mathrm{E}-01$ & $.315804 \mathrm{E}+00$ & $.000000 \mathrm{E}+00$ & $.739186 \mathrm{E}-02$ \\
\hline
\end{tabular}

${ }^{*}$ Diffusion coefficients are in $\mathrm{cm}$ and cross sections are in $\mathrm{cm}^{-1}$; no upscattering.

${ }^{* *}$ From left to right of the assembly

Table 3-5. Cross Section* Data for Assembly 2

\begin{tabular}{|c|c|c|c|c|c|c|c|}
\hline Material \# & $\mathbf{D}_{1}$ & $v \sigma_{f 1}$ & $\sigma_{\mathrm{a} 1}$ & $\sigma_{12}$ & $\mathbf{D}_{2}$ & $v \sigma_{f 2}$ & $\sigma_{\mathrm{a} 2}$ \\
\hline 1 & $.129066 \mathrm{E}+01$ & $.000000 \mathrm{E}+00$ & $.593008 \mathrm{E}-03$ & $.229587 \mathrm{E}-01$ & $.316129 \mathrm{E}+00$ & $.000000 \mathrm{E}+00$ & $.738181 \mathrm{E}-02$ \\
\hline 2 & $.133083 \mathrm{E}+01$ & 448700E-02 & $.921768 \mathrm{E}-02$ & $.120335 \mathrm{E}-01$ & $.413772 \mathrm{E}+00$ & 937679E-01 & $.700652 \mathrm{E}-01$ \\
\hline 3 & $.134491 \mathrm{E}+01$ & $.480552 \mathrm{E}-02$ & $.889558 \mathrm{E}-02$ & $.112858 \mathrm{E}-01$ & $.412123 \mathrm{E}+00$ & $.102478 \mathrm{E}+00$ & $.741872 \mathrm{E}-01$ \\
\hline 4 & $.133999 \mathrm{E}+01$ & $.491485 \mathrm{E}-02$ & $.906971 \mathrm{E}-02$ & $.111782 \mathrm{E}-01$ & $.413368 \mathrm{E}+00$ & $.107359 \mathrm{E}+00$ & $.770120 \mathrm{E}-01$ \\
\hline 5 & $.133130 \mathrm{E}+01$ & $.358057 \mathrm{E}-02$ & $.674298 \mathrm{E}-02$ & $.152424 \mathrm{E}-01$ & $.363115 \mathrm{E}+00$ & $.723637 \mathrm{E}-01$ & $.545548 \mathrm{E}-01$ \\
\hline 6 & $.133157 \mathrm{E}+01$ & $.350162 \mathrm{E}-02$ & $.683371 \mathrm{E}-02$ & $.149244 \mathrm{E}-01$ & $.363234 \mathrm{E}+00$ & $.706760 \mathrm{E}-01$ & $.541394 \mathrm{E}-01$ \\
\hline 7 & $.134169 \mathrm{E}+01$ & $.464404 \mathrm{E}-02$ & $.900012 \mathrm{E}-02$ & $.116669 \mathrm{E}-01$ & $.414063 \mathrm{E}+00$ & $.994246 \mathrm{E}-01$ & $.732746 \mathrm{E}-01$ \\
\hline 8 & $.134633 \mathrm{E}+01$ & $.431137 \mathrm{E}-02$ & $.866630 \mathrm{E}-02$ & $.122512 \mathrm{E}-01$ & $.414260 \mathrm{E}+00$ & $.877441 \mathrm{E}-01$ & $.669033 \mathrm{E}-01$ \\
\hline 9 & $.132837 \mathrm{E}+01$ & .365292E-02 & $.904741 \mathrm{E}-02$ & $.134504 \mathrm{E}-01$ & $.418656 \mathrm{E}+00$ & $.695389 \mathrm{E}-01$ & $.581468 \mathrm{E}-01$ \\
\hline 10 & $.123725 \mathrm{E}+01$ & $.000000 \mathrm{E}+00$ & $.501013 \mathrm{E}-03$ & $.293568 \mathrm{E}-01$ & $.276130 \mathrm{E}+00$ & $.000000 \mathrm{E}+00$ & $.823674 \mathrm{E}-02$ \\
\hline
\end{tabular}

${ }^{*}$ Diffusion coefficients are in $\mathrm{cm}$ and cross sections are in $\mathrm{cm}^{-1}$; no upscattering

${ }^{* *}$ From left to right of the assembly 
Table 3-6. Cross Section* Data for Assembly 3

\begin{tabular}{|c|c|c|c|c|c|c|c|}
\hline Material \# $^{* * *}$ & $\mathbf{D}_{1}$ & $v \sigma_{f 1}$ & $\sigma_{\mathrm{a} 1}$ & $\sigma_{12}$ & $\mathbf{D}_{2}$ & $v \sigma_{f 2}$ & $\sigma_{\mathrm{a} 2}$ \\
\hline 1 & $.123391 \mathrm{E}+01$ & $.000000 \mathrm{E}+00$ & $.504241 \mathrm{E}-03$ & $.296708 \mathrm{E}-01$ & $.275660 \mathrm{E}+00$ & $.000000 \mathrm{E}+00$ & $.825518 \mathrm{E}-02$ \\
\hline 2 & $.132492 \mathrm{E}+01$ & $.343357 \mathrm{E}-02$ & $.929063 \mathrm{E}-02$ & $.135307 \mathrm{E}-01$ & $.419244 \mathrm{E}+00$ & .634313E-01 & $.564453 \mathrm{E}-01$ \\
\hline 3 & $.134308 \mathrm{E}+01$ & $.395448 \mathrm{E}-02$ & $.880972 \mathrm{E}-02$ & $.123112 \mathrm{E}-01$ & $.415354 \mathrm{E}+00$ & $.785511 \mathrm{E}-01$ & $.639516 \mathrm{E}-01$ \\
\hline 4 & $.133846 \mathrm{E}+01$ & $.424347 \mathrm{E}-02$ & $.914015 \mathrm{E}-02$ & $.117385 \mathrm{E}-01$ & $.415143 \mathrm{E}+00$ & $.892341 \mathrm{E}-01$ & $.699840 \mathrm{E}-01$ \\
\hline 5 & $.132830 \mathrm{E}+01$ & $.320441 \mathrm{E}-02$ & $.693837 \mathrm{E}-02$ & $.150491 \mathrm{E}-01$ & $.363420 \mathrm{E}+00$ & $.638225 \mathrm{E}-01$ & $.520241 \mathrm{E}-01$ \\
\hline 6 & $.132827 \mathrm{E}+01$ & $.328983 \mathrm{E}-02$ & $.683864 \mathrm{E}-02$ & $.153671 \mathrm{E}-01$ & $.363197 \mathrm{E}+00$ & $.657869 \mathrm{E}-01$ & $.526174 \mathrm{E}-01$ \\
\hline 7 & $.133723 \mathrm{E}+01$ & $.451778 \mathrm{E}-02$ & $.920275 \mathrm{E}-02$ & $.112397 \mathrm{E}-01$ & $.413921 \mathrm{E}+00$ & $.977767 \mathrm{E}-01$ & $.741315 \mathrm{E}-01$ \\
\hline 8 & $.134214 \mathrm{E}+01$ & $.442286 \mathrm{E}-02$ & $.902725 \mathrm{E}-02$ & $.113430 \mathrm{E}-01$ & $.412638 \mathrm{E}+00$ & $.934750 \mathrm{E}-01$ & $.715297 \mathrm{E}-01$ \\
\hline 9 & $.132786 \mathrm{E}+01$ & $.413453 \mathrm{E}-02$ & $.938686 \mathrm{E}-02$ & $.121126 \mathrm{E}-01$ & $.414507 \mathrm{E}+00$ & $.851878 \mathrm{E}-01$ & $.674935 \mathrm{E}-01$ \\
\hline 10 & $.128756 \mathrm{E}+01$ & $.000000 \mathrm{E}+00$ & $.596386 \mathrm{E}-03$ & $.231822 \mathrm{E}-01$ & $.315162 \mathrm{E}+00$ & $.000000 \mathrm{E}+00$ & $.741177 \mathrm{E}-02$ \\
\hline
\end{tabular}

${ }^{*}$ Diffusion coefficients are in $\mathrm{cm}$ and cross sections are in $\mathrm{cm}^{-1}$; no upscattering.

${ }^{* *}$ From left to right of the assembly

Table 3-7. Cross Section* Data for Assembly 4

\begin{tabular}{|c|c|c|c|c|c|c|c|}
\hline Material \# & $\mathbf{D}_{1}$ & $v \sigma_{\mathbf{f} 1}$ & $\sigma_{\mathrm{a} 1}$ & $\sigma_{12}$ & $\mathbf{D}_{2}$ & $v \sigma_{f 2}$ & $\sigma_{\mathrm{a} 2}$ \\
\hline 1 & $.128965 \mathrm{E}+01$ & $.000000 \mathrm{E}+00$ & $.589990 \mathrm{E}-03$ & $.232679 \mathrm{E}-01$ & $.319333 \mathrm{E}+00$ & $.000000 \mathrm{E}+00$ & $.728288 \mathrm{E}-02$ \\
\hline 2 & $.133315 \mathrm{E}+01$ & $.624849 \mathrm{E}-02$ & $.841321 \mathrm{E}-02$ & $.125178 \mathrm{E}-01$ & $.419496 \mathrm{E}+00$ & $.108700 \mathrm{E}+00$ & $.660741 \mathrm{E}-01$ \\
\hline 3 & $.133930 \mathrm{E}+01$ & $.633130 \mathrm{E}-02$ & $.887330 \mathrm{E}-02$ & $.119167 \mathrm{E}-01$ & $.400060 \mathrm{E}+00$ & $.972496 \mathrm{E}-01$ & $.963494 \mathrm{E}-01$ \\
\hline 4 & $.133295 \mathrm{E}+01$ & $.646164 \mathrm{E}-02$ & $.905883 \mathrm{E}-02$ & $.117938 \mathrm{E}-01$ & $.399344 \mathrm{E}+00$ & $.991401 \mathrm{E}-01$ & $.101514 \mathrm{E}+00$ \\
\hline 5 & $.132750 \mathrm{E}+01$ & $.487744 \mathrm{E}-02$ & $.631206 \mathrm{E}-02$ & $.157675 \mathrm{E}-01$ & $.371781 \mathrm{E}+00$ & $.805383 \mathrm{E}-01$ & $.504019 \mathrm{E}-01$ \\
\hline 6 & $.132481 \mathrm{E}+01$ & $.470393 \mathrm{E}-02$ & $.696659 \mathrm{E}-02$ & $.154214 \mathrm{E}-01$ & $.353952 \mathrm{E}+00$ & $.653003 \mathrm{E}-01$ & $.818175 \mathrm{E}-01$ \\
\hline 7 & $.133896 \mathrm{E}+01$ & $.631830 \mathrm{E}-02$ & $.893711 \mathrm{E}-02$ & $.123118 \mathrm{E}-01$ & $.397431 \mathrm{E}+00$ & $.978842 \mathrm{E}-01$ & $.101481 \mathrm{E}+00$ \\
\hline 8 & $.135244 \mathrm{E}+01$ & $.614404 \mathrm{E}-02$ & $.795681 \mathrm{E}-02$ & $.127463 \mathrm{E}-01$ & $.419030 \mathrm{E}+00$ & $.107776 \mathrm{E}+00$ & $.657387 \mathrm{E}-01$ \\
\hline 9 & $.133924 \mathrm{E}+01$ & $.517189 \mathrm{E}-02$ & $.784389 \mathrm{E}-02$ & $.137731 \mathrm{E}-01$ & $.423202 \mathrm{E}+00$ & $.870540 \mathrm{E}-01$ & $.562101 \mathrm{E}-01$ \\
\hline 10 & $.124152 \mathrm{E}+01$ & $.000000 \mathrm{E}+00$ & $.494303 \mathrm{E}-03$ & $.291780 \mathrm{E}-01$ & $.277557 \mathrm{E}+00$ & $.000000 \mathrm{E}+00$ & $.818209 \mathrm{E}-02$ \\
\hline
\end{tabular}

Diffusion coefficients are in $\mathrm{cm}$ and cross sections are in $\mathrm{cm}^{-1}$; no upscattering.

** From left to right of the assembly 
Table 3-8. Cross Section* Data for Assembly 5

\begin{tabular}{|c|c|c|c|c|c|c|c|}
\hline Material \# $^{* * *}$ & $\mathbf{D}_{1}$ & $v \sigma_{f 1}$ & $\sigma_{\mathrm{a} 1}$ & $\sigma_{12}$ & $\mathbf{D}_{2}$ & $v \sigma_{f 2}$ & $\sigma_{\mathrm{a} 2}$ \\
\hline 1 & $.122965 \mathrm{E}+01$ & $.000000 \mathrm{E}+00$ & $.509310 \mathrm{E}-03$ & $.300991 \mathrm{E}-01$ & $.274934 \mathrm{E}+00$ & $.000000 \mathrm{E}+00$ & $.828368 \mathrm{E}-02$ \\
\hline 2 & $.132110 \mathrm{E}+01$ & $.318544 \mathrm{E}-02$ & $.974767 \mathrm{E}-02$ & $.136133 \mathrm{E}-01$ & $.419990 \mathrm{E}+00$ & $.558469 \mathrm{E}-01$ & $.545154 \mathrm{E}-01$ \\
\hline 3 & $.133902 \mathrm{E}+01$ & $.345481 \mathrm{E}-02$ & $.909815 \mathrm{E}-02$ & $.123717 \mathrm{E}-01$ & $.417492 \mathrm{E}+00$ & $.645840 \mathrm{E}-01$ & $.593034 \mathrm{E}-01$ \\
\hline 4 & $.133386 \mathrm{E}+01$ & $.363393 \mathrm{E}-02$ & $.942208 \mathrm{E}-02$ & $.118380 \mathrm{E}-01$ & $.417709 \mathrm{E}+00$ & $.722484 \mathrm{E}-01$ & $.641240 \mathrm{E}-01$ \\
\hline 5 & $.132318 \mathrm{E}+01$ & $.274190 \mathrm{E}-02$ & $.715081 \mathrm{E}-02$ & $.152664 \mathrm{E}-01$ & $.364127 \mathrm{E}+00$ & $.520350 \mathrm{E}-01$ & $.480830 \mathrm{E}-01$ \\
\hline 6 & $.132341 \mathrm{E}+01$ & $.282721 \mathrm{E}-02$ & $.703014 \mathrm{E}-02$ & $.155714 \mathrm{E}-01$ & $.363790 \mathrm{E}+00$ & $.541166 \mathrm{E}-01$ & $.488156 \mathrm{E}-01$ \\
\hline 7 & $.133293 \mathrm{E}+01$ & $.386514 \mathrm{E}-02$ & $.946561 \mathrm{E}-02$ & $.113599 \mathrm{E}-01$ & $.416041 \mathrm{E}+00$ & $.802240 \mathrm{E}-01$ & $.682536 \mathrm{E}-01$ \\
\hline 8 & $.133796 \mathrm{E}+01$ & $.379774 \mathrm{E}-02$ & $.928761 \mathrm{E}-02$ & $.114561 \mathrm{E}-01$ & $.414607 \mathrm{E}+00$ & $.771718 \mathrm{E}-01$ & $.661796 \mathrm{E}-01$ \\
\hline 9 & $.132366 \mathrm{E}+01$ & $.361035 \mathrm{E}-02$ & $.972077 \mathrm{E}-02$ & $.122524 \mathrm{E}-01$ & $.416248 \mathrm{E}+00$ & $.712566 \mathrm{E}-01$ & $.630325 \mathrm{E}-01$ \\
\hline 10 & $.128269 \mathrm{E}+01$ & $.000000 \mathrm{E}+00$ & $.602301 \mathrm{E}-03$ & $.235516 \mathrm{E}-01$ & $.313506 \mathrm{E}+00$ & $.000000 \mathrm{E}+00$ & $.746432 \mathrm{E}-02$ \\
\hline
\end{tabular}

${ }^{*}$ Diffusion coefficients are in $\mathrm{cm}$ and cross sections are in $\mathrm{cm}^{-1}$; no upscattering.

${ }^{* *}$ From left to right of the assembly

Table 3-9. Cross Section* Data for Assembly 6

\begin{tabular}{|c|c|c|c|c|c|c|c|}
\hline Material \# & $\mathbf{D}_{1}$ & $v \sigma_{f 1}$ & $\sigma_{\mathrm{a} 1}$ & $\sigma_{12}$ & $\mathbf{D}_{2}$ & $v \sigma_{f 2}$ & $\sigma_{\mathrm{a} 2}$ \\
\hline 1 & $.129676 \mathrm{E}+01$ & $.000000 \mathrm{E}+00$ & $.586354 \mathrm{E}-03$ & $.225763 \mathrm{E}-01$ & $.318163 \mathrm{E}+00$ & $.000000 \mathrm{E}+00$ & $.732088 \mathrm{E}-02$ \\
\hline 2 & $.133757 \mathrm{E}+01$ & $.537239 \mathrm{E}-02$ & $.880688 \mathrm{E}-02$ & $.119636 \mathrm{E}-01$ & $.414007 \mathrm{E}+00$ & $.110721 \mathrm{E}+00$ & $.737301 \mathrm{E}-01$ \\
\hline 3 & $.135063 \mathrm{E}+01$ & $.568988 \mathrm{E}-02$ & $.857664 \mathrm{E}-02$ & $.112871 \mathrm{E}-01$ & $.412227 \mathrm{E}+00$ & $.116708 \mathrm{E}+00$ & $.794471 \mathrm{E}-01$ \\
\hline 4 & $.134570 \mathrm{E}+01$ & $.582692 \mathrm{E}-02$ & $.873877 \mathrm{E}-02$ & $.111657 \mathrm{E}-01$ & $.413776 \mathrm{E}+00$ & $.122522 \mathrm{E}+00$ & $.820451 \mathrm{E}-01$ \\
\hline 5 & $.133753 \mathrm{E}+01$ & $.426455 \mathrm{E}-02$ & $.649957 \mathrm{E}-02$ & $.150814 \mathrm{E}-01$ & $.364382 \mathrm{E}+00$ & $.839712 \mathrm{E}-01$ & $.567871 \mathrm{E}-01$ \\
\hline 6 & $.133846 \mathrm{E}+01$ & $.420883 \mathrm{E}-02$ & $.657689 \mathrm{E}-02$ & $.147676 \mathrm{E}-01$ & $.363679 \mathrm{E}+00$ & $.826763 \mathrm{E}-01$ & $.578628 \mathrm{E}-01$ \\
\hline 7 & $.134912 \mathrm{E}+01$ & $.560637 \mathrm{E}-02$ & $.864986 \mathrm{E}-02$ & $.115892 \mathrm{E}-01$ & $.413849 \mathrm{E}+00$ & $.118378 \mathrm{E}+00$ & $.785372 \mathrm{E}-01$ \\
\hline 8 & $.135434 \mathrm{E}+01$ & $.522557 \mathrm{E}-02$ & $.832292 \mathrm{E}-02$ & $.121641 \mathrm{E}-01$ & $.413774 \mathrm{E}+00$ & $.106964 \mathrm{E}+00$ & $.718649 \mathrm{E}-01$ \\
\hline 9 & $.133755 \mathrm{E}+01$ & $.433802 \mathrm{E}-02$ & $.848741 \mathrm{E}-02$ & $.132915 \mathrm{E}-01$ & $.418015 \mathrm{E}+00$ & $.853734 \mathrm{E}-01$ & $.619111 \mathrm{E}-01$ \\
\hline 10 & $.124513 \mathrm{E}+01$ & $.000000 \mathrm{E}+00$ & $.493887 \mathrm{E}-03$ & $.286684 \mathrm{E}-01$ & $.277157 \mathrm{E}+00$ & $.000000 \mathrm{E}+00$ & $.819725 \mathrm{E}-02$ \\
\hline
\end{tabular}

${ }^{*}$ Diffusion coefficients are in $\mathrm{cm}$ and cross sections are in $\mathrm{cm}^{-1}$; no upscattering

${ }^{* *}$ From left to right of the assembly 


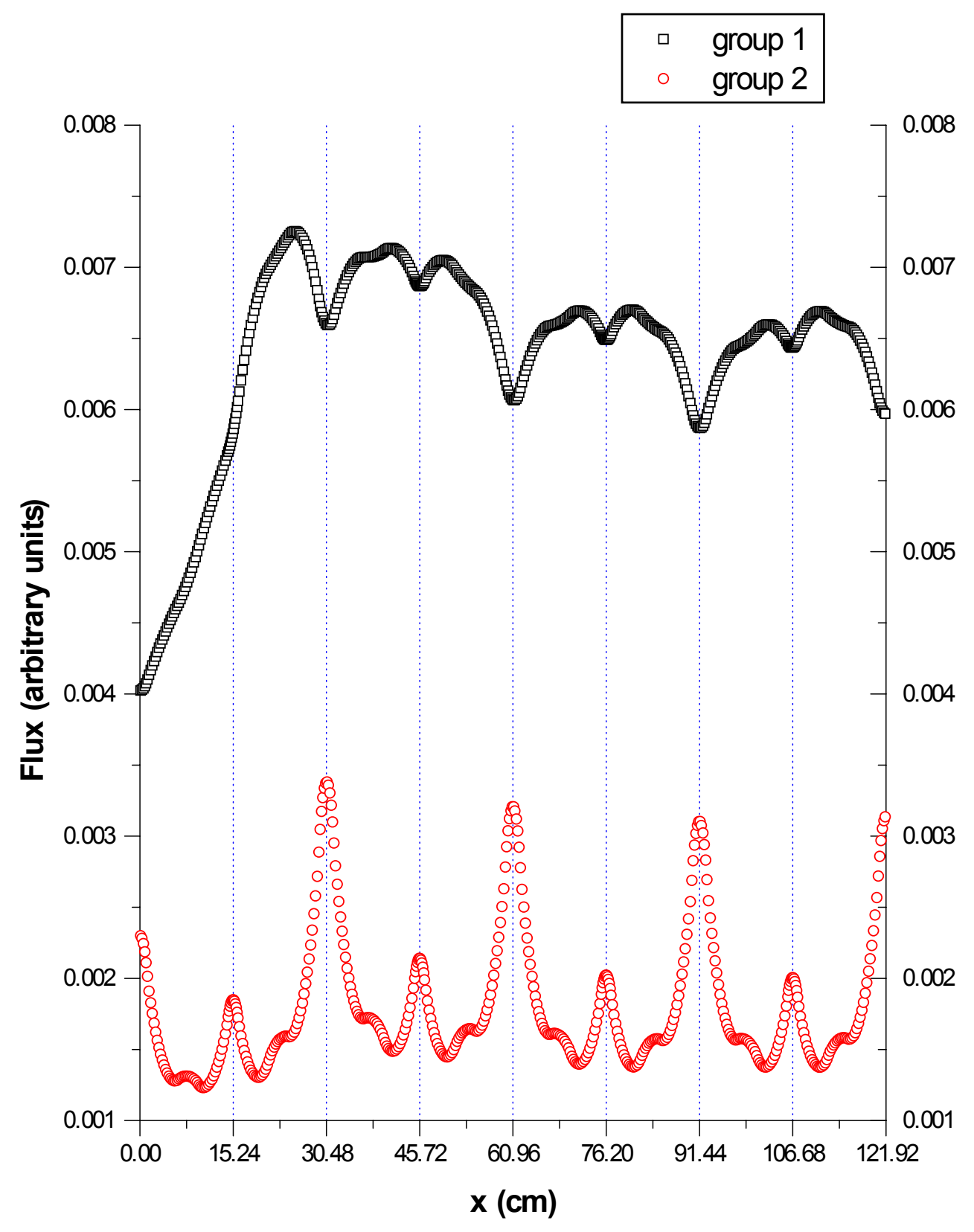

Figure 3-6. Flux Distribution in Configuration A 


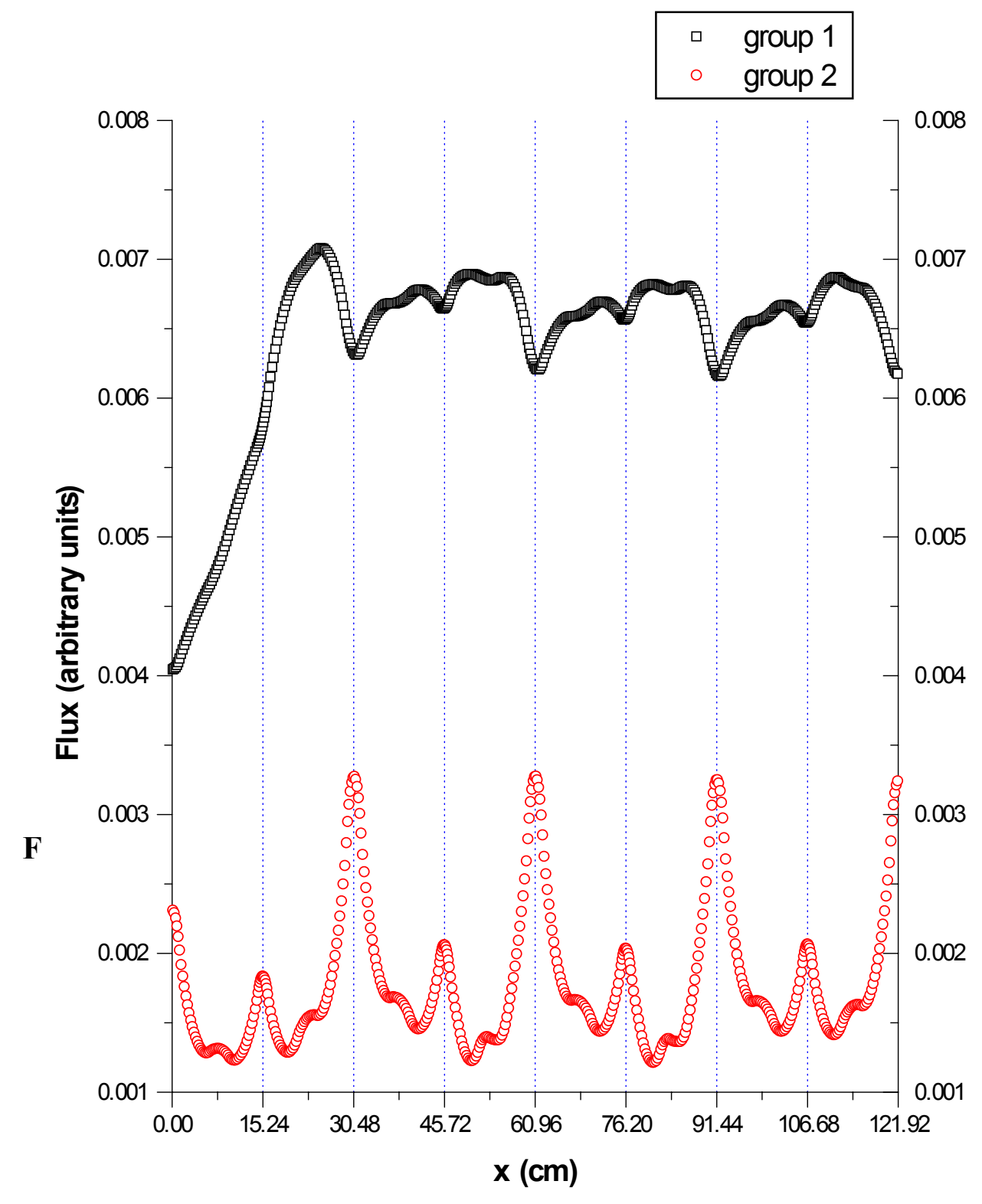

Figure 3-7. Flux Distribution in Configuration B 


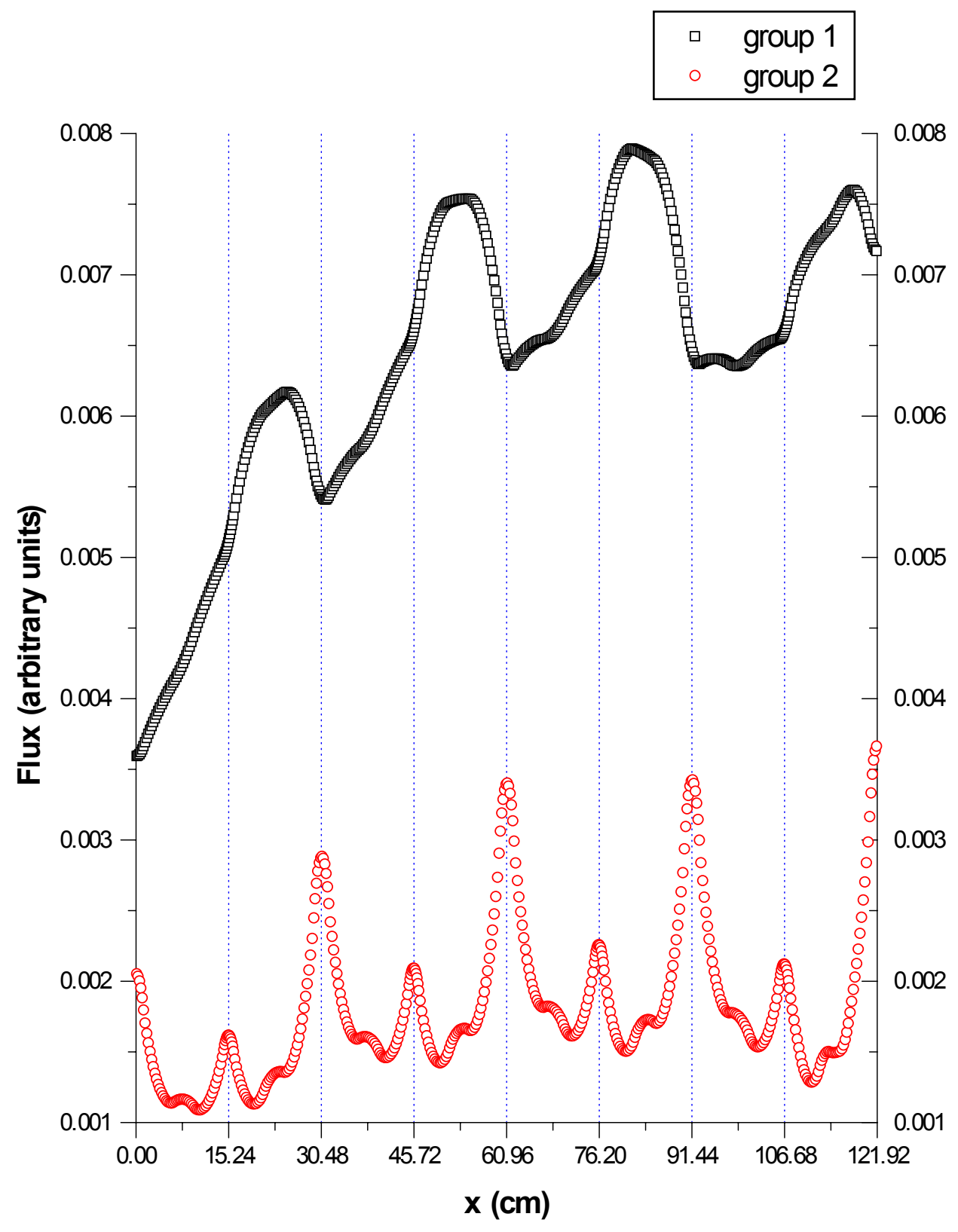

Figure 3-8. Flux Distribution in Configuration $\mathrm{C}$ 


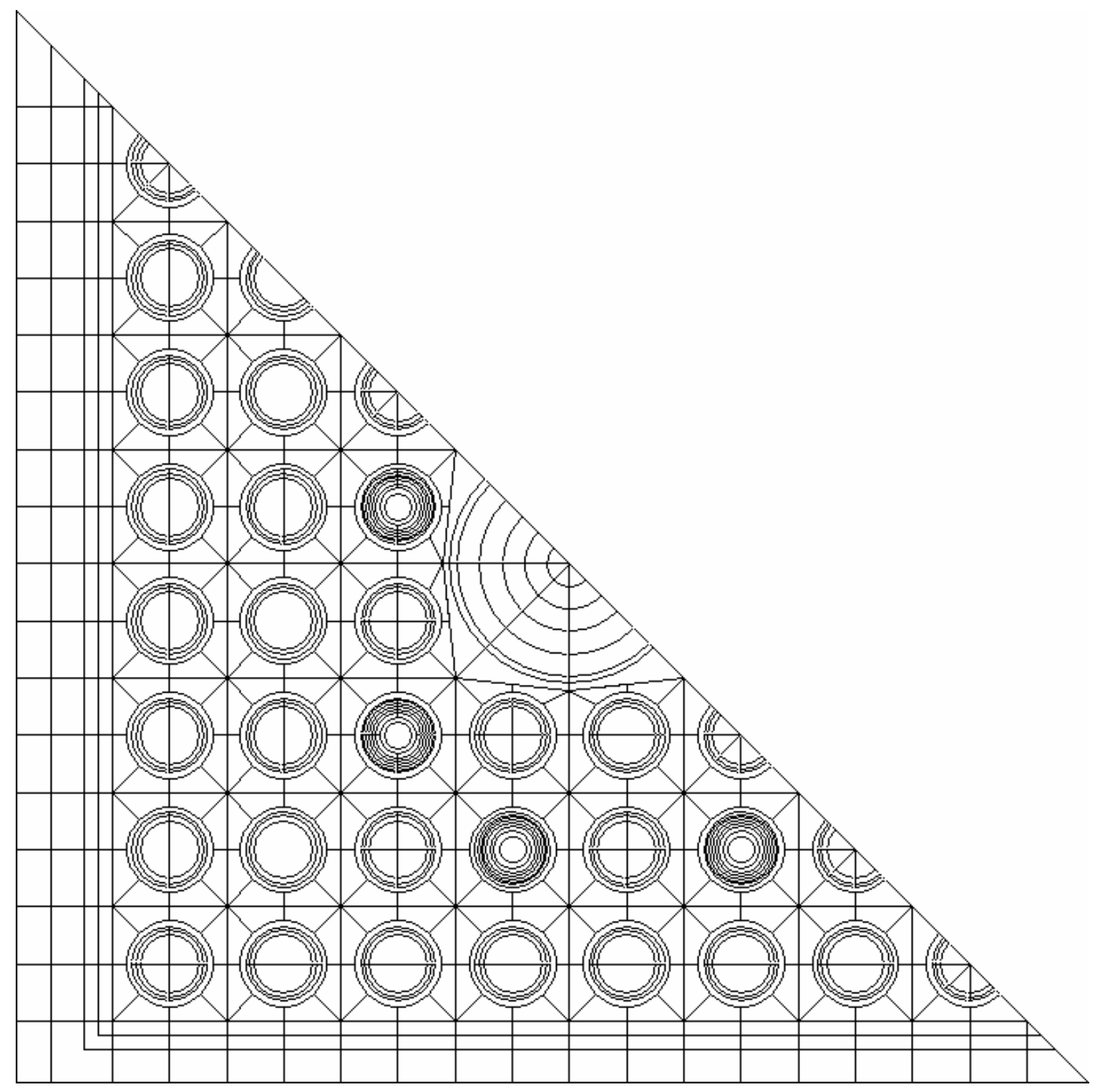

Figure 3-9. HELIOS Model of the GE-9 Fuel Assembly 


\subsection{Two-dimensional configurations}

The benchmark configuration used for two-dimensional problems is the HAFAS core ${ }^{6}$ representing a BWR core. The core, made up of forty-nine assemblies of seven types, is $153.1 \mathrm{~cm}$ by $153.1 \mathrm{~cm}$ (see Figure 3-10). Each assembly contains three distinct types of fuel and water. The mesh layout for an assembly is shown in Figure 3-11. The material map for each assembly type is presented in Table 3-10, and the material composition of each fuel type is found in Table 3-11. The voided assemblies are marked as A7/B7 (70\% void) and A4/B4 (40\% void). The controlled assemblies are identified with a "+" sign. Boxes marked with "W" contain water only.

$$
\mathrm{J}_{\mathrm{in}}=0
$$

\begin{tabular}{|l|l|l|l|l|l|l|l|l|l|}
\hline W & W & W & W & W & W & W & W & W & W \\
\hline A & B & A & B & A & B & A & W & W & W \\
\hline B & A & B & A & B & A & B & W & W & W \\
\hline J & B+ & A+ & B & A & B & A & B & A & W \\
\hline B & A+ & B+ & A & B & A & B & A & B & W \\
\hline A+ & B & A & B+ & A+ & B & A & B & A & W \\
\hline \hline B+ & A & B & A+ & B+ & A & B & A & B & W \\
\hline A7 & B4 & A4 & B & A & B+ & A+ & B & A & W \\
\hline B7 & A4 & B4 & A & B & A+ & B+ & A & B & W \\
\hline A7 & B7 & A7 & B+ & A+ & B & A & B & A & W \\
\hline
\end{tabular}

Figure 3-10. HAFAS core

Table 3-10. Material map for HAFAS assemblies*

\begin{tabular}{|c|c|c|c|c|c|c|c|c|c|}
\hline & A & A4 & A7 & A+ & B & B4 & B7 & B+ & W \\
\hline I & 1 & 5 & 9 & 1 & 2 & 6 & 10 & 2 & 15 \\
\hline II & 2 & 6 & 10 & 2 & 3 & 7 & 11 & 3 & 15 \\
\hline III & 3 & 7 & 11 & 3 & 4 & 8 & 12 & 4 & 15 \\
\hline IV & 13 & 13 & 13 & 14 & 13 & 13 & 13 & 14 & 15 \\
\hline V & 13 & 13 & 13 & 13 & 13 & 13 & 13 & 13 & 15 \\
\hline
\end{tabular}




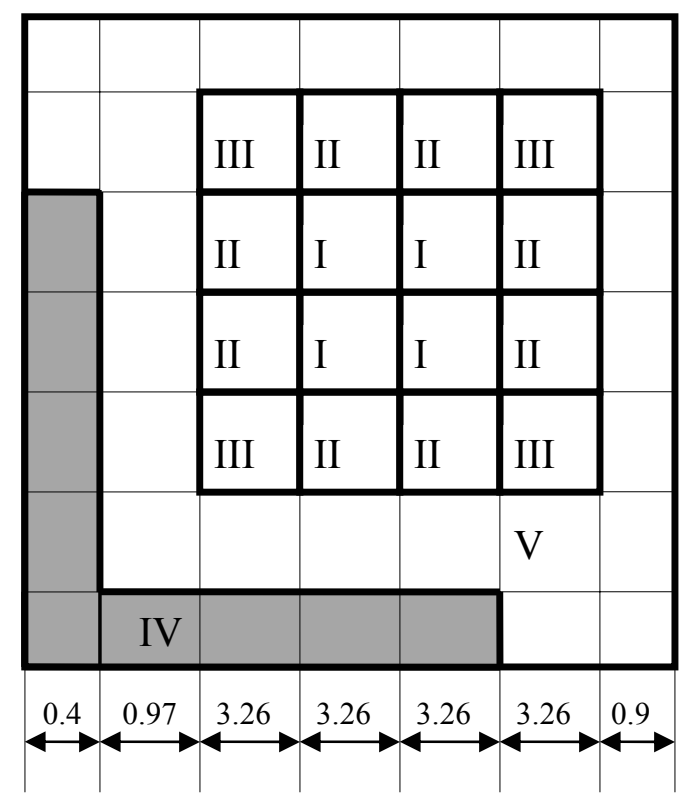

Figure 3-11. Configuration and mesh layout for each assembly

Table 3-11. Material properties for the HAFAS core

\begin{tabular}{|c|c|c|c|c|c|c|c|}
\hline Material & $\begin{array}{c}\mathrm{D}_{1} \\
(\mathrm{~cm})\end{array}$ & $\begin{array}{c}\mathrm{D}_{2} \\
(\mathrm{~cm})\end{array}$ & $\begin{array}{c}\Sigma_{1} \\
\left(\mathrm{~cm}^{-1}\right)\end{array}$ & $\begin{array}{c}\Sigma_{2} \\
\left(\mathrm{~cm}^{-1}\right)\end{array}$ & $\begin{array}{c}\Sigma_{12} \\
\left(\mathrm{~cm}^{-1}\right)\end{array}$ & $\begin{array}{c}v \sum_{\mathrm{f} 1} \\
\left(\mathrm{~cm}^{-1}\right)\end{array}$ & $\begin{array}{c}v \sum_{\mathrm{f} 2} \\
\left(\mathrm{~cm}^{-1}\right)\end{array}$ \\
\hline 1: Fuel a(v & 14000 & 03750 & 0.0090 & & 0.0160 & 0.0065 & 0.1220 \\
\hline 2: $\quad$ Fuel b(void $0 \%)$ & 4000 & 750 & 0090 & 0700 & 0170 & .0057 & .1000 \\
\hline 3: Fuel c & 4000 & 3750 & .0090 & .0600 & .0180 & .0051 & .0800 \\
\hline 4: $\quad$ Fuel d & 4000 & & 90 & & & & .0700 \\
\hline 5: Fuel a & & & & & & & \\
\hline 6: Fuel b & 6800 & 5300 & 0.0085 & .0670 & & .0055 & 0.0960 \\
\hline 7: $\quad$ Fuel c & 6800 & 300 & 0.0090 & & & 0049 & 0.0780 \\
\hline 8: Fuel d & & & & & & & \\
\hline 9: Fuel a & 001 & 0049 & 0.0680 & .0730 & & 0.0061 & 0.1140 \\
\hline 10: Fuel b & 0000 & 8000 & 0.0082 & 0.0630 & .0053 & 0.0053 & 0.0920 \\
\hline 11: Fuel c & 0000 & 00 & & & & 0047 & 0.0720 \\
\hline 12: Fuel d & .0000 & 8000 & & 0430 & & .0047 & .0620 \\
\hline 13: $\mathrm{Can}+\mathrm{W}$ & .5300 & 2950 & 0.0005 & 0.00900 & 0.0031 & 0.0000 & 0.0000 \\
\hline 14: Contro & 1.1100 & 0.1850 & 0.08375 & 0.9500 & 0.00375 & 0.0000 & 0.0000 \\
\hline 15: Water & 2.0000 & 0.3000 & 0.0000 & 0.0100 & 0.0400 & 0.0000 & 0.0000 \\
\hline
\end{tabular}




\section{RESULTS}

\subsection{Convergence of the Expansion Series}

\subsubsection{One-group one-dimensional problems}

The convergence of the expansion series (see Eqs. 2-11, 2-12, 2-19) is tested using as a benchmark an assembly typical of a BWR in slab geometry, as shown in Figure 3-1. An infinite-medium (net zero current) boundary condition is used as the initial state of the assembly. Then different perturbations of the boundary condition (current-to-flux ratio) are considered: those subjected to when the assembly is located in configuration 2 (see Figure 3-1). These current-to-flux ratios are determined for each assembly by performing fine-mesh diffusion calculations for the full core. For each perturbation, the expansion coefficients for flux, eigenvalue and homogenized cross section are calculated, and the corrected values are compared to the "exact" values. The "exact" value here means the flux and eigenvalue obtained from fine-mesh assembly calculation, using for the boundary condition the corresponding current-to-flux ratio obtained from the fine-mesh full core calculation.

The results for assembly type 3 are shown in Tables 4-1 and 4-2. The corresponding results for assembly type 1 are given in Tables 4-3 and 4-4. The "exact" case for each assembly is the single assembly fine-mesh calculation with 1200 meshes per assembly. The "exact" eigenvalue for each case does not perfectly match the eigenvalue for the core (0.8969) due to numerical limitations in determining the albedo and in computations. The comparison of the reference and the calculated flux distributions is made by means of the flux RMS, which is defined as:

$$
R M S=100\left[\frac{1}{N-1} \sum_{i=1}^{N}\left(\frac{\phi_{\text {reference }, i}-\phi_{\text {calculated }, i}}{\phi_{\text {reference }, i}}\right)^{2}\right]^{1 / 2}
$$

In the above equation, $\mathrm{N}$ is the total number of meshes. As seen from the tables, the accuracy improves with increasing order of the expansion terms. The fourth order expansion seems sufficient to significantly reduce the errors in the homogenized cross sections. The error in the heterogeneous discontinuity factor $\chi$ (defined as the ratio of the surface average flux to the assembly average flux) becomes insignificantly small when $7^{\text {th }}$ order perturbation theory is used. The $4^{\text {th }}$ order corrected flux models very well the reference flux distribution in comparison to the unperturbed $\left(0^{\text {th }}\right.$ order $)$ flux. In case 1 for example the flux RMS at $4^{\text {th }}$ order is 0.2 versus $20.2 \%$ for the $0^{\text {th }}$ order. 
Table 4-1. Flux and eigenvalue results for assembly $\# 1^{*}$

\begin{tabular}{|c|c|c|c|c|c|c|c|}
\hline $\begin{array}{l}\# \\
0 \\
0 \\
0 \\
0 \\
0\end{array}$ & $(\mathrm{~J} / \Phi)_{\text {left }}$ & $(\mathrm{J} / \Phi)_{\text {right }}$ & $\begin{array}{c}\text { Reference } \\
\text { Eigenvalue } \\
\lambda_{\text {ref }}\end{array}$ & $\begin{array}{l}\text { Ord. of } \\
\text { Pert. }\end{array}$ & $\begin{array}{c}\text { Calculated } \\
\text { Eigenvalue } \\
\lambda_{\text {calc }}\end{array}$ & Error $^{* * *}$ & $\begin{array}{c}\text { Flux } \\
\text { RMS } \\
(\%)\end{array}$ \\
\hline $1^{*}$ & 0. & 0.13321 & 0.8969 & $\begin{array}{l}0 \\
1 \\
2 \\
3 \\
\end{array}$ & $\begin{array}{l}0.7248 \\
1.0006 \\
0.8414 \\
0.9230\end{array}$ & $\begin{array}{c}19.0 \\
-12.0 \\
6.2 \\
-2.9 \\
\end{array}$ & $\begin{array}{c}20.2 \\
9.7 \\
3.9 \\
1.2^{\mathrm{a}} \\
\end{array}$ \\
\hline $2^{* *}$ & 0.00904 & 0.10706 & 0.8970 & $\begin{array}{l}0 \\
1 \\
2 \\
3 \\
\end{array}$ & $\begin{array}{l}0.7248 \\
0.9652 \\
0.8680 \\
0.9081\end{array}$ & $\begin{array}{c}19.0 \\
-7.6 \\
3.2 \\
-1.2 \\
\end{array}$ & $\begin{array}{c}15.3 \\
6.1 \\
2.0 \\
0.5^{\mathrm{b}} \\
\end{array}$ \\
\hline
\end{tabular}

Table 4-2. Homogenized cross sections" for assembly \#1

\begin{tabular}{|c|c|c|c|c|c|c|}
\hline $\begin{array}{l}\# \\
0 \\
\mathscr{E} \\
\tilde{J}\end{array}$ & $\begin{array}{l}\text { Order } \\
\text { of } \\
\text { Pert. }\end{array}$ & $\begin{array}{c}\mathrm{D} \\
(\mathrm{err})^{\mathrm{e}}\end{array}$ & $\begin{array}{l}v \sigma_{\mathrm{f}} \\
\text { (err) }\end{array}$ & $\begin{array}{c}\sigma_{\mathrm{a}} \\
\text { (err) }\end{array}$ & $\begin{array}{l}\chi_{\text {left }}{ }^{f} \\
\text { (err) }\end{array}$ & $\begin{array}{l}\chi_{\text {right }} \\
\text { (err) }\end{array}$ \\
\hline \multirow{5}{*}{$1^{* *}$} & reference & 1.2588 & 0.03161 & 0.02284 & 1.1575 & 0.6297 \\
\hline & 0 & $\begin{array}{c}1.2616 \\
(-0.2)\end{array}$ & $\begin{array}{c}0.03103 \\
(1.8)\end{array}$ & $\begin{array}{c}0.02249 \\
(1.5) \\
\end{array}$ & $\begin{array}{l}0.9907 \\
(-14.4)\end{array}$ & $\begin{array}{l}0.9907 \\
(57.3)\end{array}$ \\
\hline & 1 & $\begin{array}{c}1.2570 \\
(-0.2)\end{array}$ & $\begin{array}{c}0.03192 \\
(-1.0)\end{array}$ & $\begin{array}{c}0.02303 \\
(-0.8)\end{array}$ & $\begin{array}{c}1.2312 \\
(6.4)\end{array}$ & $\begin{array}{l}0.4475 \\
(-28.9) \\
\end{array}$ \\
\hline & 2 & $\begin{array}{c}1.2594 \\
(-0.1)\end{array}$ & $\begin{array}{c}0.03145 \\
(0.5) \\
\end{array}$ & $\begin{array}{c}0.02275 \\
(0.4) \\
\end{array}$ & $\begin{array}{c}1.1311 \\
(-2.3)\end{array}$ & $\begin{array}{c}0.7090 \\
(12.6) \\
\end{array}$ \\
\hline & 3 & $\begin{array}{c}1.2583 \\
(0.0)\end{array}$ & $\begin{array}{c}0.03166 \\
(-0.2)\end{array}$ & $\begin{array}{c}0.02288 \\
(-0.2)\end{array}$ & $\begin{array}{c}1.1629 \\
\left(0.5^{\mathrm{a}}\right)\end{array}$ & $\begin{array}{l}0.6023 \\
\left(-4.4^{b}\right)\end{array}$ \\
\hline \multirow{5}{*}{$2^{* * *}$} & reference & 1.2421 & 0.03161 & 0.02284 & 1.0953 & 0.6917 \\
\hline & 0 & $\begin{array}{c}1.2444 \\
(-0.2)\end{array}$ & $\begin{array}{c}0.03103 \\
(1.8)\end{array}$ & $\begin{array}{c}0.02249 \\
(1.5)\end{array}$ & $\begin{array}{c}0.9907 \\
(-9.6)\end{array}$ & $\begin{array}{l}0.9907 \\
(43.2)\end{array}$ \\
\hline & 1 & $\begin{array}{c}1.2411 \\
(0.1)\end{array}$ & $\begin{array}{c}0.03181 \\
(-0.6)\end{array}$ & $\begin{array}{c}0.02296 \\
(-0.5)\end{array}$ & $\begin{array}{c}1.1471 \\
(4.7)\end{array}$ & $\begin{array}{l}0.5705 \\
(-17.5)\end{array}$ \\
\hline & 2 & $\begin{array}{c}1.2424 \\
(-0.0)\end{array}$ & $\begin{array}{c}0.03153 \\
(0.3)\end{array}$ & $\begin{array}{c}0.02279 \\
(0.2)\end{array}$ & $\begin{array}{l}1.1311 \\
(-2.3)\end{array}$ & $\begin{array}{c}0.7346 \\
(6.2)\end{array}$ \\
\hline & 3 & $\begin{array}{c}1.2419 \\
(0.0)\end{array}$ & $\begin{array}{c}0.03163 \\
(-0.1)\end{array}$ & $\begin{array}{c}0.02286 \\
(-0.1))\end{array}$ & $\begin{array}{c}1.1629 \\
\left(0.5^{\mathrm{a}}\right)\end{array}$ & $\begin{array}{c}0.6794 \\
\left(0.3^{\mathrm{b}}\right)\end{array}$ \\
\hline
\end{tabular}


Table 4-3. Flux and eigenvalue results for assembly $\# 3^{*}$

\begin{tabular}{|c|c|c|c|c|c|c|c|}
\hline 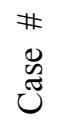 & $(\mathrm{J} / \Phi)_{\text {left }}$ & $(\mathrm{J} / \Phi)_{\text {right }}$ & $\begin{array}{c}\text { Reference } \\
\text { Eigenvalue } \\
\lambda_{\text {ref }}\end{array}$ & $\begin{array}{l}\text { Ord. of } \\
\text { Pert. }\end{array}$ & $\begin{array}{c}\text { Calculated } \\
\text { Eigenvalue } \\
\lambda_{\text {calc }}\end{array}$ & Error $^{* * *}$ & $\begin{array}{c}\text { Flux } \\
\text { RMS } \\
(\%)\end{array}$ \\
\hline $1^{*}$ & -0.13321 & -0.00904 & 0.8968 & $\begin{array}{l}0 \\
1 \\
2 \\
3 \\
\end{array}$ & $\begin{array}{l}2.1629 \\
1.4838 \\
1.0805 \\
0.8964\end{array}$ & $\begin{array}{l}-141.0 \\
-65.0 \\
-20.0 \\
-0.04\end{array}$ & $\begin{array}{c}56.6 \\
9.8 \\
7.6 \\
5.7^{\text {a }} \\
\end{array}$ \\
\hline $2^{* *}$ & -0.10706 & -0.10706 & 0.9022 & $\begin{array}{l}0 \\
1 \\
2 \\
3 \\
\end{array}$ & $\begin{array}{l}2.1629 \\
1.1407 \\
0.9441 \\
0.9092 \\
\end{array}$ & $\begin{array}{c}-141.0 \\
-26.0 \\
-4.6 \\
-0.77\end{array}$ & $\begin{array}{l}9.5 \\
1.4 \\
0.2 \\
0.0 \\
\end{array}$ \\
\hline
\end{tabular}

Table 4-4. Homogenized cross sections" for assembly \#3

\begin{tabular}{|c|c|c|c|c|c|c|}
\hline 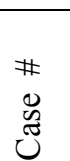 & $\begin{array}{l}\text { Order } \\
\text { of } \\
\text { Pert. }\end{array}$ & $\begin{array}{l}\mathrm{D} \\
(\mathrm{err})^{\mathrm{e}}\end{array}$ & $\begin{array}{l}\nu \sigma_{\mathrm{f}} \\
\text { (err) }\end{array}$ & $\begin{array}{l}\sigma_{\mathrm{a}} \\
\text { (err) }\end{array}$ & $\begin{array}{l}\chi_{\text {left }}{ }^{f} \\
\text { (err) }\end{array}$ & $\begin{array}{l}\chi_{\text {right }} \\
\text { (err) }\end{array}$ \\
\hline \multirow{5}{*}{$1^{* *}$} & reference & 1.3010 & 0.01744 & 0.03582 & 2.2680 & 0.5942 \\
\hline & 0 & $\begin{array}{l}1.2968 \\
(0.32) \\
\end{array}$ & $\begin{array}{c}0.01765 \\
(-1.2) \\
\end{array}$ & $\begin{array}{c}0.03818 \\
(1.5)\end{array}$ & $\begin{array}{l}1.1664 \\
(-48.6)\end{array}$ & $\begin{array}{l}1.1664 \\
(96.3)\end{array}$ \\
\hline & 1 & $\begin{array}{l}1.2993 \\
(0.13) \\
\end{array}$ & $\begin{array}{c}0.01755 \\
(-0.6) \\
\end{array}$ & $\begin{array}{c}0.03686 \\
(-2.9) \\
\end{array}$ & $\begin{array}{l}1.9353 \\
(-14.7) \\
\end{array}$ & $\begin{array}{l}0.6895 \\
(16.0) \\
\end{array}$ \\
\hline & 2 & $\begin{array}{l}1.3007 \\
(0.02) \\
\end{array}$ & $\begin{array}{c}0.01748 \\
(-0.2) \\
\end{array}$ & $\begin{array}{c}0.03611 \\
(-0.8) \\
\end{array}$ & $\begin{array}{c}2.2807 \\
(0.6) \\
\end{array}$ & $\begin{array}{l}0.5132 \\
(-13.6) \\
\end{array}$ \\
\hline & 3 & $\begin{array}{l}1.3013 \\
(-0.02)\end{array}$ & $\begin{array}{c}0.01745 \\
(0.0)\end{array}$ & $\begin{array}{c}0.03579 \\
(0.1)\end{array}$ & $\begin{array}{c}2.3354 \\
\left(3.0^{\mathrm{a}}\right)\end{array}$ & $\begin{array}{c}0.5324 \\
\left(-10.4^{b}\right)\end{array}$ \\
\hline \multirow{5}{*}{$2^{* * *}$} & reference & 1.3010 & 0.01745 & 0.03583 & 1.4300 & 1.4297 \\
\hline & 0 & $\begin{array}{l}1.2968 \\
(0.32)\end{array}$ & $\begin{array}{c}0.01765 \\
(-1.2)\end{array}$ & $\begin{array}{c}0.03818 \\
(-6.6)\end{array}$ & $\begin{array}{l}1.1664 \\
(-18.4)\end{array}$ & $\begin{array}{l}1.1664 \\
(-18.4)\end{array}$ \\
\hline & 1 & $\begin{array}{l}1.3005 \\
(0.04)\end{array}$ & $\begin{array}{c}0.01750 \\
(-0.3)\end{array}$ & $\begin{array}{c}0.03619 \\
(-1.0)\end{array}$ & $\begin{array}{c}1.3861 \\
(-3.1)\end{array}$ & $\begin{array}{c}1.3862 \\
(-3.0)\end{array}$ \\
\hline & 2 & $\begin{array}{l}1.3012 \\
(-0.01) \\
\end{array}$ & $\begin{array}{c}0.01746 \\
(-0.1)\end{array}$ & $\begin{array}{c}0.03588 \\
(-0.1)\end{array}$ & $\begin{array}{c}1.4235 \\
(-0.5) \\
\end{array}$ & $\begin{array}{c}1.4235 \\
(-0.4) \\
\end{array}$ \\
\hline & 3 & $\begin{array}{l}1.3013 \\
(-0.02) \\
\end{array}$ & $\begin{array}{c}0.01745 \\
(-0.0) \\
\end{array}$ & $\begin{array}{c}0.03585 \\
(0.0)\end{array}$ & $\begin{array}{c}1.4291 \\
(-0.1)\end{array}$ & $\begin{array}{c}1.4292 \\
(-0.0) \\
\end{array}$ \\
\hline
\end{tabular}




\section{4-1.2. Two-group one-dimensional problems}

A two-group fine-mesh diffusion code was developed to precompute the data (forward and ajoint fluxes, and Green's function) required for calculating the expansion coefficients. The fine-mesh calculations are performed with six meshes per each material region, leading to a total of thirty-six meshes per assembly.

\section{Results for assembly \#1}

The flux and eigenvalue results for assembly type 1 (see Figure 3-1) are shown in Table 4-5 for different magnitudes of the perturbation, corresponding to four different positions of the assembly in configurations 1 and 2 . The first two cases correspond to assembly 1 in first and third position from left to right in configuration 1, and the other two cases correspond to the same positions in configuration 2. The results corresponding to the assembly in the seventh and fifth position from left to right in the same configuration are not shown in the table, but they are similar. The similarity of the results corresponding to symmetric positions of the assembly (e.g. first with seventh, third with fifth) in a configuration constituted one of the tests for assessing the correctness of the numerical implementation. Another test consisted of verifying if the integral over the phase-space of any high-order coefficient in the flux expansion is zero, as predicted by the theoretical model. In one case for example (see case 1 in Table 4-5), with $\left|\varphi_{1, g}(i)\right|>10^{-4}, i=1, . . N \quad, g=1,2$, where $\mathrm{i}$ is a mesh index and $\mathrm{g}$ is a group index, a value of the order $10^{-8}$ was obtained for the integral of the first-order flux.

The method produces very good results. The flux RMS is less than $0.1 \%$ and the corrected eigenvalue is within $0.6 \%$ of the reference value for all four cases. For small perturbations (cases 1 and 2) an expansion up to the second order is sufficient to obtain a very good agreement, whereas for larger perturbations (cases 3 and 4) four or five orders need to be considered. To illustrate the change in the flux distribution with the order of the perturbation, the flux distribution for case 3 is shown in Figure 4-1 up to the fourth order. It can be seen that there is a large shape difference between the infinite medium flux and the exact (reference) flux, especially for the fast group; the corrected solutions oscillate around the reference, until at the fourth order most of the difference is accounted for by the perturbation method. For the other three cases the flux distributions are shown in Figures 4-2 to 4-4.

The high-order corrected assembly-homogenized cross sections and discontinuity factors, corresponding to that magnitude of the perturbation as considered in Table 4-5, are presented in Table 4-6 for the fast group, and in Table 4-7 for the thermal group. For small perturbations, one or two terms in the expansion of the homogenized cross sections are sufficient to reproduce the reference values, whereas for larger perturbations five terms are needed to obtain a similar agreement.

The agreement is also very good for the discontinuity factors, even though the magnitude of the initial perturbation is larger compared to that for the cross sections (e.g., the error for the heterogeneous discontinuity factor on the right boundary is $-34 \%$ in case 3 and - 
$20 \%$ in case 4 ). The second order correction of the discontinuity factors reproduce the reference values in cases 1 and 2. In cases 3 and 4, the corrected values at the fifth order are within $0.15 \%$ of the reference results.

Table 4-5. Flux and eigenvalue results for assembly $\# 1$ *

\begin{tabular}{|c|c|c|c|c|c|c|c|c|}
\hline $\begin{array}{l}7 \\
\text { Z } \\
0 \\
\tilde{z} \\
\tilde{z}\end{array}$ & $\begin{array}{c}(\mathrm{J} / \Phi)_{\text {left }} \\
\text { fast/ } \\
\text { thermal }\end{array}$ & $\begin{array}{l}(\mathrm{J} / \Phi)_{\text {right }} \\
\text { fast/ } \\
\text { thermal }\end{array}$ & $\begin{array}{c}\text { Reference } \\
\text { Eigenvalue } \\
\lambda_{\text {ref }}\end{array}$ & $\begin{array}{l}\text { Ord. } \\
\text { of } \\
\text { Pert. }\end{array}$ & $\begin{array}{c}\text { Calculated } \\
\text { Eigenvalue } \\
\lambda_{\text {calc }}\end{array}$ & Error $^{b}$ & $\begin{array}{c}\text { Fast } \\
\text { Flux } \\
\text { RMS } \\
(\%)\end{array}$ & $\begin{array}{c}\text { Thermal } \\
\text { Flux } \\
\text { RMS } \\
(\%)\end{array}$ \\
\hline 1 & $\begin{array}{l}0 . \\
0 .\end{array}$ & $\begin{array}{r}0.4556 \mathrm{E}-02 \\
-0.3652 \mathrm{E}-03\end{array}$ & 0.75766 & $\begin{array}{l}0 \\
1 \\
2 \\
3\end{array}$ & $\begin{array}{l}0.75037 \\
0.75764 \\
0.75754 \\
0.75754\end{array}$ & $\begin{array}{c}-0.96 \\
0.00 \\
-0.02 \\
-0.02\end{array}$ & $\begin{array}{l}0.71 \\
0.01 \\
0.01 \\
0.01\end{array}$ & $\begin{array}{l}0.53 \\
0.01 \\
0.01 \\
0.01\end{array}$ \\
\hline 2 & $\begin{array}{r}-0.1988 \mathrm{E}-02 \\
0.5822 \mathrm{E}-03\end{array}$ & $\begin{array}{c}0.3129 \mathrm{E}-02 \\
-0.4851 \mathrm{E}-03\end{array}$ & 0.75794 & $\begin{array}{l}0 \\
1 \\
2 \\
3\end{array}$ & $\begin{array}{l}0.75037 \\
0.75762 \\
0.75756 \\
0.75756\end{array}$ & $\begin{array}{l}-1.00 \\
-0.04 \\
-0.05 \\
-0.05\end{array}$ & $\begin{array}{l}0.31 \\
0.00 \\
0.00 \\
0.00\end{array}$ & $\begin{array}{l}0.24 \\
0.00 \\
0.00 \\
0.00\end{array}$ \\
\hline 3 & $\begin{array}{l}0 . \\
0 .\end{array}$ & $\begin{array}{l}0.1026 \\
0.1178 \mathrm{E}-01\end{array}$ & 0.89167 & $\begin{array}{l}0 \\
1 \\
2 \\
3 \\
4 \\
5\end{array}$ & $\begin{array}{l}0.75037 \\
0.94218 \\
0.88328 \\
0.89731 \\
0.89515 \\
0.89512\end{array}$ & $\begin{array}{r}-15.85 \\
5.66 \\
-0.94 \\
0.63 \\
0.39 \\
0.39\end{array}$ & $\begin{array}{r}15.75 \\
4.03 \\
0.60 \\
0.11 \\
0.13 \\
0.07\end{array}$ & $\begin{array}{c}18.75 \\
5.31 \\
0.98 \\
0.21 \\
0.12 \\
0.08\end{array}$ \\
\hline 4 & $\begin{array}{l}-0.1382 \mathrm{E}-01 \\
-0.5439 \mathrm{E}-02\end{array}$ & $\begin{array}{l}0.7057 \mathrm{E}-01 \\
0.9505 \mathrm{E}-02\end{array}$ & 0.89170 & $\begin{array}{l}0 \\
1 \\
2 \\
3 \\
4 \\
5\end{array}$ & $\begin{array}{l}0.75037 \\
0.91549 \\
0.89365 \\
0.89714 \\
0.89670 \\
0.89672\end{array}$ & $\begin{array}{r}-15.85 \\
2.67 \\
0.22 \\
0.61 \\
0.56 \\
0.56\end{array}$ & $\begin{array}{l}8.97 \\
1.72 \\
0.17 \\
0.06 \\
0.05 \\
0.05\end{array}$ & $\begin{array}{c}11.01 \\
2.42 \\
0.33 \\
0.10 \\
0.05 \\
0.05\end{array}$ \\
\hline
\end{tabular}

*as shown in Figure 3-1

${ }^{a}$ cases 1 and 2 refer to two different positions in configuration 1, cases 3 and 4 refer to two different positions in configuration 2

${ }^{\mathrm{b}}$ calculated as $100 *\left(\lambda_{\text {calc }}-\lambda_{\text {ref }}\right) / \lambda_{\text {ref }}$ 

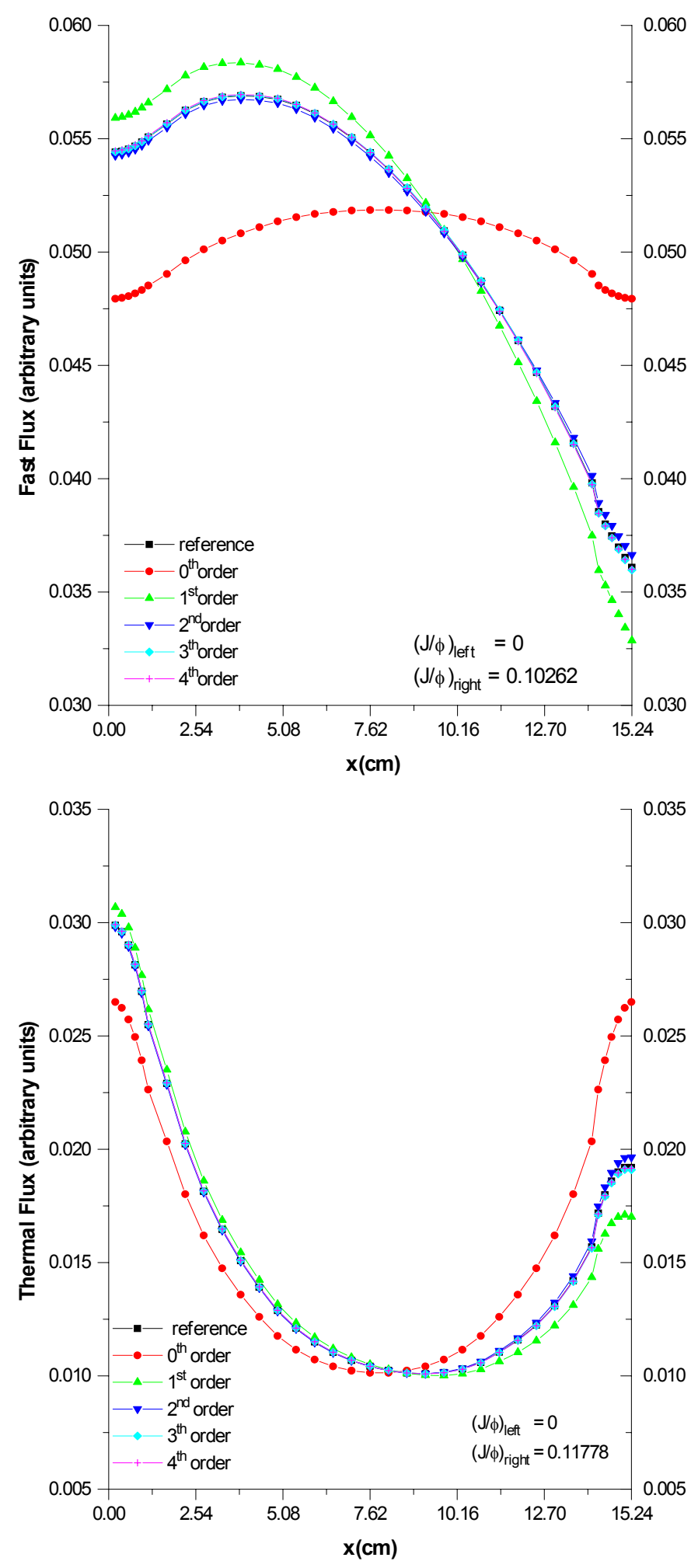

Figure 4-1. Flux distribution for case 3 
Table 4-6. Fast group cross sections" for assembly \#1

\begin{tabular}{|c|c|c|c|c|c|c|c|}
\hline $\begin{array}{l}\text { * } \\
* \\
* \\
0 \\
0 \\
\tilde{J} \\
\tilde{J}\end{array}$ & $\begin{array}{l}\text { Order } \\
\text { of } \\
\text { Pert. }\end{array}$ & $\stackrel{\mathrm{D}}{(\mathrm{err})^{\mathrm{e}}}$ & $\begin{array}{l}v \sigma_{\mathrm{f}} \\
\text { (err) }\end{array}$ & $\begin{array}{c}\sigma_{\mathrm{r}} \\
\text { (err) }\end{array}$ & $\begin{array}{c}\sigma_{12} \\
\text { (err) }\end{array}$ & $\begin{array}{l}\chi_{\text {left }}^{f} \\
\text { (err) }\end{array}$ & $\begin{array}{l}\chi_{\text {right }} \\
\text { (err) }\end{array}$ \\
\hline \multirow{4}{*}{$1^{\mathrm{a}}$} & reference & 1.5182 & $6.2100 \mathrm{E}-3$ & $8.4738 \mathrm{E}-3$ & $1.9046 \mathrm{E}-2$ & 0.9548 & 0.9362 \\
\hline & 0 & $\begin{array}{l}1.5184 \\
(-0.01)\end{array}$ & $\begin{array}{c}6.2063 \mathrm{E}-3 \\
(0.06)\end{array}$ & $\begin{array}{c}8.4793 \mathrm{E}-3 \\
(0.05)\end{array}$ & $\begin{array}{c}1.9056 \mathrm{E}-2 \\
(-0.05)\end{array}$ & $\begin{array}{c}0.9490 \\
(0.61)\end{array}$ & $\begin{array}{l}0.9490 \\
(-1.37)\end{array}$ \\
\hline & 1 & $\begin{array}{l}1.5182 \\
(0.00)\end{array}$ & $\begin{array}{c}6.2100 \mathrm{E}-3 \\
(0.00)\end{array}$ & $\begin{array}{c}8.4738 \mathrm{E}-3 \\
(0.00)\end{array}$ & $\begin{array}{c}1.9046 \mathrm{E}-2 \\
(0.00)\end{array}$ & $\begin{array}{l}0.9549 \\
(-0.01)\end{array}$ & $\begin{array}{c}0.9360 \\
(0.02)\end{array}$ \\
\hline & 2 & $\begin{array}{l}1.5182 \\
(0.00)\end{array}$ & $\begin{array}{c}6.2100 \mathrm{E}-3 \\
(0.00)\end{array}$ & $\begin{array}{c}8.4738 \mathrm{E}-3 \\
(0.00)\end{array}$ & $\begin{array}{c}1.9046 \mathrm{E}-2 \\
(0.00)\end{array}$ & $\begin{array}{c}0.9548 \\
(0.00)\end{array}$ & $\begin{array}{c}0.9362 \\
(0.00)\end{array}$ \\
\hline \multirow{3}{*}{$2^{b}$} & reference & 1.5182 & $6.2104 \mathrm{E}-3$ & $8.4743 \mathrm{E}-3$ & $1.9045 \mathrm{E}-2$ & 0.9476 & 0.9476 \\
\hline & 0 & $\begin{array}{l}1.5184 \\
(-0.01)\end{array}$ & $\begin{array}{c}6.2063 \mathrm{E}-3 \\
(0.07)\end{array}$ & $\begin{array}{c}8.4793 \mathrm{E}-3 \\
(0.06)\end{array}$ & $\begin{array}{c}1.9056 \mathrm{E}-2 \\
(-0.06)\end{array}$ & $\begin{array}{l}0.9490 \\
(-0.15)\end{array}$ & $\begin{array}{l}0.9490 \\
(-0.67)\end{array}$ \\
\hline & 1 & $\begin{array}{l}1.5182 \\
(0.00)\end{array}$ & $\begin{array}{c}6.2004 \mathrm{E}-3 \\
(0.00)\end{array}$ & $\begin{array}{c}8.4743 \mathrm{E}-3 \\
(0.00)\end{array}$ & $\begin{array}{c}1.9045 \mathrm{E}-2 \\
(0.00)\end{array}$ & $\begin{array}{l}0.9476 \\
(0.00)\end{array}$ & $\begin{array}{l}0.9426 \\
(0.01)\end{array}$ \\
\hline \multirow{7}{*}{$3^{c}$} & reference & 1.5162 & $6.2713 \mathrm{E}-3$ & $8.5476 \mathrm{E}-3$ & $1.8880 \mathrm{E}-2$ & 1.0769 & 0.7083 \\
\hline & 0 & $\begin{array}{l}1.5184 \\
(-0.14)\end{array}$ & $\begin{array}{c}6.2063 \mathrm{E}-3 \\
(1.04)\end{array}$ & $\begin{array}{c}8.4793 \mathrm{E}-3 \\
(0.92)\end{array}$ & $\begin{array}{c}1.9056 \mathrm{E}-2 \\
(-0.93)\end{array}$ & $\begin{array}{l}0.9490 \\
(11.14)\end{array}$ & $\begin{array}{c}0.9490 \\
(-33.97)\end{array}$ \\
\hline & 1 & $\begin{array}{l}1.5155 \\
(0.05)\end{array}$ & $\begin{array}{c}6.2929 \mathrm{E}-3 \\
(-0.34)\end{array}$ & $\begin{array}{c}8.5737 \mathrm{E}-3 \\
(-0.31)\end{array}$ & $\begin{array}{c}1.8821 \mathrm{E}-2 \\
(0.31)\end{array}$ & $\begin{array}{l}1.0942 \\
(-2.46)\end{array}$ & $\begin{array}{c}0.6430 \\
(9.22)\end{array}$ \\
\hline & 2 & $\begin{array}{l}1.5164 \\
(-0.01)\end{array}$ & $\begin{array}{c}6.2660 \mathrm{E}-3 \\
(0.08)\end{array}$ & $\begin{array}{c}8.5411 \mathrm{E}-3 \\
(0.08)\end{array}$ & $\begin{array}{c}1.8895 \mathrm{E}-2 \\
(-0.08)\end{array}$ & $\begin{array}{l}1.0658 \\
(0.20)\end{array}$ & $\begin{array}{l}0.7197 \\
(-1.61)\end{array}$ \\
\hline & 3 & $\begin{array}{l}1.5161 \\
(0.00)\end{array}$ & $\begin{array}{c}6.2726 \mathrm{E}-3 \\
(-0.02)\end{array}$ & $\begin{array}{c}8.5492 \mathrm{E}-3 \\
(-0.02)\end{array}$ & $\begin{array}{c}1.8876 \mathrm{E}-2 \\
(0.02)\end{array}$ & $\begin{array}{l}1.0681 \\
(-0.01)\end{array}$ & $\begin{array}{c}0.7060 \\
(0.33)\end{array}$ \\
\hline & 4 & $\begin{array}{l}1.5162 \\
(0.00)\end{array}$ & $\begin{array}{c}6.2715 \mathrm{E}-3 \\
(0.00)\end{array}$ & $\begin{array}{c}8.5478 \mathrm{E}-3 \\
(0.00)\end{array}$ & $\begin{array}{c}1.8880 \mathrm{E}-2 \\
(0.00)\end{array}$ & $\begin{array}{l}1.0691 \\
(-0.11)\end{array}$ & $\begin{array}{l}0.7067 \\
(0.22)\end{array}$ \\
\hline & 5 & $\begin{array}{l}1.5162 \\
(0.00)\end{array}$ & $\begin{array}{c}6.2715 \mathrm{E}-3 \\
(0.00)\end{array}$ & $\begin{array}{c}8.5478 \mathrm{E}-3 \\
(0.00)\end{array}$ & $\begin{array}{c}1.8880 \mathrm{E}-2 \\
(0.00)\end{array}$ & $\begin{array}{l}1.0691 \\
(-0.06)\end{array}$ & $\begin{array}{l}0.7067 \\
(0.15)\end{array}$ \\
\hline \multirow{6}{*}{$4^{\mathrm{d}}$} & reference & 1.5163 & $6.2693 \mathrm{E}-3$ & $8.5451 \mathrm{E}-3$ & $1.8886 \mathrm{E}-2$ & 0.9915 & 0.7890 \\
\hline & 0 & $\begin{array}{l}1.5184 \\
(-0.14)\end{array}$ & $\begin{array}{c}6.2063 \mathrm{E}-3 \\
(1.00)\end{array}$ & $\begin{array}{c}8.4793 \mathrm{E}-3 \\
(0.89)\end{array}$ & $\begin{array}{c}1.9056 \mathrm{E}-2 \\
(-0.90)\end{array}$ & $\begin{array}{c}0.9490 \\
(4.29)\end{array}$ & $\begin{array}{c}0.9490 \\
(-20.28) \\
\end{array}$ \\
\hline & 1 & $\begin{array}{l}1.5159 \\
(0.02)\end{array}$ & $\begin{array}{c}6.2782 \mathrm{E}-3 \\
(-0.14)\end{array}$ & $\begin{array}{c}8.5559 \mathrm{E}-3 \\
(-0.13)\end{array}$ & $\begin{array}{c}1.8861 \mathrm{E}-2 \\
(0.13)\end{array}$ & $\begin{array}{l}1.0052 \\
(-1.39)\end{array}$ & $\begin{array}{l}0.7597 \\
(3.71)\end{array}$ \\
\hline & 2 & $\begin{array}{l}1.5163 \\
(0.00)\end{array}$ & $\begin{array}{c}6.2680 \mathrm{E}-3 \\
(0.02)\end{array}$ & $\begin{array}{c}8.5434 \mathrm{E}-3 \\
(0.02)\end{array}$ & $\begin{array}{c}1.8889 \mathrm{E}-2 \\
(-0.02)\end{array}$ & $\begin{array}{l}0.9903 \\
(0.12)\end{array}$ & $\begin{array}{l}0.7924 \\
(-0.43)\end{array}$ \\
\hline & 3 & $\begin{array}{l}1.5162 \\
(0.00)\end{array}$ & $\begin{array}{c}6.2697 \mathrm{E}-3 \\
(-0.01)\end{array}$ & $\begin{array}{c}8.5456 \mathrm{E}-3 \\
(-0.01)\end{array}$ & $\begin{array}{c}1.8885 \mathrm{E}-2 \\
(0.01)\end{array}$ & $\begin{array}{l}0.9919 \\
(-0.04)\end{array}$ & $\begin{array}{c}0.7878 \\
(0.14)\end{array}$ \\
\hline & 4 & $\begin{array}{l}1.5162 \\
(0.00)\end{array}$ & $\begin{array}{c}6.2695 \mathrm{E}-3 \\
(0.00)\end{array}$ & $\begin{array}{c}8.5453 \mathrm{E}-3 \\
(0.00)\end{array}$ & $\begin{array}{c}1.8885 \mathrm{E}-2 \\
(0.00)\end{array}$ & $\begin{array}{l}0.9919 \\
(-0.04)\end{array}$ & $\begin{array}{c}0.7882 \\
(0.10)\end{array}$ \\
\hline $\begin{array}{l}{ }^{*} \text { the } \\
{ }^{*} \text { cas } \\
\text { a }(\mathrm{J} / \phi \\
\mathrm{b}(\mathrm{J} / \phi \\
\mathrm{c}(\mathrm{J} / \phi \\
\mathrm{d}(\mathrm{J} / \phi \\
{ }^{\mathrm{c}} \mathrm{calc}\end{array}$ & $\begin{array}{l}\text { usion coeffici } \\
\text { and } 2-\text { two } d \\
=0 ;(\mathrm{J} / \phi)_{\text {right }}=0 \\
=-0.1988 \mathrm{E}-02 \\
=0 ;(\mathrm{J} / \phi)_{\text {right }}=0 \\
=-0.1382 \mathrm{E}-01 \\
\text { ed as } 100^{*}(\mathrm{re}\end{array}$ & $\begin{array}{l}\mathrm{sin} \mathrm{cm}, \text { an } \\
\text { ent positio } \\
6 \mathrm{E}-02 \\
\phi)_{\text {right }}=0.31 \\
6 \\
\phi)_{\text {right }}=0.7 \\
\text { cce-calcula }\end{array}$ & $\begin{array}{l}\text { cross sections a } \\
\text { config. } 1 \text {; cases }\end{array}$ & $\begin{array}{l}\mathrm{m}^{-1} \\
4-\text { two differe }\end{array}$ & tions in config. & & \\
\hline
\end{tabular}


Table 4-7. Thermal group cross sections" for assembly \#1

\begin{tabular}{|c|c|c|c|c|c|c|}
\hline $\begin{array}{l}\stackrel{*}{*} \\
\ddot{E} \\
\tilde{U} \\
\tilde{U}\end{array}$ & $\begin{array}{c}\text { Order } \\
\text { of } \\
\text { Pert. }\end{array}$ & $\begin{array}{c}\mathrm{D} \\
(\mathrm{err})^{\mathrm{e}}\end{array}$ & $\begin{array}{l}v \sigma_{f} \\
(\text { err })\end{array}$ & $\begin{array}{c}\sigma_{\mathrm{r}} \\
(\mathrm{err})\end{array}$ & $\begin{array}{l}\chi_{\text {left }}^{f} \\
(\text { err) }\end{array}$ & $\begin{array}{l}\chi_{\text {right }} \\
\text { (err) }\end{array}$ \\
\hline \multirow{4}{*}{$1^{\mathrm{a}}$} & reference & $3.0591 \mathrm{E}-1$ & $1.0198 \mathrm{E}-1$ & $6.3763 \mathrm{E}-2$ & 1.7649 & 1.7431 \\
\hline & 0 & $\begin{array}{c}3.0589 \mathrm{E}-1 \\
(0.00)\end{array}$ & $\begin{array}{c}1.0196 \mathrm{E}-1 \\
(0.02)\end{array}$ & $\begin{array}{c}6.3752 \mathrm{E}-2 \\
(0.02)\end{array}$ & $\begin{array}{l}1.7545 \\
(0.59)\end{array}$ & $\begin{array}{l}1.7545 \\
(-0.65)\end{array}$ \\
\hline & 1 & $\begin{array}{c}3.0591 \mathrm{E}-1 \\
(0.00)\end{array}$ & $\begin{array}{c}1.0198 \mathrm{E}-1 \\
(0.00)\end{array}$ & $\begin{array}{c}6.3763 \mathrm{E}-2 \\
(0.00)\end{array}$ & $\begin{array}{l}1.7650 \\
(-0.01)\end{array}$ & $\begin{array}{l}1.7430 \\
(0.01)\end{array}$ \\
\hline & 2 & $\begin{array}{c}3.0591 \mathrm{E}-1 \\
(0.00)\end{array}$ & $\begin{array}{c}1.0198 \mathrm{E}-1 \\
(0.00)\end{array}$ & $\begin{array}{c}6.3763 \mathrm{E}-2 \\
(0.00)\end{array}$ & $\begin{array}{l}1.7649 \\
(0.00)\end{array}$ & $\begin{array}{l}1.7431 \\
(0.00)\end{array}$ \\
\hline \multirow{3}{*}{$2^{b}$} & reference & $3.0587 \mathrm{E}-1$ & $1.0193 \mathrm{E}-1$ & $6.3739 \mathrm{E}-2$ & 1.7617 & 1.7524 \\
\hline & 0 & $\begin{array}{c}3.0589 \mathrm{E}-1 \\
(-0.01)\end{array}$ & $\begin{array}{c}1.0196 \mathrm{E}-1 \\
(-0.02)\end{array}$ & $\begin{array}{c}6.3752 \mathrm{E}-2 \\
(-0.02)\end{array}$ & $\begin{array}{l}1.7545 \\
(0.41)\end{array}$ & $\begin{array}{l}1.7545 \\
(-0.12)\end{array}$ \\
\hline & 1 & $\begin{array}{c}3.0587 \mathrm{E}-1 \\
(0.00)\end{array}$ & $\begin{array}{c}1.0193 \mathrm{E}-1 \\
(0.00)\end{array}$ & $\begin{array}{c}6.3739 \mathrm{E}-2 \\
(0.00)\end{array}$ & $\begin{array}{l}1.7617 \\
(0.00) \\
\end{array}$ & $\begin{array}{l}1.7524 \\
(0.00) \\
\end{array}$ \\
\hline \multirow{7}{*}{$3^{c}$} & reference & $3.0695 \mathrm{E}-1$ & $1.0351 \mathrm{E}-1$ & $6.4558 \mathrm{E}-2$ & 2.0371 & 1.3086 \\
\hline & 0 & $\begin{array}{c}3.0589 \mathrm{E}-1 \\
(0.35)\end{array}$ & $\begin{array}{c}1.0196 \mathrm{E}-1 \\
(1.50)\end{array}$ & $\begin{array}{c}6.3752 \mathrm{E}-2 \\
(1.25)\end{array}$ & $\begin{array}{l}1.7545 \\
(13.87) \\
\end{array}$ & $\begin{array}{r}1.7545 \\
(-34.08) \\
\end{array}$ \\
\hline & 1 & $\begin{array}{c}3.0728 \mathrm{E}-1 \\
(-0.01)\end{array}$ & $\begin{array}{c}1.0399 \mathrm{E}-1 \\
(-0.47)\end{array}$ & $\begin{array}{c}6.4808 \mathrm{E}-2 \\
(-0.39)\end{array}$ & $\begin{array}{l}2.1134 \\
(-3.75)\end{array}$ & $\begin{array}{r}1.1720 \\
(10.44) \\
\end{array}$ \\
\hline & 2 & $\begin{array}{c}3.0688 \mathrm{E}-1 \\
(0.02)\end{array}$ & $\begin{array}{c}1.0341 \mathrm{E}-1 \\
(0.10)\end{array}$ & $\begin{array}{c}6.4507 \mathrm{E}-2 \\
(0.08) \\
\end{array}$ & $\begin{array}{c}2.0259 \\
(0.55) \\
\end{array}$ & $\begin{array}{l}1.3352 \\
(-2.03) \\
\end{array}$ \\
\hline & 3 & $\begin{array}{c}3.0696 \mathrm{E}-1 \\
(0.00)\end{array}$ & $\begin{array}{c}1.0353 \mathrm{E}-1 \\
(-0.02)\end{array}$ & $\begin{array}{c}6.4568 \mathrm{E}-2 \\
(-0.01)\end{array}$ & $\begin{array}{l}2.0392 \\
(-0.10) \\
\end{array}$ & $\begin{array}{l}1.3027 \\
(0.45) \\
\end{array}$ \\
\hline & 4 & $\begin{array}{c}3.0696 \mathrm{E}-1 \\
(0.00)\end{array}$ & $\begin{array}{c}1.0352 \mathrm{E}-1 \\
(-0.01)\end{array}$ & $\begin{array}{c}6.4562 \mathrm{E}-2 \\
(-0.01)\end{array}$ & $\begin{array}{l}2.0393 \\
(-0.11) \\
\end{array}$ & $\begin{array}{l}1.3061 \\
(0.19) \\
\end{array}$ \\
\hline & 5 & $\begin{array}{c}3.0696 \mathrm{E}-1 \\
(0.00)\end{array}$ & $\begin{array}{c}1.0352 \mathrm{E}-1 \\
(0.00)\end{array}$ & $\begin{array}{c}6.4560 \mathrm{E}-2 \\
(0.00)\end{array}$ & $\begin{array}{l}2.0384 \\
(-0.07) \\
\end{array}$ & $\begin{array}{l}1.3061 \\
(0.15) \\
\end{array}$ \\
\hline \multirow{6}{*}{$4^{\mathrm{d}}$} & reference & $3.0719 \mathrm{E}-1$ & $1.0385 \mathrm{E}-1$ & $6.4736 \mathrm{E}-2$ & 1.8335 & 1.4682 \\
\hline & 0 & $\begin{array}{c}3.0589 \mathrm{E}-1 \\
(0.42)\end{array}$ & $\begin{array}{c}1.0196 \mathrm{E}-1 \\
(1.83)\end{array}$ & $\begin{array}{c}6.3752 \mathrm{E}-2 \\
(1.52)\end{array}$ & $\begin{array}{l}1.7545 \\
(4.31)\end{array}$ & $\begin{array}{r}1.7545 \\
(-19.50)\end{array}$ \\
\hline & 1 & $\begin{array}{c}3.0731 \mathrm{E}-1 \\
(-0.04)\end{array}$ & $\begin{array}{c}1.0403 \mathrm{E}-1 \\
(-0.17)\end{array}$ & $\begin{array}{c}6.4828 \mathrm{E}-2 \\
(-0.14)\end{array}$ & $\begin{array}{l}1.8712 \\
(-2.05) \\
\end{array}$ & $\begin{array}{c}1.4010 \\
(4.58) \\
\end{array}$ \\
\hline & 2 & $\begin{array}{c}3.0718 \mathrm{E}-1 \\
(0.00)\end{array}$ & $\begin{array}{c}1.0384 \mathrm{E}-1 \\
(0.02)\end{array}$ & $\begin{array}{c}6.4727 \mathrm{E}-2 \\
(0.01)\end{array}$ & $\begin{array}{l}1.8280 \\
(0.30)\end{array}$ & $\begin{array}{l}1.4779 \\
(-0.66) \\
\end{array}$ \\
\hline & 3 & $\begin{array}{c}3.0720 \mathrm{E}-1 \\
(0.00)\end{array}$ & $\begin{array}{c}1.0386 \mathrm{E}-1 \\
(-0.01)\end{array}$ & $\begin{array}{c}6.4740 \mathrm{E}-2 \\
(-0.01)\end{array}$ & $\begin{array}{l}1.8349 \\
(-0.07) \\
\end{array}$ & $\begin{array}{l}1.4655 \\
(0.18) \\
\end{array}$ \\
\hline & 4 & $\begin{array}{c}3.0720 \mathrm{E}-1 \\
(0.00)\end{array}$ & $\begin{array}{c}1.0386 \mathrm{E}-1 \\
(-0.01)\end{array}$ & $\begin{array}{c}6.4739 \mathrm{E}-2 \\
(0.00)\end{array}$ & $\begin{array}{l}1.8343 \\
(-0.04)\end{array}$ & $\begin{array}{l}1.4669 \\
(0.09)\end{array}$ \\
\hline \multicolumn{7}{|c|}{$\begin{array}{l}\text { * the diffusion coefficient is in cm, and the cross } \\
{ }^{* *} \text { cases } 1 \text { and } 2-\text { two different positions in config. } \\
\text { a }(\mathrm{J} / \phi)_{\text {left }}=0 ;(\mathrm{J} / \phi)_{\text {right }}=-0.3652 \mathrm{E}-3 \\
\text { b }(\mathrm{J} / \phi)_{\text {left }}=0.5822 \mathrm{E}-03 ;(\mathrm{J} / \phi)_{\text {right }}=-0.4851 \mathrm{E}-03 \\
{ }^{\mathrm{c}}(\mathrm{J} / \phi)_{\text {left }}=0 ;(\mathrm{J} / \phi)_{\text {right }}=0.1178 \mathrm{E}-01 \\
\text { d }(\mathrm{J} / \phi)_{\text {left }}=-0.5439 \mathrm{E}-02 ;(\mathrm{J} / \phi)_{\text {right }}=0.9505 \mathrm{E}-02 \\
\text { e } 0 \text { calculated as } 100^{*}(\text { reference-calculated }) / \text { referen } \\
\text { f heterogeneous discontinuity factor calculated as }\end{array}$} \\
\hline
\end{tabular}




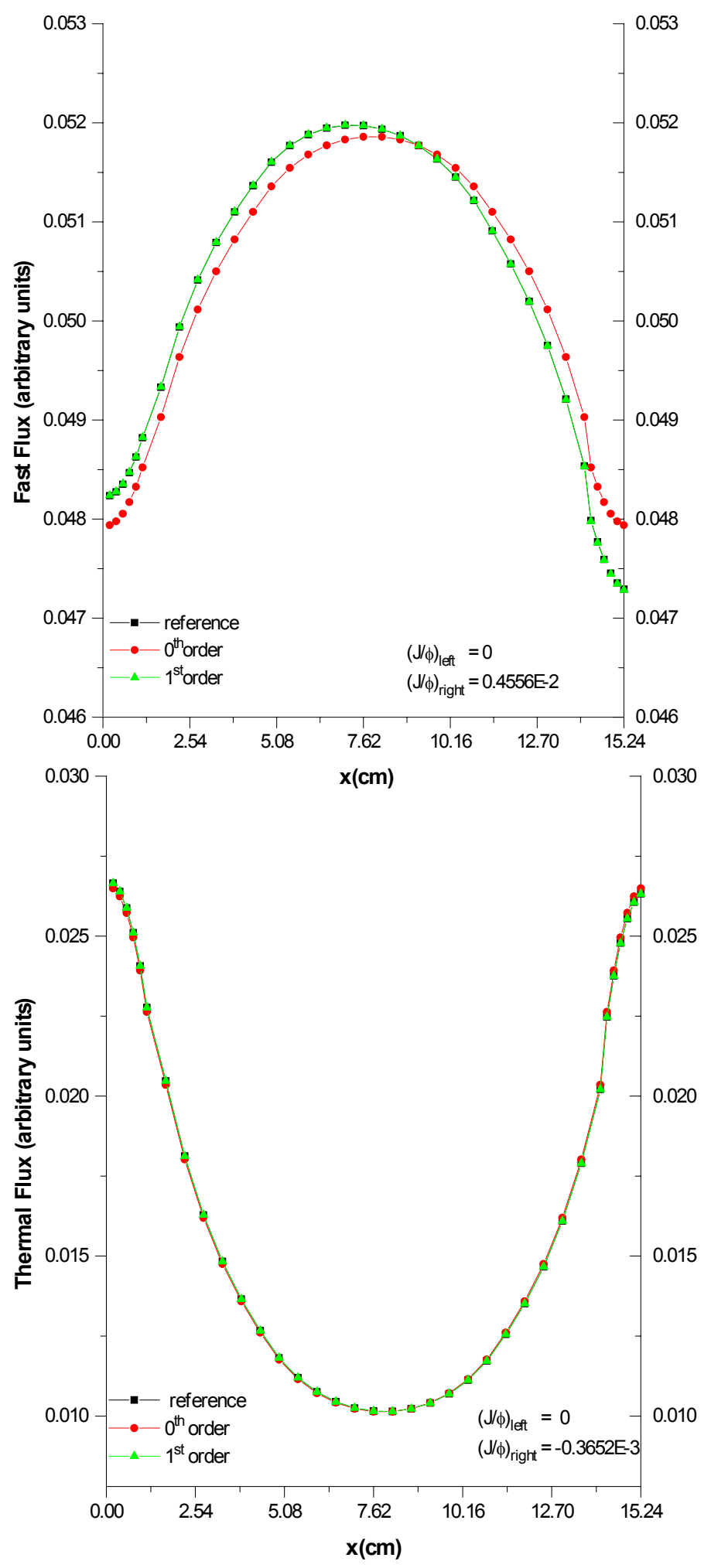

Figure 4-2. Flux distribution for case 1 


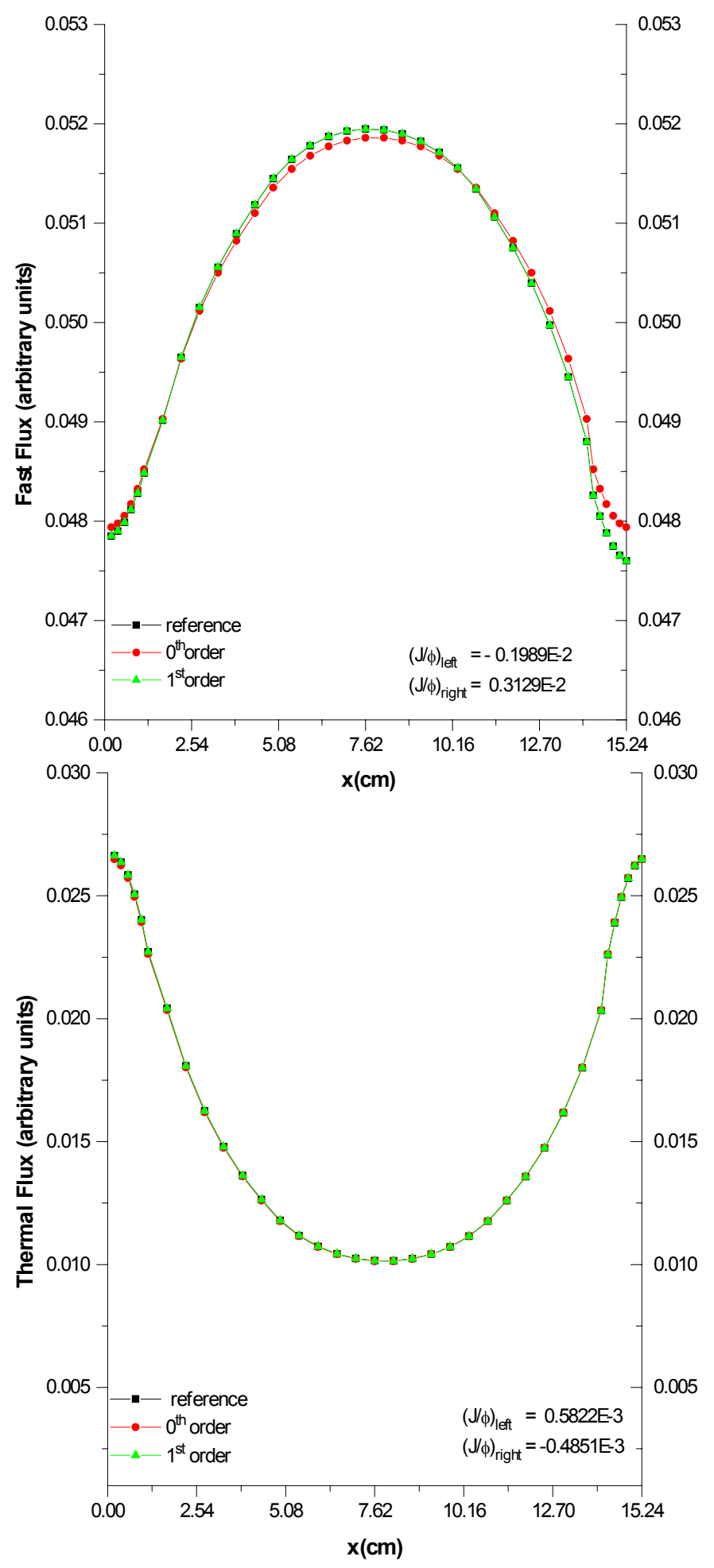

Figure 4-3. Flux distribution for case 2 


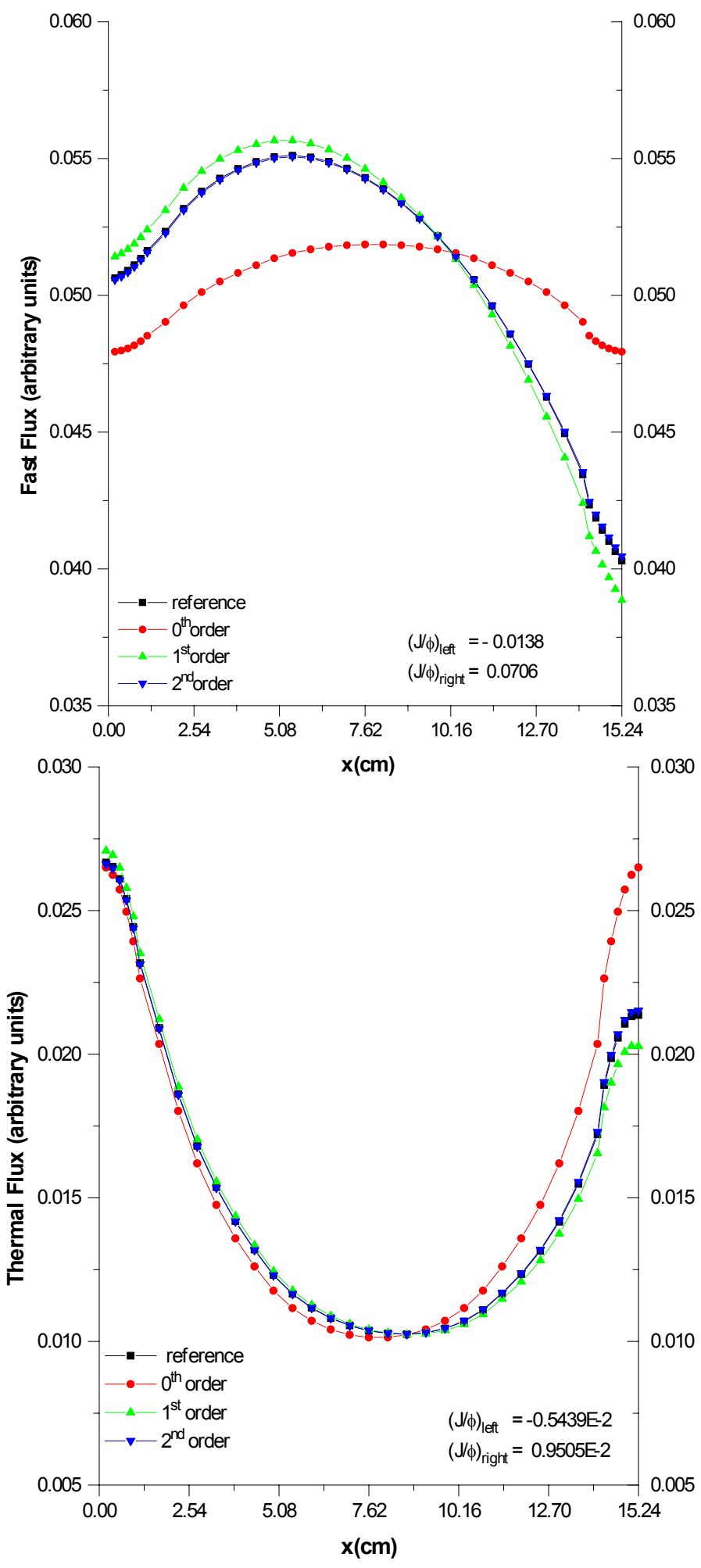

Figure 4-4. Flux distribution for case 4 


\section{Results for assembly \#3}

The flux and eigenvalue results for assembly 3 (see Figure 3-1) are shown in Table 4-8 for two values of the perturbation of the boundary condition, corresponding to the following position of the assembly in configuration 2: second from left to right, and at the center. The magnitude of the perturbation is quite large, compared to the perturbation of the boundary condition for assembly 1 in the same configuration. In case 5 for example, the initial eigenvalue is $68 \%$ off from the reference value, whereas the initial flux RMS error is $21 \%$ for the fast flux and $23 \%$ for the thermal flux. A plot of the flux distribution for this last case is shown in Figure 4-5. This figure gives a good indication of how large the perturbations are and how the method improves the results substantially. Flux distribution for case 6 is shown in Figure 4-6.

The high-order homogenized cross sections and discontinuity factors corresponding to assembly 3 are shown in Table 4-9 and 4-10 for the fast group and for the thermal group, respectively. The corrected values agree very well with the reference results. If the initial perturbation is larger, as it is the case for the discontinuity factors, higher orders corrections are needed to obtain a very good agreement. For example, five orders are required to reduce an initial error of $-32 \%$ in the thermal discontinuity factor on the right boundary down to $0.05 \%$.

Table 4-8. Flux and eigenvalue results for assembly \#3*

\begin{tabular}{|c|c|c|c|c|c|c|c|c|}
\hline $\begin{array}{l}\approx \\
\# \\
0 \\
\tilde{z} \\
\tilde{z}\end{array}$ & $\begin{array}{l}(\mathrm{J} / \Phi)_{\text {left }} \\
\text { fast/ } \\
\text { thermal }\end{array}$ & $\begin{array}{l}(\mathrm{J} / \Phi)_{\text {right }} \\
\text { fast/ } \\
\text { thermal }\end{array}$ & $\begin{array}{c}\text { Reference } \\
\text { Eigenvalue } \\
\lambda_{\text {ref }}\end{array}$ & $\begin{array}{l}\text { Ord. } \\
\text { of } \\
\text { Pert. }\end{array}$ & $\begin{array}{c}\text { Calculated } \\
\text { Eigenvalue } \\
\lambda_{\text {calc }}\end{array}$ & Error $^{b}$ & $\begin{array}{c}\text { Fast } \\
\text { Flux } \\
\text { RMS } \\
(\%)\end{array}$ & $\begin{array}{c}\text { Thermal } \\
\text { Flux } \\
\text { RMS } \\
(\%)\end{array}$ \\
\hline 5 & $\begin{array}{l}0.1026 \\
0.1178 \mathrm{E}-01\end{array}$ & $\begin{array}{l}-0.1382 \mathrm{E}-1 \\
-0.5439 \mathrm{E}-2\end{array}$ & 0.89168 & $\begin{array}{l}0 \\
1 \\
2 \\
3 \\
4 \\
5\end{array}$ & $\begin{array}{l}1.49772 \\
1.03008 \\
0.93150 \\
0.91292 \\
0.91289 \\
0.91421\end{array}$ & $\begin{array}{c}67.97 \\
15.52 \\
4.47 \\
2.38 \\
2.38 \\
2.53\end{array}$ & $\begin{array}{c}21.24 \\
3.15 \\
0.51 \\
0.37 \\
0.11 \\
0.05\end{array}$ & $\begin{array}{c}22.68 \\
4.54 \\
0.42 \\
0.35 \\
0.11 \\
0.05\end{array}$ \\
\hline 6 & $\begin{array}{l}0.7057 \mathrm{E}-1 \\
0.9505 \mathrm{E}-2\end{array}$ & $\begin{array}{l}-0.7057 \mathrm{E}-1 \\
-0.9505 \mathrm{E}-2\end{array}$ & 0.89170 & $\begin{array}{l}0 \\
1 \\
2 \\
3 \\
4 \\
5\end{array}$ & $\begin{array}{l}1.49772 \\
0.93438 \\
0.91297 \\
0.91365 \\
0.91385 \\
0.91386\end{array}$ & $\begin{array}{l}67.96 \\
4.79 \\
2.39 \\
2.46 \\
2.48 \\
2.49\end{array}$ & $\begin{array}{l}5.00 \\
0.31 \\
0.03 \\
0.02 \\
0.02 \\
0.02\end{array}$ & $\begin{array}{l}8.21 \\
0.85 \\
0.11 \\
0.04 \\
0.03 \\
0.03\end{array}$ \\
\hline
\end{tabular}

* as shown in Figure 3-1

${ }^{a}$ cases 1 and 2 refer to two different positions in configuration 2

${ }^{\mathrm{b}}$ calculated as $100 *\left(\lambda_{\text {calc }}-\lambda_{\text {ref }}\right) / \lambda_{\text {ref }}$ 

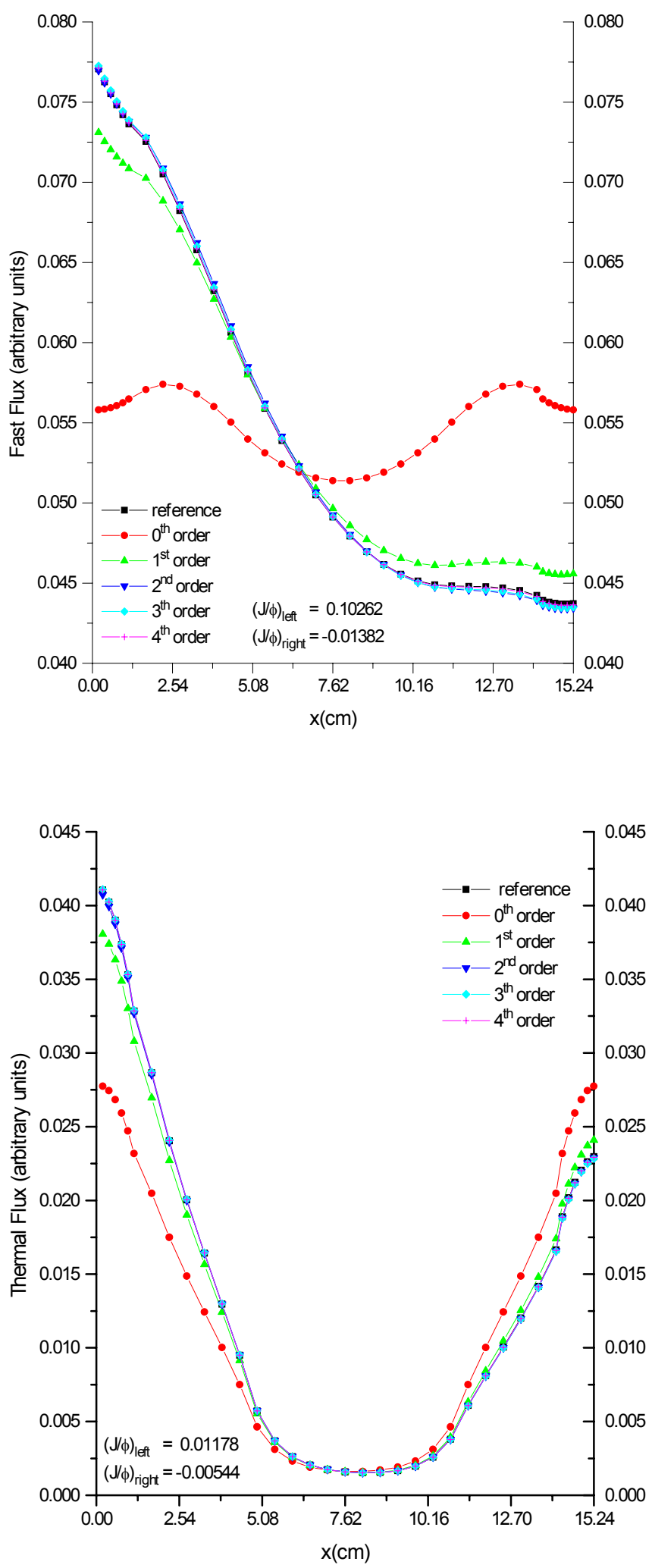

Figure 4-5. Flux distribution for case 5 
Table 4-5. Fast group cross sections" for assembly \#3

\begin{tabular}{|c|c|c|c|c|c|c|c|}
\hline 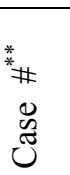 & $\begin{array}{l}\text { Order } \\
\text { of } \\
\text { Pert. }\end{array}$ & $\underset{(\mathrm{err})^{\mathrm{d}}}{\mathrm{D}}$ & $\begin{array}{l}v \sigma_{f} \\
\text { (err) }\end{array}$ & $\begin{array}{c}\sigma_{\mathrm{r}} \\
\text { (err) }\end{array}$ & $\begin{array}{c}\sigma_{12} \\
\text { (err) }\end{array}$ & $\begin{array}{l}\chi_{\text {left }} \\
\text { (err) }\end{array}$ & $\begin{array}{l}\chi_{\text {right }} \\
\text { (err) }\end{array}$ \\
\hline \multirow{7}{*}{$5^{\mathrm{a}}$} & reference & 1.54594 & $5.14140 \mathrm{E}-3$ & $9.56391 \mathrm{E}-3$ & $1.88051 \mathrm{E}-2$ & 1.43396 & 0.81358 \\
\hline & 0 & $\begin{array}{c}1.54312 \\
(0.18) \\
\end{array}$ & $\begin{array}{c}5.21060 \mathrm{E}-3 \\
(-1.35) \\
\end{array}$ & $\begin{array}{c}9.73547 \mathrm{E}-3 \\
(-1.79) \\
\end{array}$ & $\begin{array}{c}1.84941 \mathrm{E}-2 \\
(1.65) \\
\end{array}$ & $\begin{array}{l}1.01945 \\
(28.91) \\
\end{array}$ & $\begin{array}{r}0.8136 \\
(-25.30) \\
\end{array}$ \\
\hline & 1 & $\begin{array}{l}1.54526 \\
(0.04)\end{array}$ & $\begin{array}{c}5.15810 \mathrm{E}-3 \\
(-0.32)\end{array}$ & $\begin{array}{c}9.60378 \mathrm{E}-3 \\
(-0.42) \\
\end{array}$ & $\begin{array}{c}1.87318 \mathrm{E}-2 \\
(0.39)\end{array}$ & $\begin{array}{c}1.35486 \\
(5.52)\end{array}$ & $\begin{array}{c}0.84464 \\
(-3.82)\end{array}$ \\
\hline & 2 & $\begin{array}{c}1.54580 \\
(0.01)\end{array}$ & $\begin{array}{c}5.14489 \mathrm{E}-3 \\
(-0.07)\end{array}$ & $\begin{array}{c}9.57187 \mathrm{E}-3 \\
(-0.08)\end{array}$ & $\begin{array}{c}1.87902 \mathrm{E}-2 \\
(0.08)\end{array}$ & $\begin{array}{c}1.43080 \\
(0.22)\end{array}$ & $\begin{array}{c}0.80743 \\
(0.76)\end{array}$ \\
\hline & 3 & $\begin{array}{c}1.54592 \\
(0.00)\end{array}$ & $\begin{array}{c}5.14189 \mathrm{E}-3 \\
(-0.01)\end{array}$ & $\begin{array}{c}9.56487 \mathrm{E}-3 \\
(-0.01)\end{array}$ & $\begin{array}{c}1.88032 \mathrm{E}-2 \\
(0.01)\end{array}$ & $\begin{array}{c}1.43750 \\
(-0.25) \\
\end{array}$ & $\begin{array}{c}0.80901 \\
(0.56)\end{array}$ \\
\hline & 4 & $\begin{array}{c}1.54593 \\
(0.00) \\
\end{array}$ & $\begin{array}{c}5.14160 \mathrm{E}-3 \\
(0.00)\end{array}$ & $\begin{array}{c}9.56431 \mathrm{E}-3 \\
(0.00)\end{array}$ & $\begin{array}{c}1.88043 \mathrm{E}-2 \\
(0.00)\end{array}$ & $\begin{array}{c}1.43484 \\
(-0.06) \\
\end{array}$ & $\begin{array}{c}0.81219 \\
(0.17) \\
\end{array}$ \\
\hline & 5 & $\begin{array}{c}1.54593 \\
(0.00)\end{array}$ & $\begin{array}{c}5.14169 \mathrm{E}-3 \\
(-0.01)\end{array}$ & $\begin{array}{c}9.56457 \mathrm{E}-3 \\
(-0.01)\end{array}$ & $\begin{array}{c}1.88038 \mathrm{E}-2 \\
(0.01)\end{array}$ & $\begin{array}{c}1.43373 \\
(0.02)\end{array}$ & $\begin{array}{c}0.81293 \\
(0.08)\end{array}$ \\
\hline \multirow{5}{*}{$6^{\mathrm{b}}$} & reference & 1.54594 & $5.14140 \mathrm{E}-3$ & $9.56392 \mathrm{E}-3$ & $1.88051 \mathrm{E}-2$ & 1.12377 & 1.12377 \\
\hline & 0 & $\begin{array}{c}1.54312 \\
(0.18)\end{array}$ & $\begin{array}{c}5.21060 \mathrm{E}-3 \\
(-1.35)\end{array}$ & $\begin{array}{c}9.73547 \mathrm{E}-3 \\
(-1.79)\end{array}$ & $\begin{array}{c}1.84941 \mathrm{E}-2 \\
(1.65)\end{array}$ & $\begin{array}{c}1.01945 \\
(9.28)\end{array}$ & $\begin{array}{c}0.8136 \\
(9.28)\end{array}$ \\
\hline & 1 & $\begin{array}{l}1.54571 \\
(0.02)\end{array}$ & $\begin{array}{c}5.14706 \mathrm{E}-3 \\
(-0.11)\end{array}$ & $\begin{array}{c}9.57627 \mathrm{E}-3 \\
(-0.13)\end{array}$ & $\begin{array}{c}1.87815 \mathrm{E}-2 \\
(0.13)\end{array}$ & $\begin{array}{c}1.11683 \\
(0.62)\end{array}$ & $\begin{array}{c}1.11683 \\
(0.62)\end{array}$ \\
\hline & 2 & $\begin{array}{c}1.54591 \\
(0.00)\end{array}$ & $\begin{array}{c}5.14202 \mathrm{E}-3 \\
(-0.01)\end{array}$ & $\begin{array}{c}9.56517 \mathrm{E}-3 \\
(-0.01)\end{array}$ & $\begin{array}{c}1.88026 \mathrm{E}-2 \\
(0.01)\end{array}$ & $\begin{array}{c}1.12314 \\
(0.06)\end{array}$ & $\begin{array}{c}1.12314 \\
(0.06)\end{array}$ \\
\hline & 3 & $\begin{array}{c}1.54593 \\
(0.00)\end{array}$ & $\begin{array}{c}5.14167 \mathrm{E}-3 \\
(-0.01)\end{array}$ & $\begin{array}{c}9.56450 \mathrm{E}-3 \\
(-0.01)\end{array}$ & $\begin{array}{c}1.88040 \mathrm{E}-2 \\
(0.01)\end{array}$ & $\begin{array}{c}1.12340 \\
(0.03)\end{array}$ & $\begin{array}{c}1.12340 \\
(0.03)\end{array}$ \\
\hline
\end{tabular}


Table 4-6. Thermal group cross sections" for assembly \#3

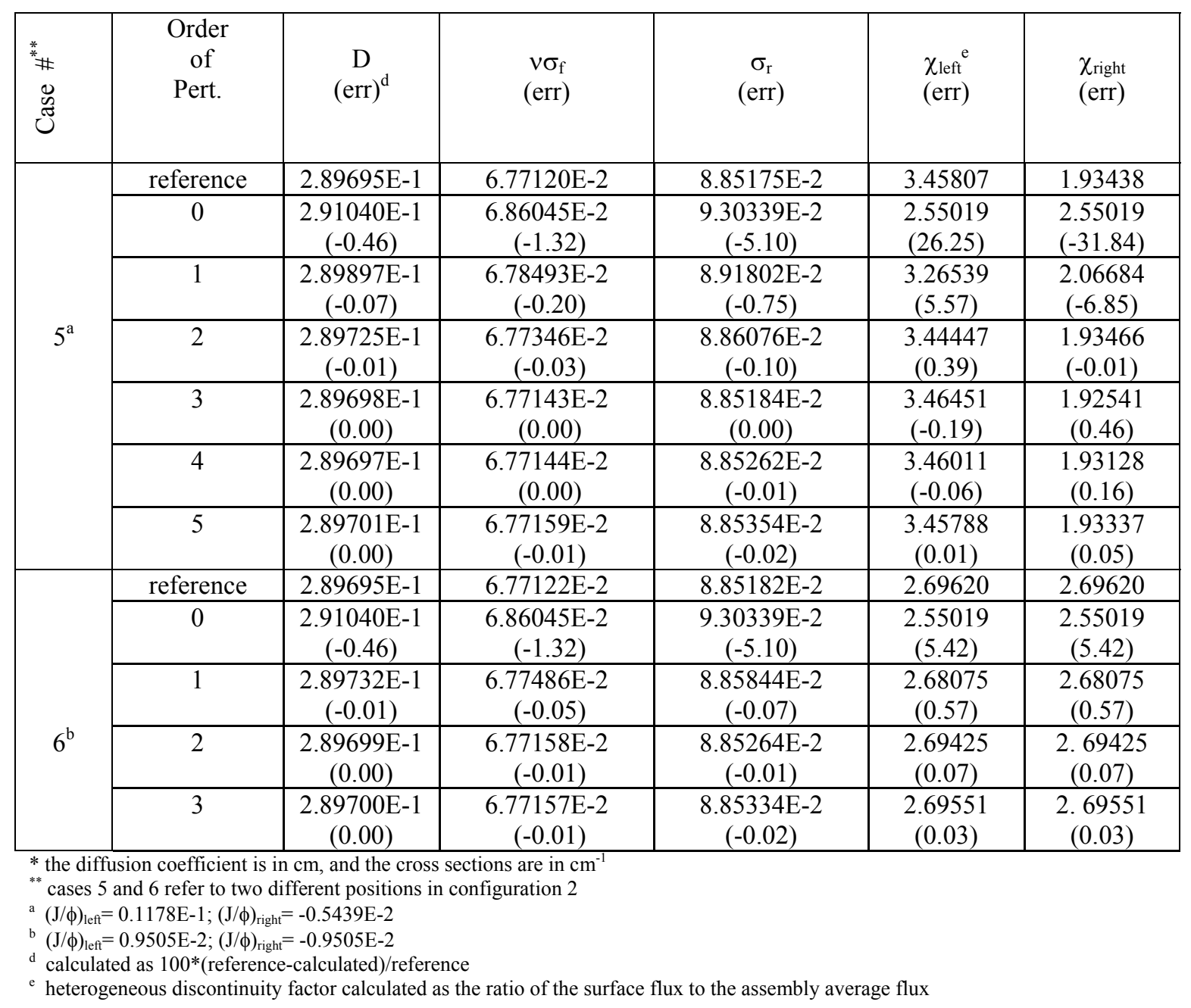



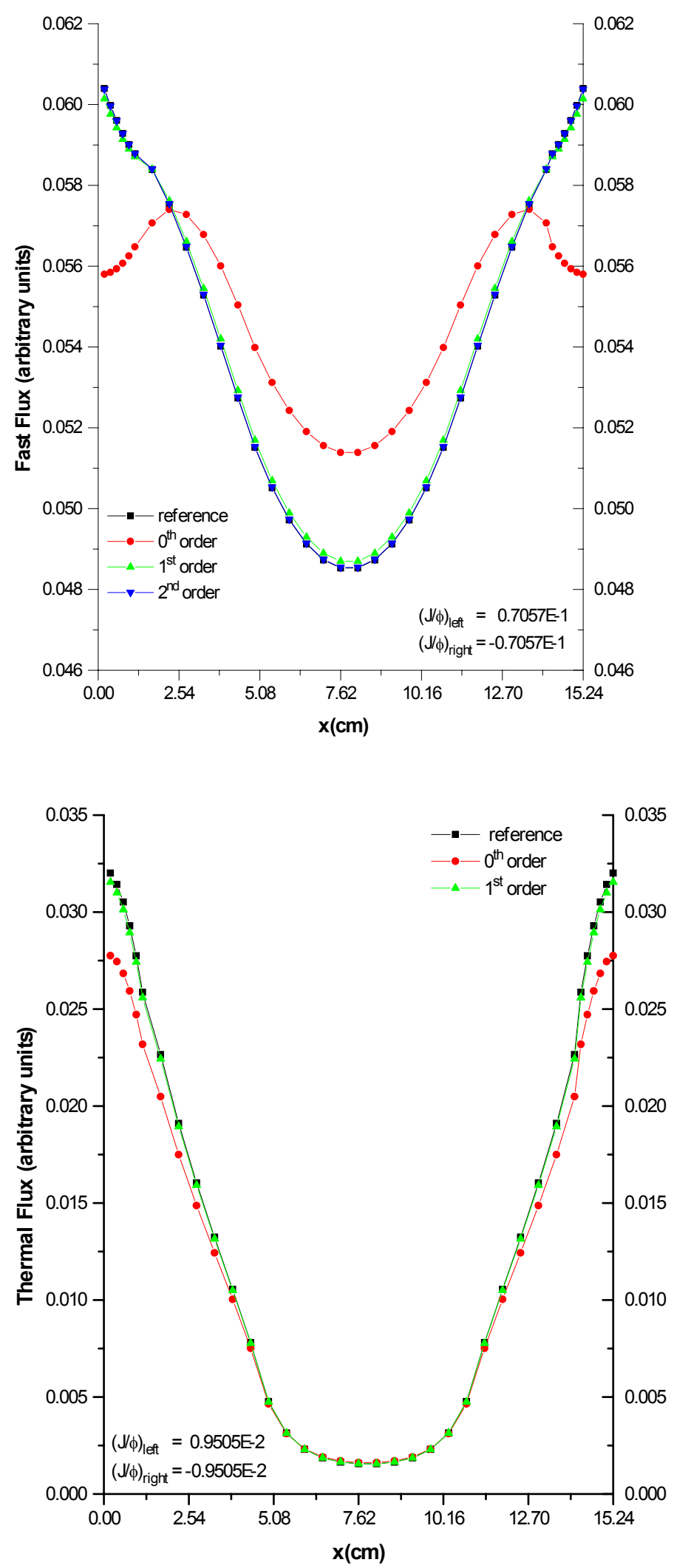

Figure 4-6. Flux distribution for case 6 


\subsubsection{Two-group two-dimensional problems}

Different types of assemblies from HAFAS core $^{6}$ are used to test the convergence of the expansion series. The results corresponding to three types of assemblies are shown here:

- regular assembly $A,(i=2, j=4)$

- $\quad$ voided (70\%) assembly $A 70(i=1, j=1)$

- controlled assembly $A+(i=4, j=4)$

where $i$ and $j$ specify the position of the assembly in the core: $i$ stands for the row number and $\mathrm{j}$ for the column number (see Figure 3-10).

For each assembly an infinite-medium (zero current) boundary condition is used as the initial state. Then different perturbations of the boundary condition (current-to-flux ratio) are considered. The perturbation values chosen are those found at the assembly/assembly interfaces in the HAFAS core. These current-to-flux ratios are determined for each assembly by performing fine-mesh diffusion calculations of the full core. They are calculated as the ratios of the average current to the average flux at the assembly interface:

$$
\frac{\bar{J}^{x+}}{\bar{\Phi}^{x+}}=\frac{\sum_{j=j_{\min }}^{j=j_{\max }} J_{i j}^{x+} \Delta y_{j}}{\sum_{j=j_{\min }}^{j=j_{\max }} \Phi_{i j}^{x+} \Delta y_{j}}
$$

$J_{i j}^{x+}$ and $\Phi_{i j}^{x+}$ are the current on side $\mathrm{x}+$ of mesh $(\mathrm{i}, \mathrm{j})$ in the assembly, and $\Delta y_{j}$ is the length on y of mesh $(i, j)$ (see figure below).

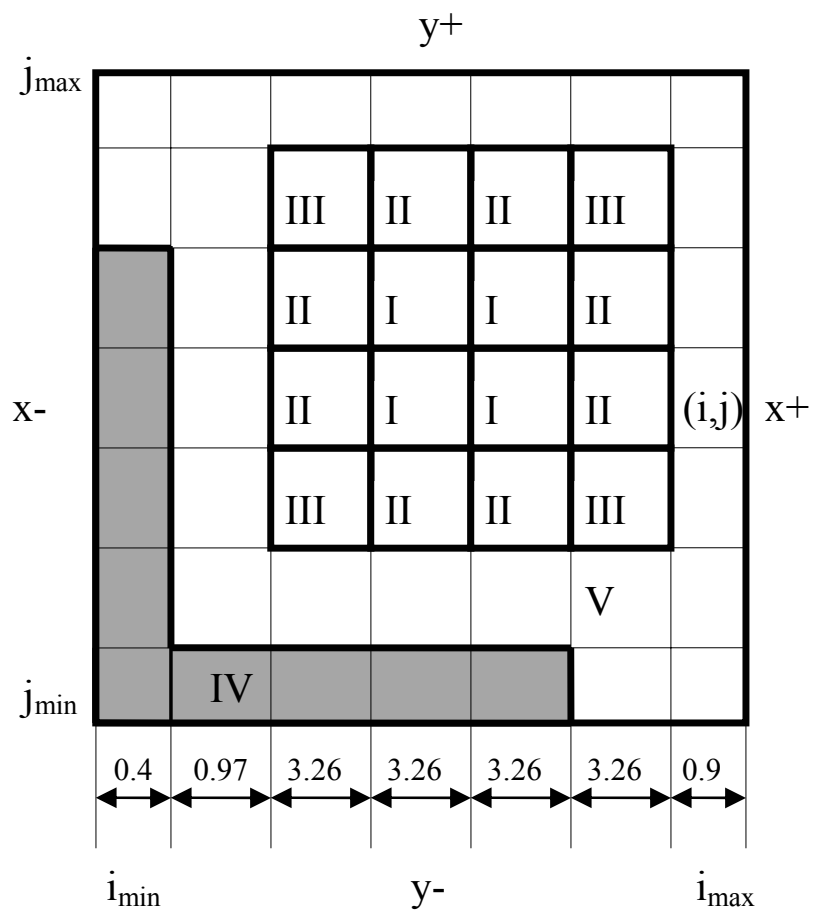


The flux and eigenvalue expansion coefficients and the high-order corrections for the homogenized cross sections are calculated and compared to each of the two following "reference" cases:

1. reference 1 - a fine-mesh assembly calculation, using for the boundary condition the corresponding current-to-flux ratio obtained from the fine-mesh full core calculation (albedo determined as in Eq. 4-2)

2. reference 2 - the flux and homogenized cross sections calculated based on the solution for the fine-mesh full core.

The results for the homogenized parameters of assembly type A are shown in Tables 4-7 and 4-8, and the flux RMS and maximum pin flux errors are shown in Table 4-9. If reference case 1 is considered for comparison, a $2^{\text {nd }}$ order correction is sufficient to reproduce the reference value for all homogenized parameters, as well as the flux distribution, irrespective of their $0^{\text {th }}$ order error. For example, the error in the fast group discontinuity factor on $\mathrm{y}+$ is reduced from $-12.2 \%$ to $0.0 \%$. If reference case 2 is considered for comparison, at the $3^{\text {rd }}$ order of the correction the cross sections are almost reproduced and the error of the discontinuity factors are significantly reduced (for example from $-12.2 \%$ to $-1.4 \%$ for the discontinuity factor on $\left.y^{+}\right)$. The flux error for each mesh and group for this case are presented in Figure 4-7. According to the figure, errors as large as $-16.9 \%$ in the fast group and $-16.6 \%$ in the thermal group are reduced to $-1.9 \%$ and $-3.6 \%$, respectively.

The results for assembly A70, which is a voided assembly, are shown in Tables 4-10 and 4-11, as well as in Figure 4-8. For this assembly, which is placed at the center of the core, the values of the standard $\left(0^{\text {th }}\right.$ order $)$ parameters are not far from the reference 2 values. A $2^{\text {nd }}$ order correction is sufficient to reproduce the reference homogenized parameters and decrease the flux RMS to less than 1.0 (at 0.4 and 0.8 for the fast and thermal group, respectively).

Assembly $\mathrm{A}+$ is a controlled assembly, with the control blade regions in the $\mathrm{x}^{+}$and $\mathrm{y}^{+}$ sides of the assembly. The results for the homogenized parameters are shown in Tables 4-12 and 4-13. If reference 1 is considered for comparison, a $2^{\text {nd }}$ order correction reproduces the homogenized cross sections and reduces the error in the discontinuity factor, which is up to about $10 \%$, to less than $1 \%$. If reference 2 is used, a $3^{\text {rd }}$ order correction reproduces the homogenized cross sections and discontinuity factors at two the interfaces of the assembly ( $\mathrm{y}-$ and $\mathrm{x}-$ ) that are not inside a control blade region. The errors of the $3^{\text {rd }}$ order corrected discontinuity factors on interfaces $\mathrm{x}+$ and $\mathrm{y}+$ (inside a control blade) are 1.3 and 2.9 for the fast and thermal group, respectively. The comparison of the flux distributions is shown in Figures 4-9 and 4-10.

It can be observed from the comparisons that there is a difference in results depending on the case used as reference. The difference is very small for assemblies with small boundary perturbations (e.g. assembly A70), and increases with increasing magnitude of the perturbation (e.g. controlled assembly $\mathrm{A}+$ ). This difference is due to the approximation used for estimating the magnitude of the perturbation (the value of the current-to-flux ratio calculated according to Eq. 4-2). 
Irrespective of the considered reference, the method converges: the errors of the homogenized parameters and flux distribution decrease with increasing order of the correction. However, how well the corrected values approximate the reference values depend on the considered reference model. If the reference considered is the fine-mesh assembly with an albedo boundary condition (calculated as in Eq. 4-2), the agreement of the corrected and the reference values is excellent, both for the homogenized parameters and flux distribution. This can be explained by the absolute consistency between the compared cases: the current-to-flux ratio at each interface is constant over the interface. If the reference considered is the assembly data as provided by the full-core fine-mesh calculation, the agreement between the reference and the high-order corrected data is still excellent for the homogenized parameters, but not as good for the flux distribution (i.e. the flux in meshes adjacent or close to the boundary). However, the errors of the $0^{\text {th }}$ order values are significantly reduced by the high-order correction.

Table 4-7. Homogenized cross sections for assembly A (reference 1*)

\begin{tabular}{|c|c|c|c|c|c|}
\hline 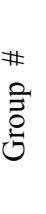 & $\begin{array}{l}\text { Order of } \\
\text { pert. } \\
\text { Cross } \\
\text { Section } \\
\left(\text { err }^{* *}\right)\end{array}$ & reference & $0^{\text {th }}$ order & $1^{\text {st }}$ order & $2^{\text {nd }}$ order \\
\hline \multirow{7}{*}{1} & $\begin{array}{c}\mathrm{D} \\
\text { (err) }^{\mathrm{d}} \\
\end{array}$ & 1.4328 & $\begin{array}{c}1.4336 \\
(-0.1) \\
\end{array}$ & $\begin{array}{c}1.4327 \\
(0.0) \\
\end{array}$ & $\begin{array}{c}1.4328 \\
(0.0) \\
\end{array}$ \\
\hline & $\begin{array}{l}v \sigma_{\mathrm{f}} \\
(\mathrm{err}) \\
\end{array}$ & $4.3113 \mathrm{E}-03$ & $\begin{array}{c}4.2744 \mathrm{E}-03 \\
(0.9)\end{array}$ & $\begin{array}{c}4.3164 \mathrm{E}-03 \\
(-0.1)\end{array}$ & $\begin{array}{c}4.3111 \mathrm{E}-03 \\
(0.0)\end{array}$ \\
\hline & $\begin{array}{c}\sigma_{\mathrm{a}} \\
\text { (err) }\end{array}$ & $6.8537 \mathrm{E}-03$ & $\begin{array}{c}\text { 6.8040E-03 } \\
(0.7)\end{array}$ & $\begin{array}{c}\text { 6.8606E-03 } \\
(0.1)\end{array}$ & $\begin{array}{c}6.8536 \mathrm{E}-03 \\
(0.0)\end{array}$ \\
\hline & $\begin{array}{l}\mathrm{f}^{\mathrm{X}^{+}} \\
\text {(err) }\end{array}$ & 0.9335 & $\begin{array}{c}0.9199 \\
(1.4) \\
\end{array}$ & $\begin{array}{c}0.9351 \\
(-0.2) \\
\end{array}$ & $\begin{array}{c}0.9337 \\
(0.0) \\
\end{array}$ \\
\hline & $\begin{array}{l}\mathrm{f}^{\mathrm{y}^{+}} \\
\text {(err) }\end{array}$ & 0.8198 & $\begin{array}{l}0.9199 \\
(-12.2) \\
\end{array}$ & $\begin{array}{c}0.8111 \\
(1.1) \\
\end{array}$ & $\begin{array}{c}0.8203 \\
(0.0)\end{array}$ \\
\hline & $\begin{array}{l}\mathrm{f}^{\mathrm{X}-} \\
\text { (err) }\end{array}$ & 0.8867 & $\begin{array}{c}0.9604 \\
(-8.3)\end{array}$ & $\begin{array}{c}0.8805 \\
(0.7)\end{array}$ & $\begin{array}{c}0.8864 \\
(-0.1)\end{array}$ \\
\hline & $\begin{array}{l}\mathrm{f}^{y-} \\
\text { (err) }\end{array}$ & 1.0361 & $\begin{array}{c}0.9604 \\
(7.3) \\
\end{array}$ & $\begin{array}{c}1.0365 \\
(0.0) \\
\end{array}$ & $\begin{array}{c}.0358 \\
(0.0)\end{array}$ \\
\hline \multirow{7}{*}{2} & $\begin{array}{c}\mathrm{D} \\
(\mathrm{err})^{\mathrm{d}}\end{array}$ & 0.3447 & $\begin{array}{c}0.34444 \\
(0.1) \\
\end{array}$ & $\begin{array}{c}0.3447 \\
(0.0)\end{array}$ & $\begin{array}{c}0.3447 \\
(0.0) \\
\end{array}$ \\
\hline & $\begin{array}{l}v \sigma_{f} \\
\text { (err) }\end{array}$ & $6.0960 \mathrm{E}-02$ & $\begin{array}{c}\text { 6.0574E-02 } \\
(0.6)\end{array}$ & $\begin{array}{c}\text { 6.1002E-02 } \\
(-0.1)\end{array}$ & $\begin{array}{c}6.0960 \mathrm{E}-02 \\
(0.0)\end{array}$ \\
\hline & $\begin{array}{c}\sigma_{\mathrm{a}} \\
(\mathrm{err})\end{array}$ & 4.6193E-02 & $\begin{array}{c}\text { 4.5967E-02 } \\
(0.5)\end{array}$ & $\begin{array}{c}\text { 4.6218E-02 } \\
(0.1)\end{array}$ & $\begin{array}{c}4.6194 \mathrm{E}-02 \\
(0.0)\end{array}$ \\
\hline & $\begin{array}{l}\mathrm{f}^{\mathrm{x}+} \\
\text { (err) }\end{array}$ & 1.6036 & $\begin{array}{c}1.5251 \\
(4.9)\end{array}$ & $\begin{array}{c}1.6070 \\
(-0.2)\end{array}$ & $\begin{array}{c}1.6037 \\
(0.0)\end{array}$ \\
\hline & $\begin{array}{l}\mathrm{f}^{y^{+}} \\
\text {(err) }\end{array}$ & 1.4335 & $\begin{array}{c}1.5251 \\
(-6.4)\end{array}$ & $\begin{array}{c}1.4260 \\
(0.5)\end{array}$ & $\begin{array}{c}1.4341 \\
(0.0) \\
\end{array}$ \\
\hline & $\begin{array}{c}\mathrm{f}^{\mathrm{x}-} \\
(\mathrm{err})\end{array}$ & 1.2059 & $\begin{array}{l}1.2885 \\
(-6.9)\end{array}$ & $\begin{array}{c}1.1993 \\
(0.5)\end{array}$ & $\begin{array}{c}1.2058 \\
(0.0)\end{array}$ \\
\hline & $\begin{array}{l}\mathrm{f}^{y-} \\
\text { (err) }\end{array}$ & 1.3281 & $\begin{array}{c}1.2885 \\
(3.0)\end{array}$ & $\begin{array}{c}1.3319 \\
(-0.3)\end{array}$ & $\begin{array}{l}1.3274 \\
(0.01) \\
\end{array}$ \\
\hline
\end{tabular}


Table 4-8. Homogenized cross sections for assembly A (reference $2^{*}$ )

\begin{tabular}{|c|c|c|c|c|c|c|}
\hline $\begin{array}{l}\# \\
\text { \# } \\
\text { ठ․ }\end{array}$ & $\begin{array}{l}\text { Order of } \\
\text { pert. }\end{array}$ & reference & $0^{\text {th }}$ order & $1^{\text {st }}$ order & $2^{\text {nd }}$ order & $3^{\text {rd }}$ order \\
\hline \multirow{7}{*}{1} & $\begin{array}{c}\mathrm{D} \\
\left(\text { (err) }^{\mathrm{d}}\right. \\
\end{array}$ & 1.4328 & $\begin{array}{c}1.4336 \\
(-0.1) \\
\end{array}$ & $\begin{array}{c}1.4327 \\
(0.0) \\
\end{array}$ & $\begin{array}{c}1.4328 \\
(0.0) \\
\end{array}$ & $\begin{array}{c}1.4328 \\
(0.0) \\
\end{array}$ \\
\hline & $\begin{array}{l}v \sigma_{\mathrm{f}} \\
(\mathrm{err})\end{array}$ & $4.3111 \mathrm{E}-03$ & $\begin{array}{c}4.2744 \mathrm{E}-03 \\
(0.9)\end{array}$ & $\begin{array}{c}.3164 \mathrm{E}-03 \\
(-0.1) \\
\end{array}$ & $\begin{array}{c}4.3111 \mathrm{E}-03 \\
(0.0) \\
\end{array}$ & $\begin{array}{c}4.3115 \mathrm{E}-03 \\
(-0.1)\end{array}$ \\
\hline & $\begin{array}{l}\sigma_{\mathrm{a}} \\
(\mathrm{err})\end{array}$ & $6.8540 \mathrm{E}-03$ & $\begin{array}{c}\text { 6.8040E-03 } \\
(0.7)\end{array}$ & $\begin{array}{c}6.8606 \mathrm{E}-03 \\
(-0.1)\end{array}$ & $\begin{array}{c}6.8536 \mathrm{E}-03 \\
(0.0)\end{array}$ & $\begin{array}{c}6.8541 \mathrm{E}-03 \\
(0.0)\end{array}$ \\
\hline & $\begin{array}{l}\mathrm{f}^{\mathrm{x}+} \\
\text { (err) }\end{array}$ & 0.9313 & $\begin{array}{c}0.9199 \\
(1.2)\end{array}$ & $\begin{array}{c}0.9351 \\
(-0.4) \\
\end{array}$ & $\begin{array}{c}0.9337 \\
(-0.3) \\
\end{array}$ & $\begin{array}{c}0.9338 \\
(-0.3) \\
\end{array}$ \\
\hline & $\begin{array}{l}\mathrm{f}^{\mathrm{y}^{+}} \\
\text {(err) }\end{array}$ & 0.8080 & $\begin{array}{l}0.9199 \\
(-13.9) \\
\end{array}$ & $\begin{array}{c}0.8111 \\
(-0.4) \\
\end{array}$ & $\begin{array}{c}0.8203 \\
(-1.5) \\
\end{array}$ & $\begin{array}{c}0.8195 \\
(-1.4)\end{array}$ \\
\hline & $\begin{array}{l}\mathrm{f}^{\mathrm{X}-} \\
\text { (err) }\end{array}$ & 0.8838 & $\begin{array}{c}0.9604 \\
(-8.7)\end{array}$ & $\begin{array}{c}0.8805 \\
(0.4)\end{array}$ & $\begin{array}{c}0.8864 \\
(-0.3)\end{array}$ & $\begin{array}{c}0.8860 \\
(-0.2)\end{array}$ \\
\hline & $\begin{array}{l}\mathrm{f}^{y-} \\
\text { (err) }\end{array}$ & 1.0534 & $\begin{array}{c}0.9604 \\
(8.8) \\
\end{array}$ & $\begin{array}{c}1.0365 \\
(1.6)\end{array}$ & $\begin{array}{c}1.0358 \\
(1.7) \\
\end{array}$ & $\begin{array}{c}1.0360 \\
(1.6)\end{array}$ \\
\hline \multirow{7}{*}{2} & $\begin{array}{c}\mathrm{D} \\
\text { (err) }^{\mathrm{d}}\end{array}$ & 0.3448 & $\begin{array}{c}0.3444 \\
(0.1) \\
\end{array}$ & $\begin{array}{c}0.3447 \\
(0.0) \\
\end{array}$ & $\begin{array}{c}0.3447 \\
(0.0) \\
\end{array}$ & $\begin{array}{c}0.3447 \\
(0.0) \\
\end{array}$ \\
\hline & $\begin{array}{l}v \sigma_{\mathrm{f}} \\
(\mathrm{err})\end{array}$ & $6.1048 \mathrm{E}-02$ & $\begin{array}{c}\text { 6.0574E-02 } \\
(0.8)\end{array}$ & $\begin{array}{c}6.1002 \mathrm{E}-02 \\
(0.1) \\
\end{array}$ & $\begin{array}{c}6.0960 \mathrm{E}-02 \\
(0.1) \\
\end{array}$ & $\begin{array}{c}6.0962 \mathrm{E}-02 \\
(0.1) \\
\end{array}$ \\
\hline & $\begin{array}{c}\sigma_{\mathrm{a}} \\
(\mathrm{err})\end{array}$ & 4.6247E-02 & $\begin{array}{c}\text { 4.5967E-02 } \\
(0.6)\end{array}$ & $\begin{array}{c}4.6218 \mathrm{E}-02 \\
(0.1)\end{array}$ & $\begin{array}{c}\text { 4.6194E-02 } \\
(0.1)\end{array}$ & $\begin{array}{c}4.6195 \mathrm{E}-02 \\
(0.1)\end{array}$ \\
\hline & $\begin{array}{l}\mathrm{f}^{\mathrm{x}+} \\
\text { (err) }\end{array}$ & 1.6036 & $\begin{array}{c}1.5251 \\
(4.9)\end{array}$ & $\begin{array}{c}1.6070 \\
(-0.2)\end{array}$ & $\begin{array}{c}1.6037 \\
(0.0)\end{array}$ & $\begin{array}{c}1.6039 \\
(0.0)\end{array}$ \\
\hline & $\begin{array}{l}\mathrm{f}^{\mathrm{y}^{+}} \\
\text {(err) }\end{array}$ & 1.4057 & $\begin{array}{c}1.5251 \\
(-8.5)\end{array}$ & $\begin{array}{c}1.4260 \\
(-1.4)\end{array}$ & $\begin{array}{c}1.4341 \\
(-2.0)\end{array}$ & $\begin{array}{c}1.4334 \\
(-2.0)\end{array}$ \\
\hline & $\begin{array}{l}\mathrm{f}^{\mathrm{X}-} \\
\text { (err) }\end{array}$ & 1.2012 & $\begin{array}{l}1.2885 \\
(-7.3)\end{array}$ & $\begin{array}{c}1.1993 \\
(0.2)\end{array}$ & $\begin{array}{c}1.2058 \\
(-0.4)\end{array}$ & $\begin{array}{l}1.2058 \\
(-0.3)\end{array}$ \\
\hline & $\begin{array}{l}\mathrm{f}^{\mathrm{y}-} \\
\text { (err) }\end{array}$ & 1.3377 & $\begin{array}{c}1.2885 \\
(3.7)\end{array}$ & $\begin{array}{c}1.3319 \\
(0.4)\end{array}$ & $\begin{array}{c}1.3274 \\
(0.8)\end{array}$ & $\begin{array}{c}1.3274 \\
(0.7)\end{array}$ \\
\hline
\end{tabular}

Table 4-9. Flux comparison for assembly A

\begin{tabular}{|c|c|c|c|c|c|}
\hline \multirow{2}{*}{$\begin{array}{c}\text { Group } \\
\#\end{array}$} & & \multicolumn{2}{|c|}{${\text { Case } 1^{*}}^{*}$ Case $2^{* *}$} \\
\cline { 3 - 6 } & & $0^{\text {th }}$ order & $3^{\text {rd }}$ order & $0^{\text {th }}$ order & $3^{\text {rd }}$ order \\
\hline \multirow{3}{*}{1} & RMS $^{* * *}$ & 8.5 & 0.0 & 9.5 & 1.6 \\
\cline { 2 - 6 } & pin max error & -14.7 & -0.1 & -16.9 & 2.6 \\
\hline \multirow{3}{*}{2} & RMS & 6.5 & 0.0 & 8.5 & 2.4 \\
\cline { 2 - 6 } & pin max error & -12.4 & -0.1 & -16.6 & -3.6 \\
\hline
\end{tabular}

reference case $=$ fine-mesh assembly with albedo boundary condition

${ }^{* *}$ reference case $=$ fine-mesh full core

${ }^{* * *}$ calculated as in Eq. 4-1 


\begin{tabular}{|l|c|c|c|c|c|c|}
\hline-24.0 & -18.5 & -13.3 & -10.2 & -8.7 & -8.7 & -8.8 \\
-2.7 & -1.9 & -1.5 & -1.0 & -0.1 & -0.6 & -0.8 \\
\hline-22.5 & -16.9 & -11.6 & -8.6 & -7.3 & -7.5 & -7.6 \\
-2.8 & -1.9 & -1.4 & -0.9 & -0.2 & 0.4 & 0.6 \\
\hline-17.7 & -11.9 & -6.6 & -3.8 & -2.9 & -3.9 & -4.1 \\
-2.8 & -1.8 & -1.1 & -0.7 & -0.3 & -0.1 & -0.1 \\
\hline-10.4 & -5.4 & -0.9 & 1.4 & 1.9 & 0.6 & 0.2 \\
-1.2 & -0.6 & -0.4 & -0.4 & -0.4 & -0.6 & -0.6 \\
\hline-3.8 & 0.1 & 3.5 & 5.4 & 5.7 & 4.4 & 4.0 \\
1.2 & 1.0 & 0.4 & 0.0 & -0.2 & -0.4 & -0.5 \\
\hline 2.3 & 4.8 & 7.0 & 8.4 & 8.7 & 7.9 & 7.6 \\
4.1 & 2.6 & 1.0 & 0.2 & 0.0 & 0.1 & 0.1 \\
\hline 5.9 & 7.3 & 8.7 & 9.7 & 10.3 & 9.9 & 9.7 \\
5.5 & 3.4 & 1.0 & -0.2 & -0.1 & 0.3 & 0.5 \\
\hline
\end{tabular}

\begin{tabular}{|c|c|c|c|c|c|c|}
\hline-24.8 & -16.9 & -10.0 & -6.3 & -5.0 & -5.3 & -5.4 \\
-8.5 & -3.7 & -0.9 & -0.2 & -0.9 & -2.6 & -3.1 \\
\hline-23.7 & -16.6 & -10.0 & -6.2 & -4.7 & -4.6 & -4.5 \\
-7.8 & -3.6 & -1.1 & -0.4 & -0.9 & -2.1 & -2.5 \\
\hline-18.3 & -14.0 & -8.3 & -4.6 & -2.7 & -1.7 & -1.1 \\
-4.7 & -2.9 & -1.3 & -0.6 & -0.6 & -0.8 & -0.7 \\
\hline-8.7 & -7.1 & -3.0 & 0.0 & 1.7 & 2.9 & 3.5 \\
0.1 & -0.4 & -0.4 & -0.3 & -0.2 & 0.0 & 0.2 \\
\hline-1.7 & -1.1 & 1.7 & 4.0 & 5.3 & 6.3 & 6.9 \\
3.2 & 1.8 & 0.8 & 0.2 & 0.1 & 0.3 & 0.4 \\
\hline 0.6 & 1.3 & 3.8 & 5.6 & 6.6 & 7.5 & 7.9 \\
3.8 & 2.7 & 1.4 & 0.7 & 0.4 & 0.2 & 0.2 \\
\hline-2.5 & -0.3 & 2.8 & 4.7 & 5.4 & 6.0 & 6.0 \\
2.5 & 2.5 & 1.6 & 1.0 & 0.7 & 0.5 & 0.1 \\
\hline
\end{tabular}

\begin{tabular}{|l|}
$0^{\text {th }}$ order \\
$3^{\text {rd }}$ order \\
\hline
\end{tabular}

Figure 4-7. Pin flux comparison for assembly A (reference 2)

Table 4-10. Homogenized cross sections for assembly A70 (reference $2^{*}$ )

\begin{tabular}{|c|c|c|c|c|c|}
\hline $\begin{array}{l}\text { \# } \\
\text { Oे } \\
\text { O. } \\
0\end{array}$ & $\begin{array}{l}\text { Order of } \\
\text { pert. } \\
\text { Cross } \\
\text { Section } \\
\left(\text { err }^{* *}\right)\end{array}$ & reference & $0^{\text {th }}$ order & $1^{\text {st }}$ order & $2^{\text {nd }}$ order \\
\hline \multirow{7}{*}{1} & $\begin{array}{c}\mathrm{D} \\
\text { (err) }^{\mathrm{d}} \\
\end{array}$ & $1.8775 \mathrm{E}+00$ & $\begin{array}{c}1.8770 \mathrm{E}+00 \\
(0.0)\end{array}$ & $\begin{array}{c}1.8776 \mathrm{E}+00 \\
(0.0)\end{array}$ & $\begin{array}{c}1.8775 \mathrm{E}+00 \\
(0.0) \\
\end{array}$ \\
\hline & $\begin{array}{l}v \sigma_{\mathrm{f}} \\
\text { (err) }\end{array}$ & $3.9650 \mathrm{E}-03$ & $\begin{array}{c}\text { 3.9574E-03 } \\
(0.2)\end{array}$ & $\begin{array}{c}3.9652 \mathrm{E}-03 \\
(0.0)\end{array}$ & $\begin{array}{c}3.9659 \mathrm{E}-03 \\
(0.0)\end{array}$ \\
\hline & $\begin{array}{c}\sigma_{\mathrm{a}} \\
(\mathrm{err})\end{array}$ & $6.1885 \mathrm{E}-03$ & $\begin{array}{c}\text { 6.1800E-03 } \\
(0.1)\end{array}$ & $\begin{array}{c}\text { 6.1887E-03 } \\
(0.0)\end{array}$ & $\begin{array}{c}6.1886 \mathrm{E}-03 \\
(0.0)\end{array}$ \\
\hline & $\begin{array}{r}\mathrm{f}^{\mathrm{X}+} \\
\text { (err) }\end{array}$ & $9.4563 \mathrm{E}-01$ & $\begin{array}{c}\text { 9.6971E-01 } \\
(-2.5)\end{array}$ & $\begin{array}{c}9.4548 \mathrm{E}-01 \\
(0.0)\end{array}$ & $\begin{array}{c}\text { 9. 4637E-01 } \\
(-0.1)\end{array}$ \\
\hline & $\begin{array}{l}\mathrm{f}^{\mathrm{y}^{+}} \\
\text {(err) }\end{array}$ & 9. $4563 \mathrm{E}-01$ & $\begin{array}{c}9.6971 \mathrm{E}-01 \\
(-2.5)\end{array}$ & $\begin{array}{c}9.4548 \mathrm{E}-01 \\
(0.0)\end{array}$ & $\begin{array}{c}\text { 9. 4637E-01 } \\
(-0.1)\end{array}$ \\
\hline & $\begin{array}{c}\mathrm{f}^{\mathrm{X}-} \\
(\mathrm{err})\end{array}$ & 9. $4073 \mathrm{E}-01$ & $\begin{array}{c}9.3456 \mathrm{E}-01 \\
(0.7)\end{array}$ & $\begin{array}{c}\text { 9. 4232E-01 } \\
(-0.2)\end{array}$ & $\begin{array}{c}\text { 9. 4195E-01 } \\
(-0.1)\end{array}$ \\
\hline & $\begin{array}{c}\mathrm{f}^{y-} \\
\text { (err) }\end{array}$ & $9.4073 \mathrm{E}-01$ & $\begin{array}{c}\text { 9.3456E-01 } \\
(0.7) \\
\end{array}$ & $\begin{array}{c}\text { 9. 4232E-01 } \\
(-0.2)\end{array}$ & $\begin{array}{c}\text { 9. 4195E-01 } \\
(-0.1)\end{array}$ \\
\hline \multirow{7}{*}{2} & $\begin{array}{c}\mathrm{D} \\
\text { (err) }^{\mathrm{d}}\end{array}$ & $6.0359 \mathrm{E}-01$ & $\begin{array}{c}\text { 6.0370E-01 } \\
(0.0)\end{array}$ & $\begin{array}{c}\text { 6.0337E-01 } \\
(0.0) \\
\end{array}$ & $\begin{array}{c}6.0337 \mathrm{E}-01 \\
(0.0) \\
\end{array}$ \\
\hline & $\begin{array}{l}v \sigma_{\mathrm{f}} \\
\text { (err) }\end{array}$ & $5.5032 \mathrm{E}-02$ & $\begin{array}{c}5.5060 \mathrm{E}-02 \\
(-0.1)\end{array}$ & $\begin{array}{c}5.4989 \mathrm{E}-02 \\
(0.10)\end{array}$ & $\begin{array}{c}5.4990 \mathrm{E}-02 \\
(0.1)\end{array}$ \\
\hline & $\begin{array}{c}\sigma_{\mathrm{a}} \\
(\mathrm{err})\end{array}$ & 4.1287E-02 & $\begin{array}{c}\text { 4.1303E-02 } \\
(0.0)\end{array}$ & $\begin{array}{c}\text { 4.1262E-02 } \\
(0.1)\end{array}$ & $\begin{array}{c}\text { 4.1262E-02 } \\
(0.1)\end{array}$ \\
\hline & $\begin{array}{l}\mathrm{f}^{\mathrm{X}+} \\
\text { (err) }\end{array}$ & $1.3081 \mathrm{E}+00$ & $\begin{array}{c}1.2820 \mathrm{E}+00 \\
(2.0)\end{array}$ & $\begin{array}{c}1.2952 \mathrm{E}+00 \\
(1.0)\end{array}$ & $\begin{array}{c}1.2967 \mathrm{E}+00 \\
(0.9)\end{array}$ \\
\hline & $\begin{array}{l}\mathrm{f}^{\mathrm{y}^{+}} \\
\text {(err) }\end{array}$ & $1.3081 \mathrm{E}+00$ & $\begin{array}{c}1.2820 \mathrm{E}+00 \\
(2.0)\end{array}$ & $\begin{array}{c}\text { 1. } 2952 \mathrm{E}+00 \\
(1.0)\end{array}$ & $\begin{array}{c}1.2967 \mathrm{E}+00 \\
(0.9)\end{array}$ \\
\hline & $\begin{array}{l}\mathrm{f}^{\mathrm{x}-} \\
\text { (err) }\end{array}$ & $1.6013 \mathrm{E}+00$ & $\begin{array}{c}1.6112 \mathrm{E}+00 \\
(-0.6)\end{array}$ & $\begin{array}{c}1.6081 \mathrm{E}+00 \\
(-0.4)\end{array}$ & $\begin{array}{c}1.6072 \mathrm{E}+00 \\
(-0.4)\end{array}$ \\
\hline & $\begin{array}{l}\mathrm{f}^{y-} \\
\text { (err) }\end{array}$ & $1.6013 \mathrm{E}+00$ & $\begin{array}{c}1.6112 \mathrm{E}+00 \\
(-0.6)\end{array}$ & $\begin{array}{c}\text { 1. } 6081 \mathrm{E}+00 \\
(-0.4)\end{array}$ & $\begin{array}{c}\text { 1. } 6072 \mathrm{E}+00 \\
(-0.4)\end{array}$ \\
\hline
\end{tabular}

${ }^{*}$ reference case $=$ fine-mesh assembly with albedo boundary condition

${ }^{* *}$ calculated as $100 *($ reference-calculated $) /$ reference 
Table 4-11. Flux comparison for assembly A70

\begin{tabular}{|c|c|c|c|c|c|}
\hline \multirow{2}{*}{$\begin{array}{c}\text { Group } \\
\#\end{array}$} & & \multicolumn{2}{|l|}{ Case $1^{*}$} & \multicolumn{2}{|l|}{ Case $2^{* *}$} \\
\hline & & $0^{\text {th }}$ order & $3^{\text {rd }}$ order & $0^{\text {th }}$ order & $3^{\text {rd }}$ order \\
\hline \multirow[b]{2}{*}{1} & $\mathrm{RMS}^{* * *}$ & 1.8 & 0.0 & 1.6 & 0.4 \\
\hline & pin max error & -2.4 & 0.0 & -1.4 & 0.7 \\
\hline \multirow[b]{2}{*}{2} & RMS & 1.8 & 0.0 & 1.7 & 0.7 \\
\hline & pin max error & 3.1 & 0.0 & 2.8 & 0.9 \\
\hline
\end{tabular}

Table 4-12. Homogenized cross sections for assembly A+ (reference 1*)

\begin{tabular}{|c|c|c|c|c|c|}
\hline 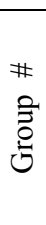 & $\begin{array}{l}\text { Order of } \\
\text { pert. } \\
\text { Cross } \\
\text { Section } \\
\left(\text { err }^{* *}\right)\end{array}$ & reference & $0^{\text {th }}$ order & $1^{\text {st }}$ order & $2^{\text {nd }}$ order \\
\hline \multirow{7}{*}{1} & $\begin{array}{c}\mathrm{D} \\
\text { (err) }^{\mathrm{d}}\end{array}$ & $1.4216 \mathrm{E}+00$ & $\begin{array}{c}1.4201 \mathrm{E}+00 \\
(0.1)\end{array}$ & $\begin{array}{c}1.4216 \mathrm{E}+00 \\
(0.0)\end{array}$ & $\begin{array}{c}1.4216 \mathrm{E}+00 \\
(0.0)\end{array}$ \\
\hline & $\begin{array}{l}v \sigma_{\mathrm{f}} \\
\text { (err) }\end{array}$ & $4.3157 \mathrm{E}-03$ & $\begin{array}{c}4.3190 \mathrm{E}-03 \\
(-0.1)\end{array}$ & $\begin{array}{c}.3223 \mathrm{E}-03 \\
(-0.2)\end{array}$ & $\begin{array}{c}4.3161 \mathrm{E}-03 \\
(0.0)\end{array}$ \\
\hline & $\begin{array}{c}\sigma_{\mathrm{a}} \\
\text { (err) }\end{array}$ & $9.0009 \mathrm{E}-03$ & $\begin{array}{c}9.2929 \mathrm{E}-03 \\
(-3.2)\end{array}$ & $\begin{array}{c}8.9953 \mathrm{E}-03 \\
(0.1)\end{array}$ & $\begin{array}{c}9.0026 \mathrm{E}-03 \\
(0.0)\end{array}$ \\
\hline & $\begin{array}{l}\mathrm{f}^{\mathrm{x}+} \\
\text { (err) }\end{array}$ & 7.4134E-01 & $\begin{array}{c}8.1691 \mathrm{E}-01 \\
(-10.2)\end{array}$ & $\begin{array}{c}7.3673 \mathrm{E}-01 \\
(0.6)\end{array}$ & $\begin{array}{c}7.4149 \mathrm{E}-01 \\
(0.0)\end{array}$ \\
\hline & $\begin{array}{l}\mathrm{f}^{y^{+}} \\
\text {(err) }\end{array}$ & $7.4134 \mathrm{E}-01$ & $\begin{array}{c}8.1691 \mathrm{E}-01 \\
(-10.2)\end{array}$ & $\begin{array}{c}7.3673 \mathrm{E}-01 \\
(0.6)\end{array}$ & $\begin{array}{c}7.4149 \mathrm{E}-01 \\
(0.0)\end{array}$ \\
\hline & $\begin{array}{l}\mathrm{f}^{\mathrm{X}-} \\
\text { (err) }\end{array}$ & $1.1482 \mathrm{E}+00$ & $\begin{array}{c}1.0402 \mathrm{E}+00 \\
(9.4)\end{array}$ & $\begin{array}{c}1.1442 \mathrm{E}+00 \\
(0.4)\end{array}$ & $\begin{array}{c}1.1476 \mathrm{E}+00 \\
(0.1)\end{array}$ \\
\hline & $\begin{array}{l}\mathrm{f}^{y-} \\
\text { (err) }\end{array}$ & $1.1482 \mathrm{E}+00$ & $\begin{array}{c}1.0402 \mathrm{E}+00 \\
(9.4)\end{array}$ & $\begin{array}{c}1.1442 \mathrm{E}+00 \\
(0.4)\end{array}$ & $\begin{array}{c}1.1476 \mathrm{E}+00 \\
(0.1)\end{array}$ \\
\hline \multirow{7}{*}{2} & $\begin{array}{c}\mathrm{D} \\
\text { (err) }^{\mathrm{d}}\end{array}$ & $3.4774 \mathrm{E}-01$ & $\begin{array}{c}3.4844 \mathrm{E}-01 \\
(-0.2)\end{array}$ & $\begin{array}{c}3.4783 \mathrm{E}-01 \\
(0.0)\end{array}$ & $\begin{array}{c}3.4775 \mathrm{E}-01 \\
(0.0)\end{array}$ \\
\hline & $\begin{array}{l}v \sigma_{\mathrm{f}} \\
\text { (err) }\end{array}$ & $6.5818 \mathrm{E}-02$ & $\begin{array}{c}6.7078 \mathrm{E}-02 \\
(-1.9)\end{array}$ & $\begin{array}{c}6.5943 \mathrm{E}-02 \\
(-0.2)\end{array}$ & $\begin{array}{c}6.5838 \mathrm{E}-02 \\
(0.0)\end{array}$ \\
\hline & $\begin{array}{l}\sigma_{\mathrm{a}} \\
\text { (err) }\end{array}$ & $5.6881 \mathrm{E}-02$ & $\begin{array}{c}5.8881 \mathrm{E}-02 \\
(-3.5)\end{array}$ & $\begin{array}{c}5.6926 \mathrm{E}-02 \\
(0.1)\end{array}$ & $\begin{array}{c}5.6926 \mathrm{E}-02 \\
(0.1)\end{array}$ \\
\hline & $\begin{array}{l}\mathrm{f}^{\mathrm{x}+} \\
\text { (err) }\end{array}$ & $6.3445 \mathrm{E}-01$ & $\begin{array}{c}6.7231 \mathrm{E}-01 \\
(-6.0)\end{array}$ & $\begin{array}{c}\text { 6.3772E-01 } \\
(-0.5)\end{array}$ & $\begin{array}{c}\text { 6.3504E-01 } \\
(-0.1)\end{array}$ \\
\hline & $\begin{array}{l}\mathrm{f}^{\mathrm{y}^{\mathrm{y}}} \\
\text { (err) }\end{array}$ & $6.3445 \mathrm{E}-01$ & $\begin{array}{c}\text { 6.7231E-01 } \\
(-6.0)\end{array}$ & $\begin{array}{c}6.3772 \mathrm{E}-01 \\
(-0.5)\end{array}$ & $\begin{array}{c}\text { 6.3504E-01 } \\
(-0.1)\end{array}$ \\
\hline & $\begin{array}{c}\mathrm{f}^{\mathrm{x}-} \\
(\mathrm{err}) \\
\end{array}$ & $1.9563 \mathrm{E}+00$ & $\begin{array}{c}1.7640 \mathrm{E}+00 \\
(9.8)\end{array}$ & $\begin{array}{c}1.9346 \mathrm{E}+00 \\
(1.1)\end{array}$ & $\begin{array}{c}1.9521 \mathrm{E}+00 \\
(0.2)\end{array}$ \\
\hline & $\begin{array}{l}\mathrm{f}^{y^{-}} \\
\text {(err) }\end{array}$ & $1.9563 \mathrm{E}+00$ & $\begin{array}{c}1.7640 \mathrm{E}+00 \\
(9.8)\end{array}$ & $\begin{array}{c}1.9346 \mathrm{E}+00 \\
(1.1)\end{array}$ & $\begin{array}{c}1.9521 \mathrm{E}+00 \\
(0.2)\end{array}$ \\
\hline
\end{tabular}




\begin{tabular}{|c|c|c|c|c|c|c|}
\hline-2.4 & -2.4 & -2.3 & -2.5 & -2.7 & -3.1 & -3.7 \\
-0.1 & -0.2 & -0.3 & -0.2 & 0.1 & 1.1 & 1.9 \\
\hline-1.1 & -1.1 & -0.9 & -1.0 & -1.4 & -2.1 & -3.1 \\
-0.2 & -0.2 & -0.2 & -0.1 & 0.2 & 0.7 & 1.1 \\
\hline 0.2 & 0.2 & 0.3 & 0.1 & -0.4 & -1.4 & -2.7 \\
-0.1 & -0.1 & -0.1 & 0.0 & 0.1 & 0.2 & 0.2 \\
\hline 0.9 & 0.9 & 1.0 & 0.7 & 0.1 & -1.0 & -2.5 \\
-0.1 & -0.1 & -0.1 & -0.1 & 0.0 & -0.1 & -0.2 \\
\hline 1.2 & 1.2 & 1.3 & 1.0 & 0.3 & -0.9 & -2.3 \\
-0.1 & -0.1 & -0.1 & -0.1 & -0.1 & -0.2 & -0.3 \\
\hline 1.2 & 1.2 & 1.2 & 0.9 & 0.2 & -1.1 & -2.4 \\
-0.1 & -0.1 & -0.1 & -0.1 & -0.1 & -0.2 & -0.2 \\
\hline 1.2 & 1.2 & 1.2 & 0.9 & 0.2 & -1.1 & -2.4 \\
-0.1 & -0.1 & -0.1 & -0.1 & -0.1 & -0.2 & -0.1 \\
\hline
\end{tabular}

\begin{tabular}{|c|c|c|c|c|c|c|}
\hline 1.0 & 1.1 & 2.0 & 2.6 & 3.0 & 3.6 & 4.3 \\
-2.1 & -2.0 & -0.6 & 0.3 & 0.9 & 1.1 & -0.1 \\
\hline 0.5 & 0.6 & 1.2 & 1.7 & 2.2 & 2.8 & 3.6 \\
-0.7 & -0.6 & -0.4 & 0.1 & 0.6 & 0.9 & 1.1 \\
\hline 0.7 & 0.7 & 0.9 & 1.2 & 1.6 & 2.2 & 3.0 \\
-0.2 & -0.2 & -0.2 & 0.0 & 0.3 & 0.6 & 0.9 \\
\hline 0.9 & 0.0 & 1.0 & 1.1 & 1.2 & 1.7 & 2.6 \\
-0.1 & -0.1 & -0.1 & -0.1 & 0.0 & 0.1 & 0.3 \\
\hline 1.1 & 1.1 & 1.1 & 1.0 & 0.9 & 1.2 & 2.0 \\
-0.1 & -0.1 & -0.1 & -0.1 & -0.2 & -0.4 & -0.6 \\
\hline 1.1 & 1.1 & 1.1 & 0.9 & 0.7 & 0.6 & 1.1 \\
-0.1 & -0.1 & -0.1 & -0.1 & -0.2 & -0.6 & -2.0 \\
\hline 1.1 & 1.1 & 1.1 & 0.9 & 0.7 & 0.5 & 1.0 \\
-0.1 & -0.1 & -0.1 & -0.1 & -0.2 & -0.7 & -2.1 \\
\hline
\end{tabular}

\begin{tabular}{|l|}
\hline $0^{\text {th }}$ order \\
$2^{\text {nd }}$ order \\
\hline
\end{tabular}

Figure 4-8. Pin flux comparison for assembly A70 (reference 2)

Table 4-13. Homogenized cross sections for assembly $A+$ (reference 2*)

\begin{tabular}{|c|c|c|c|c|c|}
\hline 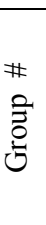 & $\begin{array}{l}\text { Order of } \\
\text { pert. } \\
\text { Cross } \\
\text { Section } \\
\left(\text { err }^{* *}\right)\end{array}$ & reference & $0^{\text {th }}$ order & $1^{\text {st }}$ order & $2^{\text {nd }}$ order \\
\hline \multirow{7}{*}{1} & $\begin{array}{c}\mathrm{D} \\
\left(\text { (err) }^{\mathrm{d}}\right.\end{array}$ & $1.4215 \mathrm{E}+00$ & $\begin{array}{c}1.4201 \mathrm{E}+00 \\
(0.1)\end{array}$ & $\begin{array}{c}1.4216 \mathrm{E}+00 \\
(0.0)\end{array}$ & $\begin{array}{c}1.4216 \mathrm{E}+00 \\
(0.0)\end{array}$ \\
\hline & $\begin{array}{l}v \sigma_{\mathrm{f}} \\
(\mathrm{err})\end{array}$ & $4.3123 \mathrm{E}-03$ & $\begin{array}{c}4.3190 \mathrm{E}-03 \\
(-0.2)\end{array}$ & $\begin{array}{c}4.3223 \mathrm{E}-03 \\
(-0.2)\end{array}$ & $\begin{array}{c}4.3161 \mathrm{E}-03 \\
(-0.1)\end{array}$ \\
\hline & $\begin{array}{c}\sigma_{\mathrm{a}} \\
(\mathrm{err})\end{array}$ & $9.0281 \mathrm{E}-03$ & $\begin{array}{c}9.2929 \mathrm{E}-03 \\
(-2.9)\end{array}$ & $\begin{array}{c}8.9953 \mathrm{E}-03 \\
(0.4)\end{array}$ & $\begin{array}{c}9.0026 \mathrm{E}-03 \\
(0.3)\end{array}$ \\
\hline & $\begin{array}{l}\mathrm{f}^{\mathrm{x}+} \\
\text { (err) }\end{array}$ & $7.5140 \mathrm{E}-01$ & $\begin{array}{c}8.1691 \mathrm{E}-01 \\
(-8.7)\end{array}$ & $\begin{array}{c}7.3673 \mathrm{E}-01 \\
(2.0)\end{array}$ & $\begin{array}{c}7.4149 \mathrm{E}-01 \\
(1.3)\end{array}$ \\
\hline & $\begin{array}{l}\mathrm{f}^{\mathrm{y}^{+}} \\
\text {(err) }\end{array}$ & $7.5140 \mathrm{E}-01$ & $\begin{array}{c}8.1691 \mathrm{E}-01 \\
(-8.7)\end{array}$ & $\begin{array}{c}\text { 7. } 3673 \mathrm{E}-01 \\
(2.0)\end{array}$ & $\begin{array}{c}7.4149 \mathrm{E}-01 \\
(1.3)\end{array}$ \\
\hline & $\begin{array}{l}\mathrm{f}^{\mathrm{X}-} \\
\text { (err) }\end{array}$ & $1.1448 \mathrm{E}+00$ & $\begin{array}{c}1.0402 \mathrm{E}+00 \\
(9.1)\end{array}$ & $\begin{array}{c}1.1442 \mathrm{E}+00 \\
(0.1)\end{array}$ & $\begin{array}{c}1.1476 \mathrm{E}+00 \\
(-0.2)\end{array}$ \\
\hline & $\begin{array}{l}\mathrm{f}^{\mathrm{y}-} \\
\text { (err) }\end{array}$ & $1.1448 \mathrm{E}+00$ & $\begin{array}{c}1.0402 \mathrm{E}+00 \\
(9.1)\end{array}$ & $\begin{array}{c}1.1442 \mathrm{E}+00 \\
(0.1)\end{array}$ & $\begin{array}{c}1.1476 \mathrm{E}+00 \\
(-0.2)\end{array}$ \\
\hline \multirow{7}{*}{2} & $\begin{array}{c}\mathrm{D} \\
(\mathrm{err})^{\mathrm{d}}\end{array}$ & $3.4773 \mathrm{E}-01$ & $\begin{array}{c}3.4844 \mathrm{E}-01 \\
(-0.2)\end{array}$ & $\begin{array}{c}3.4783 \mathrm{E}-01 \\
(0.0)\end{array}$ & $\begin{array}{c}3.4775 \mathrm{E}-01 \\
(0.0)\end{array}$ \\
\hline & $\begin{array}{l}v \sigma_{\mathrm{f}} \\
\text { (err) }\end{array}$ & $6.5846 \mathrm{E}-02$ & $\begin{array}{c}6.7078 \mathrm{E}-02 \\
(-1.9)\end{array}$ & $\begin{array}{c}6.5943 \mathrm{E}-02 \\
(-0.1)\end{array}$ & $\begin{array}{c}6.5838 \mathrm{E}-02 \\
(0.0)\end{array}$ \\
\hline & $\begin{array}{l}\sigma_{\mathrm{a}} \\
(\mathrm{err})\end{array}$ & $5.7093 \mathrm{E}-02$ & $\begin{array}{c}5.8881 \mathrm{E}-02 \\
(-3.1)\end{array}$ & $\begin{array}{c}5.6926 \mathrm{E}-02 \\
(0.3)\end{array}$ & $\begin{array}{c}5.6926 \mathrm{E}-02 \\
(0.3)\end{array}$ \\
\hline & $\begin{array}{l}\mathrm{f}^{\mathrm{x}+} \\
\text { (err) }\end{array}$ & $6.5430 \mathrm{E}-01$ & $\begin{array}{c}6.7231 \mathrm{E}-01 \\
(-2.8)\end{array}$ & $\begin{array}{c}6.3772 \mathrm{E}-01 \\
(2.5)\end{array}$ & $\begin{array}{c}6.3504 \mathrm{E}-01 \\
(2.9)\end{array}$ \\
\hline & $\begin{array}{l}\mathrm{f}^{\mathrm{y}^{+}} \\
\text {(err) }\end{array}$ & $6.5430 \mathrm{E}-01$ & $\begin{array}{c}\text { 6.7231E-01 } \\
(-2.8)\end{array}$ & $\begin{array}{c}\text { 6.3772E-01 } \\
(2.5)\end{array}$ & $\begin{array}{l}6.3504 \mathrm{E}-01 \\
(2.9)\end{array}$ \\
\hline & $\begin{array}{l}\mathrm{f}^{\mathrm{X}-} \\
\text { (err) }\end{array}$ & $1.9472 \mathrm{E}+00$ & $\begin{array}{c}1.7640 \mathrm{E}+00 \\
(9.4)\end{array}$ & $\begin{array}{c}1.9346 \mathrm{E}+00 \\
(0.6)\end{array}$ & $\begin{array}{c}1.9521 \mathrm{E}+00 \\
(-0.3)\end{array}$ \\
\hline & $\begin{array}{l}\mathrm{f}^{\mathrm{y}-} \\
\text { (err) }\end{array}$ & $1.9472 \mathrm{E}+00$ & $\begin{array}{c}1.7640 \mathrm{E}+00 \\
(9.4)\end{array}$ & $\begin{array}{c}1.9346 \mathrm{E}+00 \\
(0.6)\end{array}$ & $\begin{array}{c}1.9521 \mathrm{E}+00 \\
(-0.3)\end{array}$ \\
\hline
\end{tabular}


Table 4-14. Flux comparison for assembly $\mathrm{A}^{+}$

\begin{tabular}{|c|c|c|c|c|c|}
\hline \multirow{2}{*}{ Group \# } & & \multicolumn{2}{|c|}{${\text { Case } 1^{*}}^{\text {Case } 2^{* *}}$} \\
\cline { 2 - 6 } & $0^{\text {th }}$ order & $3^{\text {rd }}$ order & $0^{\text {th }}$ order & $3^{\text {rd }}$ order \\
\hline \multirow{2}{*}{1} & RMS $^{* * *}$ & 12.3 & 0.0 & 10.3 & 2.2 \\
\cline { 2 - 6 } & pin max error & 10.0 & 0.1 & -14.5 & -3.1 \\
\hline 2 & RMS & 11.8 & 0.1 & 10.2 & 3.7 \\
\cline { 2 - 6 } & pin max error & 17.4 & 0.2 & 12.1 & -6.2 \\
\hline
\end{tabular}
reference case = fine-mesh assembly with albedo boundary condition
reference case = fine-mesh full core
calculated as in Eq. 4-1

\begin{tabular}{|c|c|c|c|c|c|c|}
\hline 1.1 & -3.9 & -10.1 & -14.6 & -17.6 & -19.3 & -19.9 \\
3.3 & 1.8 & 0.8 & 1.0 & 2.4 & 3.8 & 4.5 \\
\hline 1.9 & -3.0 & -8.9 & -13.4 & -16.7 & -18.5 & -19.3 \\
3.2 & 1.8 & 0.9 & 1.1 & 2.3 & 3.4 & 3.8 \\
\hline 3.7 & -0.9 & -6.4 & -10.8 & -14.5 & -16.7 & -17.6 \\
2.5 & 1.6 & 1.0 & 1.1 & 1.8 & 2.3 & 2.4 \\
\hline 5.0 & 1.3 & -3.4 & -7.3 & -10.8 & -13.4 & -14.6 \\
0.1 & 0.0 & 0.2 & 0.8 & 1.1 & 1.1 & 1.0 \\
\hline 6.8 & 3.8 & -0.2 & -3.4 & -6.4 & -8.9 & -10.1 \\
-2.3 & -1.7 & -0.8 & 0.2 & 1.0 & 0.9 & 0.8 \\
\hline 10.0 & 7.2 & 3.8 & 1.3 & -0.9 & -3.0 & -3.9 \\
-3.8 & -3.1 & -1.7 & 0.0 & 1.6 & 1.8 & 1.8 \\
\hline 12.8 & 10.0 & 6.8 & 5.0 & 3.7 & 1.9 & 1.1 \\
-4.1 & -3.8 & -2.3 & 0.1 & 2.5 & 3.2 & 3.3 \\
\hline
\end{tabular}

\begin{tabular}{|c|c|c|c|c|c|c|}
\hline 10.8 & 4.8 & -1.6 & -8.6 & -13.0 & -15.3 & -16.1 \\
3.7 & 2.7 & 2.1 & 2.0 & 2.3 & 2.3 & 1.8 \\
\hline 11.3 & 5.0 & -2.3 & -9.1 & -13.3 & -15.1 & -15.3 \\
4.1 & 2.7 & 1.7 & 1.5 & 2.0 & 2.4 & 2.3 \\
\hline 12.7 & 6.2 & -1.2 & -7.5 & -11.6 & -13.3 & -13.0 \\
4.7 & 2.8 & 1.5 & 1.3 & 1.7 & 2.0 & 2.3 \\
\hline 12.7 & 7.4 & 0.9 & -4.1 & -7.5 & -9.1 & -8.6 \\
1.4 & 0.5 & 0.3 & 0.7 & 1.3 & 1.5 & 2.0 \\
\hline 13.4 & 9.3 & 4.4 & 0.9 & -1.2 & -2.3 & -1.6 \\
-3.0 & -2.7 & -1.4 & 0.3 & 1.5 & 1.7 & 2.1 \\
\hline 14.6 & 12.1 & 9.3 & 7.4 & 6.2 & 5.0 & 4.8 \\
-8.5 & -6.2 & -2.7 & 0.5 & 2.8 & 2.7 & 2.7 \\
\hline 14.8 & 14.6 & 13.4 & 12.7 & 12.7 & 11.3 & 10.8 \\
-14.5 & -8.5 & -3.0 & 1.4 & 4.7 & 4.1 & 3.7 \\
\hline
\end{tabular}

\begin{tabular}{|l|}
$0^{\text {th }}$ order \\
$3^{\text {rd }}$ order
\end{tabular}

Figure 4-9. Pin flux comparison for assembly A+ (reference 2)

\begin{tabular}{|c|c|c|c|c|c|c|}
\hline-2.2 & -5.8 & -11.0 & -15.8 & -20.6 & -24.0 & -25.6 \\
0.0 & 0.0 & 0.0 & 0.0 & 0.0 & 0.0 & 0.0 \\
\hline-1.3 & -4.9 & -10.0 & -14.7 & -19.4 & -22.7 & -24.0 \\
0.0 & 0.0 & 0.0 & 0.0 & 0.0 & 0.0 & 0.0 \\
\hline 1.2 & -2.5 & -7.5 & -12.2 & -16.6 & -19.4 & -20.6 \\
0.0 & 0.0 & -0.1 & -0.1 & -0.1 & 0.0 & 0.0 \\
\hline 5.0 & 1.3 & -3.7 & -8.1 & -12.2 & -14.7 & -15.8 \\
0.0 & 0.0 & -0.1 & -0.1 & -0.1 & 0.0 & 0.0 \\
\hline 8.9 & 5.4 & 0.6 & -3.7 & -7.5 & -10.0 & -11.0 \\
0.0 & 0.0 & 0.0 & -0.1 & -0.1 & 0.0 & 0.0 \\
\hline 13.3 & 10.0 & 5.4 & 1.3 & -2.5 & -4.9 & -5.8 \\
0.0 & 0.0 & 0.0 & 0.0 & 0.0 & 0.0 & 0.0 \\
\hline 16.3 & 13.3 & 8.9 & 5.0 & 1.2 & -1.3 & -2.2 \\
0.1 & 0.0 & 0.0 & 0.0 & 0.0 & 0.0 & 0.0 \\
\hline
\end{tabular}

\begin{tabular}{|c|c|c|c|c|c|c|}
\hline 7.6 & 2.3 & -3.8 & -10.8 & -15.7 & -18.0 & -18.2 \\
0.1 & 0.1 & 0.0 & 0.0 & 0.0 & 0.0 & 0.0 \\
\hline 7.6 & 2.4 & -4.1 & -10.8 & -15.7 & -18.0 & -18.0 \\
0.1 & 0.1 & 0.0 & 0.0 & 0.0 & 0.0 & 0.0 \\
\hline 8.5 & 3.6 & -2.7 & -8.9 & -13.6 & -15.7 & -15.7 \\
0.1 & 0.1 & 0.0 & 0.0 & 0.0 & 0.0 & 0.0 \\
\hline 11.6 & 7.0 & 0.6 & -4.9 & -8.9 & -10.8 & -10.8 \\
0.1 & 0.1 & 0.0 & 0.0 & 0.0 & 0.0 & 0.0 \\
\hline 16.1 & 11.8 & 5.7 & 0.6 & -2.7 & -4.1 & -3.8 \\
0.2 & 0.1 & 0.0 & 0.0 & 0.0 & 0.0 & 0.0 \\
\hline 21.4 & 17.4 & 11.8 & 7.0 & 3.6 & 2.4 & 2.3 \\
0.3 & 0.2 & 0.1 & 0.1 & 0.1 & 0.1 & 0.1 \\
\hline 25.9 & 21.4 & 16.1 & 11.6 & 8.5 & 7.6 & 7.6 \\
0.4 & 0.3 & 0.2 & 0.1 & 0.1 & 0.1 & 0.1 \\
\hline
\end{tabular}

$0^{\text {th }}$ order $3^{\text {rd }}$ order

Figure 4-10. Pin flux comparison for assembly $A+$ (reference 1) 


\subsection{Implemention of the high-order cross section homogenization method into nodal diffusion code}

\subsubsection{One-group one-dimensional problems}

It was found that the new homogenization method is very accurate as compared to the standard homogenization technique based on the generalized equivalence theory. The results of the nodal calculations (performed as explained is section 2.3) for configuration 2 (see Figure 3-1), with the homogenized parameters corrected up to the $4^{\text {th }}$ order, are shown in Table 4-15. Only the first four assemblies are shown due to symmetry. It can be seen that there is a large improvement compared to the $0^{\text {th }}$ order (standard GET) both for the assembly-integrated nodal flux and the assembly-integrated reconstructed flux. The large difference (of up to $418 \%$ ) between the assembly-integrated nodal-flux and the assembly-integrated reference flux is reduced to less than $1.2 \%$ at the $4^{\text {th }}$ order. The results are similar for the assembly-integrated reconstructed flux, where the large $0^{\text {th }}$ order difference (up to $62 \%$ ) is reduced to less than $2.7 \%$ at the $4^{\text {th }}$ order.

Table 4-15. Assembly Integrated Flux for Configuration 2

\begin{tabular}{|c|c|c|c|c|c|c|}
\hline $\begin{array}{c}\text { Order of } \\
\text { Perturbation }\end{array}$ & $\begin{array}{c}\text { Assembly } \\
\text { Position }\end{array}$ & Reference & Nodal & $\begin{array}{c}\text { Error }^{\mathrm{a}} \\
(\%)\end{array}$ & Reconstructed & $\begin{array}{c}\text { Error } \\
(\%)\end{array}$ \\
\hline \multirow{4}{*}{0} & 1 & 2.370 & 1.082 & -54 & 2.872 & 21 \\
\hline & 2 & 0.658 & 0.913 & 39 & 0.250 & -62 \\
\hline & 3 & 0.357 & 1.057 & 196 & 0.310 & -13 \\
\hline & 4 & 0.173 & 0.898 & 418 & 0.105 & -39 \\
\hline \multirow{4}{*}{1} & 1 & 2.370 & 2.827 & 19 & 2.823 & 19 \\
\hline & 2 & 0.658 & 0.453 & -31 & 0.454 & -31 \\
\hline & 3 & 0.357 & 0.188 & -47 & 0.188 & -47 \\
\hline & 4 & 0.173 & 0.068 & -61 & 0.068 & -61 \\
\hline \multirow{4}{*}{2} & 1 & 2.370 & 2.281 & -3.8 & 2.281 & -3.7 \\
\hline & 2 & 0.658 & 0.722 & 9.8 & 0.720 & 9.5 \\
\hline & 3 & 0.357 & 0.381 & 6.8 & 0.374 & 5.0 \\
\hline & 4 & 0.173 & 0.200 & 15 & 0.196 & 13 \\
\hline \multirow{4}{*}{3} & 1 & 2.370 & 2.465 & 4.0 & 2.487 & 4.9 \\
\hline & 2 & 0.658 & 0.641 & -2.6 & 0.650 & -1.2 \\
\hline & 3 & 0.357 & 0.304 & -15 & 0.311 & -13 \\
\hline & 4 & 0.173 & 0.144 & -17 & 0.146 & -16 \\
\hline \multirow{4}{*}{4} & 1 & 2.370 & 2.382 & 0.5 & 2.386 & 0.6 \\
\hline & 2 & 0.658 & 0.666 & 1.2 & 0.671 & 1.9 \\
\hline & 3 & 0.357 & 0.360 & 0.9 & 0.366 & 2.7 \\
\hline & 4 & 0.173 & 0.175 & 0.9 & 0.177 & 2.2 \\
\hline
\end{tabular}

${ }^{a}$ Defined as $100 *$ (calculated-reference)/reference 


\subsubsection{Two-group one-dimensional problems}

\section{Results for configurations 1 and 2}

Configuration 1 is a very simple configuration, with small gradients of the flux at the node interface (see Figure 3-2). For this configuration, the use of the standard GET nodal parameters leads to a good agreement of the nodal calculations with the fine-mesh core calculations. That is, there is no need to correct the nodal parameters in this case. Therefore, only results for configurations 2 are shown in this section.

The distribution of the nodal flux at different orders of correction for the nodal parameters is compared to the reference distribution in Figures 4-11 and 4-12 for the fast flux and thermal flux, respectively. The full core fine-mesh calculation is taken as the reference. The node-integrated flux as well as the assembly reconstructed fine-mesh flux is compared to the assembly reference flux, for different orders of the correction of the nodal cross sections, in Tables 4-16 and 4-17 for the fast and thermal flux, respectively. Only results for nodes 1 to 4 are shown, given the symmetry.

It can be seen that the $0^{\text {th }}$ order node-integrated fast flux overestimates the reference value in those nodes where assembly 1 is positioned $(3.2 \%$ and $2.3 \%)$, but underestimates the reference value in the nodes where assembly 3 is present $(-7.1 \%$ and $-7.7 \%)$. The errors corresponding to the $0^{\text {th }}$ order thermal flux in each node (up to $14 \%$ in absolute value) are about twice as large as the fast flux errors. The difference is reduced to less than $1 \%$ at the third order, for both groups, and becomes less than $0.5 \%$ at the fourth order.

The error of the assembly reconstructed flux, at a high order of the correction, has the same order of magnitude as that of the node-integrated flux in the corresponding node. The first and second order corrected reconstructed fine-mesh flux is compared to the reference fine-mesh flux distribution in Figure 4-13 for group 1 and in Figure 4-14 for group 2. Even the reconstructed flux shape corresponding to the second order approximates the shape of the reference flux in both groups very well. At the fourth order, not shown in the figures, the corrected and the reference flux shapes are practically identical.

The distribution of the zeroth order reconstructed flux is shown in Figure 4-15 for the fast flux and in Figure 4-16 for the thermal flux. The difference between the distributions is more pronounced at the center of the core for both the thermal and the fast fluxes. 


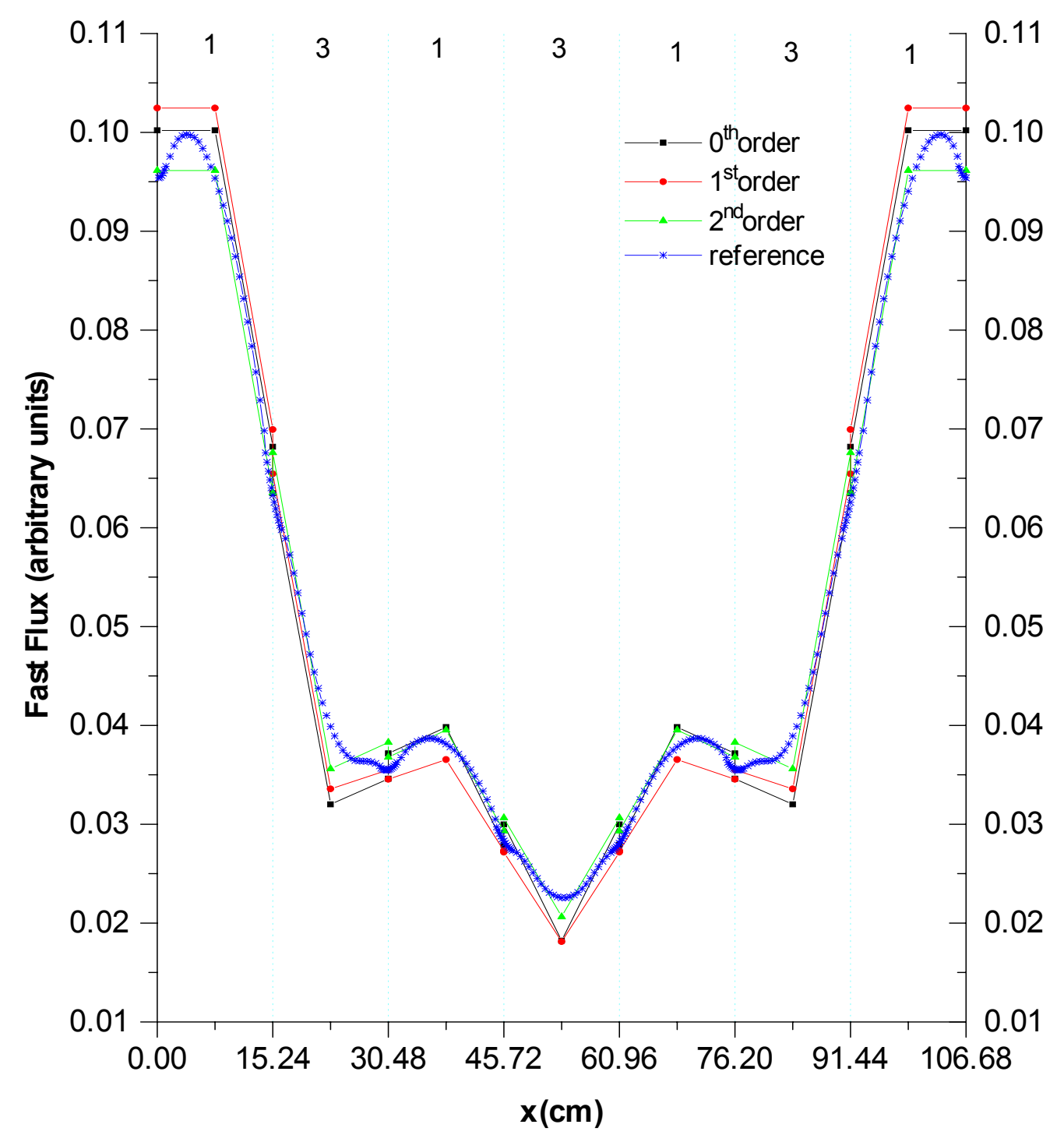

Figure 4-11. Nodal fast flux distribution in core 2 


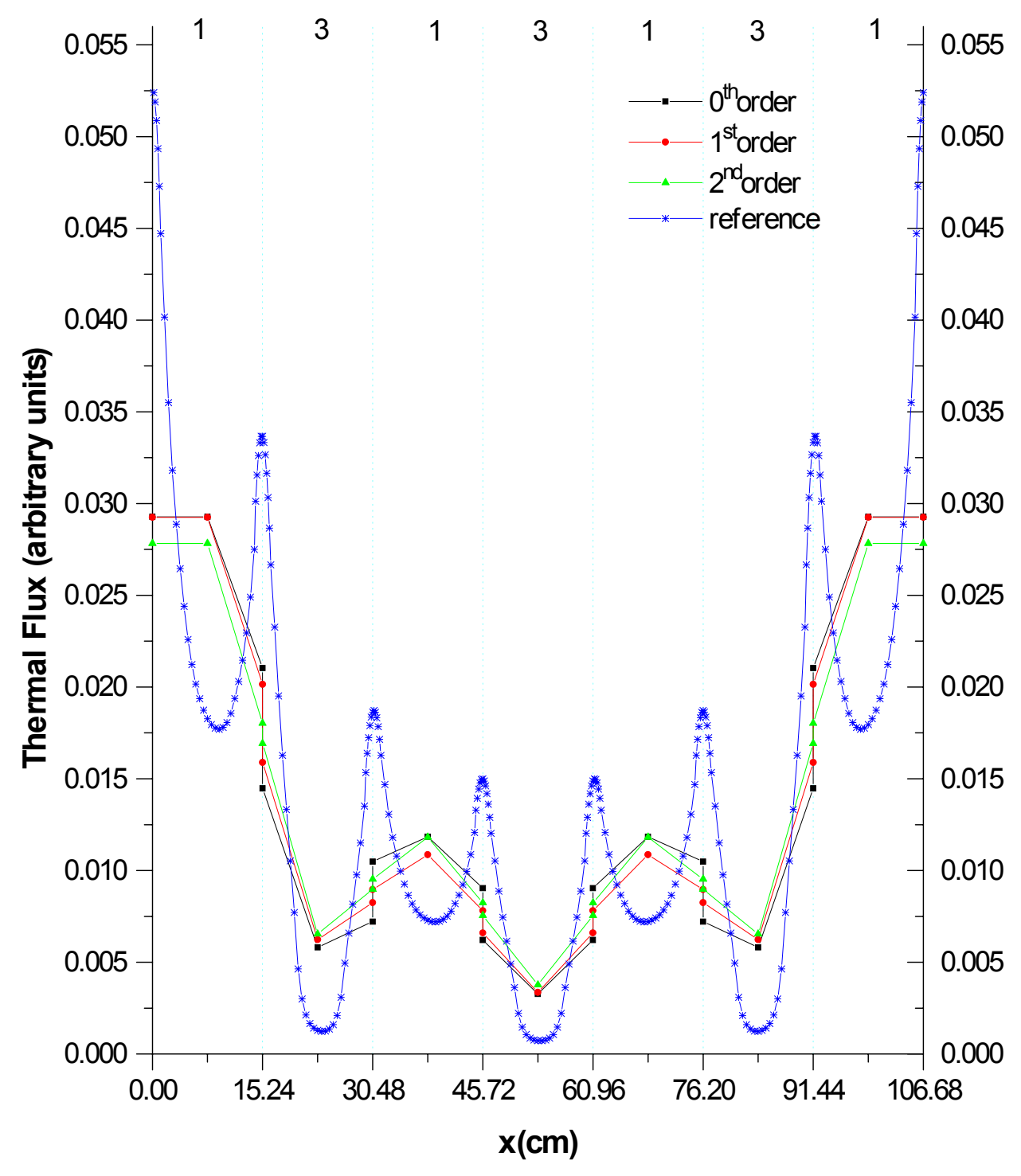

Figure 4-12. Nodal thermal flux distribution in core 2 
Table 4-16. Assembly fast flux for core 2

\begin{tabular}{|c|c|c|c|c|c|c|}
\hline $\begin{array}{c}\text { Order of } \\
\text { Perturbation }\end{array}$ & $\begin{array}{l}\text { Assembly } \\
\text { Position }\end{array}$ & Reference & Nodal & Error $^{\mathrm{a}}$ & Reconstructed & Error $^{\mathrm{a}}$ \\
\hline \multirow{4}{*}{ solo } & 1 & 1.3614 & 1.4051 & 3.20 & 1.3901 & 2.10 \\
\hline & 2 & 0.6650 & 0.6176 & -7.14 & 0.6536 & -1.72 \\
\hline & 3 & 0.5465 & 0.5593 & 2.33 & 0.5456 & -0.17 \\
\hline & 4 & 0.3807 & 0.3514 & -7.70 & 0.3366 & -11.60 \\
\hline \multirow{4}{*}{1} & 1 & 1.3614 & 1.4376 & 5.59 & 1.4404 & 5.80 \\
\hline & 2 & 0.6650 & 0.6404 & -3.69 & 0.6416 & -3.51 \\
\hline & 3 & 0.5465 & 0.5142 & -5.91 & 0.5146 & -5.83 \\
\hline & 4 & 0.3807 & 0.3450 & -9.39 & 0.3455 & -9.25 \\
\hline \multirow{4}{*}{2} & 1 & 1.3614 & 1.3409 & -1.51 & 1.3402 & -1.56 \\
\hline & 2 & 0.6650 & 0.6748 & 1.47 & 0.6752 & 1.53 \\
\hline & 3 & 0.5465 & 0.5530 & 1.18 & 0.5528 & 1.15 \\
\hline & 4 & 0.3807 & 0.3907 & 2.62 & 0.3909 & 2.66 \\
\hline \multirow{4}{*}{3} & 1 & 1.3614 & 1.3648 & 0.25 & 1.3650 & 0.26 \\
\hline & 2 & 0.6650 & 0.6674 & 0.37 & 0.6676 & 0.39 \\
\hline & 3 & 0.5465 & 0.5416 & -0.89 & 0.5416 & -0.90 \\
\hline & 4 & 0.3807 & 0.3793 & -0.38 & 0.3794 & -0.36 \\
\hline \multirow{4}{*}{4} & 1 & 1.3614 & 1.3611 & -0.02 & 1.3611 & -0.03 \\
\hline & 2 & 0.6650 & 0.6676 & 0.39 & 0.6677 & 0.40 \\
\hline & 3 & 0.5465 & 0.5442 & -0.43 & 0.5441 & -0.44 \\
\hline & 4 & 0.3807 & 0.3814 & 0.16 & 0.3814 & 0.18 \\
\hline \multirow{4}{*}{5} & 1 & 1.3614 & 1.3595 & -0.14 & 1.3595 & -0.14 \\
\hline & 2 & 0.6650 & 0.6678 & 0.42 & 0.6679 & 0.43 \\
\hline & 3 & 0.5465 & 0.5452 & -0.24 & 0.5451 & -0.25 \\
\hline & 4 & 0.3807 & 0.3822 & 0.38 & 0.3822 & 0.39 \\
\hline \multirow{4}{*}{6} & 1 & 1.3614 & 1.3599 & -0.11 & 1.3599 & -0.11 \\
\hline & 2 & 0.6650 & 0.6677 & 0.41 & 0.6678 & 0.42 \\
\hline & 3 & 0.5465 & 0.5450 & -0.29 & 0.5449 & -0.30 \\
\hline & 4 & 0.3807 & 0.3820 & 0.32 & 0.3820 & 0.34 \\
\hline \multirow{4}{*}{7} & 1 & 1.3614 & 1.3600 & -0.11 & 1.3599 & -0.11 \\
\hline & 2 & 0.6650 & 0.6678 & 0.42 & 0.6678 & 0.43 \\
\hline & 3 & 0.5465 & 0.5449 & -0.29 & 0.5448 & -0.31 \\
\hline & 4 & 0.3807 & 0.3819 & 0.32 & 0.3820 & 0.33 \\
\hline \multirow{4}{*}{8} & 1 & 1.3614 & 1.3600 & -0.11 & 1.3600 & -0.11 \\
\hline & 2 & 0.6650 & 0.6678 & 0.42 & 0.6678 & 0.43 \\
\hline & 3 & 0.5465 & 0.5449 & -0.30 & 0.5448 & -0.31 \\
\hline & 4 & 0.3807 & 0.3819 & 0.31 & 0.3820 & 0.33 \\
\hline \multirow{4}{*}{9} & 1 & 1.3614 & 1.3600 & -0.11 & 1.3600 & -0.11 \\
\hline & 2 & 0.6650 & 0.6678 & 0.42 & 0.6678 & 0.43 \\
\hline & 3 & 0.5465 & 0.5449 & -0.30 & 0.5448 & -0.31 \\
\hline & 4 & 0.3807 & 0.3819 & 0.31 & 0.3820 & 0.33 \\
\hline \multirow{4}{*}{10} & 1 & 1.3614 & 1.3600 & -0.11 & 1.3600 & -0.11 \\
\hline & 2 & 0.6650 & 0.6678 & 0.42 & 0.6678 & 0.43 \\
\hline & 3 & 0.5465 & 0.5449 & -0.30 & 0.5448 & -0.31 \\
\hline & 4 & 0.3807 & 0.3819 & 0.31 & 0.3820 & 0.33 \\
\hline
\end{tabular}

${ }^{a}$ Defined as $100^{*}$ (calculated-reference)/reference 
Table 4-17. Assembly thermal flux for core 2

\begin{tabular}{|c|c|c|c|c|c|c|}
\hline $\begin{array}{c}\text { Order of } \\
\text { Perturbation }\end{array}$ & $\begin{array}{l}\text { Assembly } \\
\text { Position }\end{array}$ & Reference & Nodal & Error $^{\mathrm{a}}$ & Reconstructed & Error $^{\mathrm{a}}$ \\
\hline \multirow{4}{*}{ 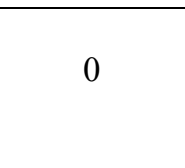 } & 1 & 0.3920 & 0.4148 & 5.80 & 0.3699 & -5.65 \\
\hline & 2 & 0.1469 & 0.1269 & -13.60 & 0.1761 & 19.88 \\
\hline & 3 & 0.1557 & 0.1646 & 5.71 & 0.1462 & -6.08 \\
\hline & 4 & 0.0841 & 0.0723 & -14.06 & 0.1004 & 19.42 \\
\hline \multirow{4}{*}{1} & 1 & 0.3920 & 0.4111 & 4.85 & 0.4082 & 4.13 \\
\hline & 2 & 0.1469 & 0.1395 & -5.00 & 0.1383 & -5.81 \\
\hline & 3 & 0.1557 & 0.1467 & -5.78 & 0.1463 & -6.05 \\
\hline & 4 & 0.0841 & 0.0759 & -9.71 & 0.0754 & -10.33 \\
\hline \multirow{4}{*}{2} & 1 & 0.3920 & 0.3867 & -1.37 & 0.3874 & -1.19 \\
\hline & 2 & 0.1469 & 0.1485 & 1.11 & 0.1481 & 0.82 \\
\hline & 3 & 0.1557 & 0.1577 & 1.33 & 0.1579 & 1.43 \\
\hline & 4 & 0.0841 & 0.0862 & 2.50 & 0.0861 & 2.36 \\
\hline \multirow{4}{*}{3} & 1 & 0.3920 & 0.3931 & 0.26 & 0.3929 & 0.22 \\
\hline & 2 & 0.1469 & 0.1471 & 0.11 & 0.1469 & 0.02 \\
\hline & 3 & 0.1557 & 0.1545 & -0.76 & 0.1546 & -0.72 \\
\hline & 4 & 0.0841 & 0.0837 & -0.50 & 0.0836 & -0.57 \\
\hline \multirow{4}{*}{4} & 1 & 0.3920 & 0.3921 & 0.00 & 0.3921 & 0.01 \\
\hline & 2 & 0.1469 & 0.1471 & 0.16 & 0.1470 & 0.10 \\
\hline & 3 & 0.1557 & 0.1552 & -0.30 & 0.1553 & -0.25 \\
\hline & 4 & 0.0841 & 0.0841 & 0.04 & 0.0841 & -0.02 \\
\hline \multirow{4}{*}{5} & 1 & 0.3920 & 0.3916 & -0.12 & 0.3916 & -0.12 \\
\hline & 2 & 0.1469 & 0.1471 & 0.18 & 0.1471 & 0.13 \\
\hline & 3 & 0.1557 & 0.1555 & -0.11 & 0.1556 & -0.07 \\
\hline & 4 & 0.0841 & 0.0843 & 0.25 & 0.0843 & 0.19 \\
\hline \multirow{4}{*}{6} & 1 & 0.3920 & 0.3917 & -0.09 & 0.3917 & -0.09 \\
\hline & 2 & 0.1469 & 0.1471 & 0.16 & 0.1471 & 0.12 \\
\hline & 3 & 0.1557 & 0.1554 & -0.16 & 0.1555 & -0.11 \\
\hline & 4 & 0.0841 & 0.0843 & 0.20 & 0.0842 & 0.14 \\
\hline \multirow{4}{*}{7} & 1 & 0.3920 & 0.3917 & -0.08 & 0.3917 & -0.08 \\
\hline & 2 & 0.1469 & 0.1471 & 0.17 & 0.1471 & 0.12 \\
\hline & 3 & 0.1557 & 0.1554 & -0.17 & 0.1555 & -0.12 \\
\hline & 4 & 0.0841 & 0.0843 & 0.19 & 0.0842 & 0.13 \\
\hline \multirow{4}{*}{8} & 1 & 0.3920 & 0.3917 & -0.08 & 0.3917 & -0.08 \\
\hline & 2 & 0.1469 & 0.1471 & 0.17 & 0.1471 & 0.12 \\
\hline & 3 & 0.1557 & 0.1554 & -0.17 & 0.1555 & -0.12 \\
\hline & 4 & 0.0841 & 0.0843 & 0.19 & 0.0842 & 0.13 \\
\hline \multirow{4}{*}{9} & 1 & 0.3920 & 0.3917 & -0.08 & 0.3917 & -0.08 \\
\hline & 2 & 0.1469 & 0.1471 & 0.17 & 0.1471 & 0.12 \\
\hline & 3 & 0.1557 & 0.1554 & -0.17 & 0.1555 & -0.12 \\
\hline & 4 & 0.0841 & 0.0843 & 0.19 & 0.0842 & 0.13 \\
\hline \multirow{4}{*}{10} & 1 & 0.3920 & 0.3917 & -0.08 & 0.3917 & -0.08 \\
\hline & 2 & 0.1469 & 0.1471 & 0.17 & 0.1471 & 0.12 \\
\hline & 3 & 0.1557 & 0.1554 & -0.17 & 0.1555 & -0.12 \\
\hline & 4 & 0.0841 & 0.0843 & 0.19 & 0.0842 & 0.13 \\
\hline
\end{tabular}

${ }^{a}$ Defined as $100^{*}$ (calculated-reference)/reference 


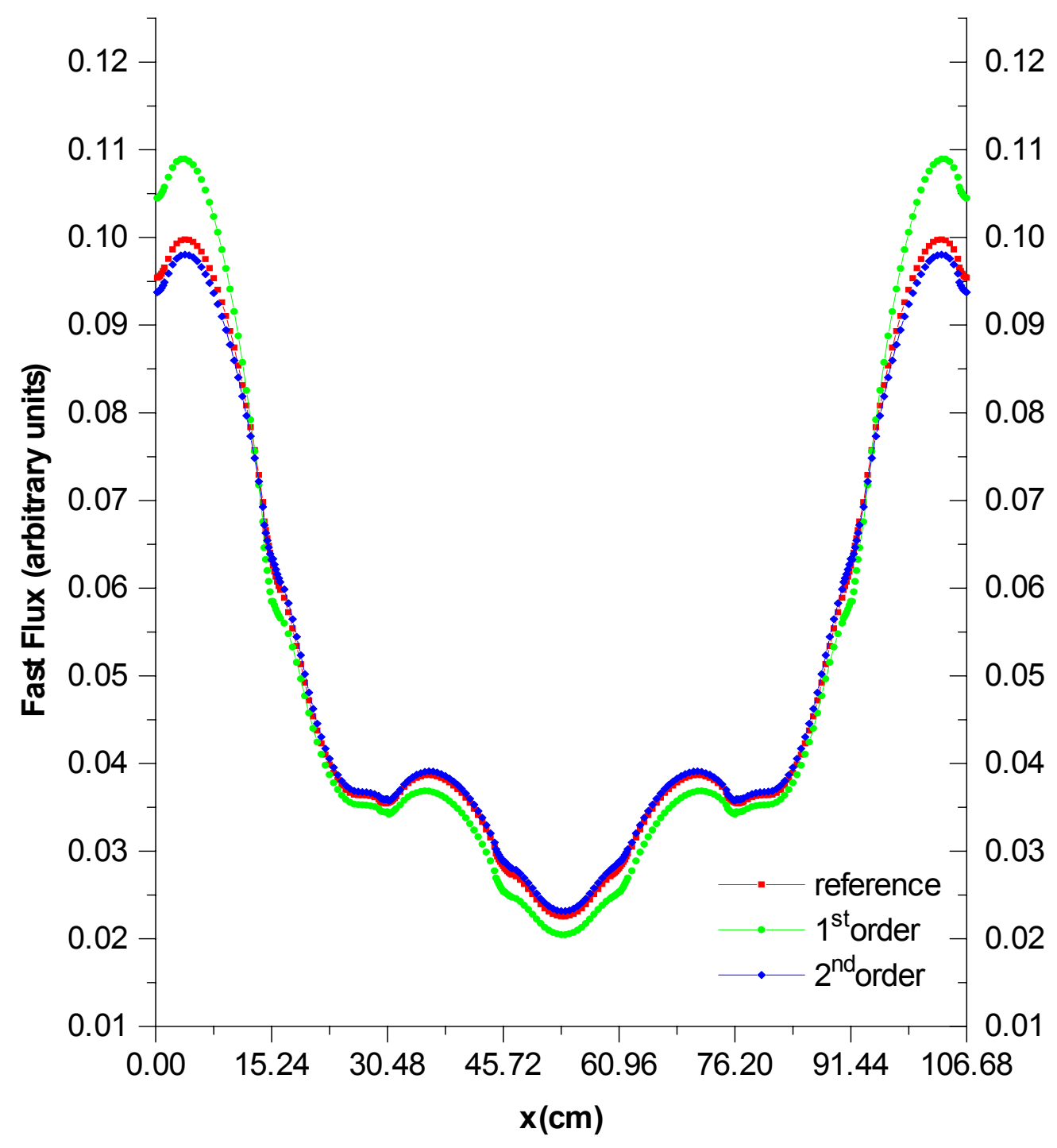

Figure 4-13. High-order reconstructed flux in group 1 for core 2 


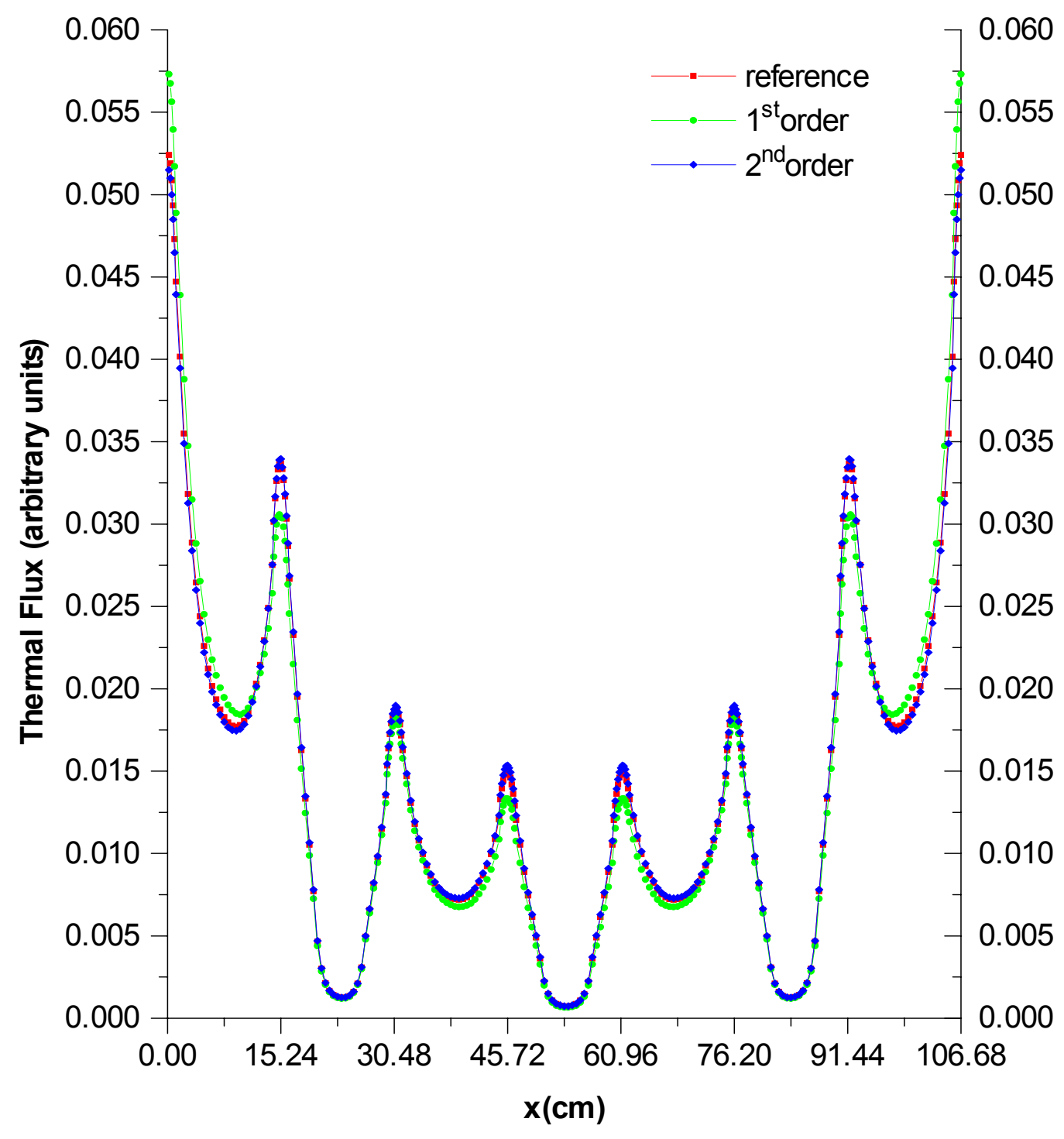

Figure 4-14. High-order reconstructed flux in group 2 for core 2 


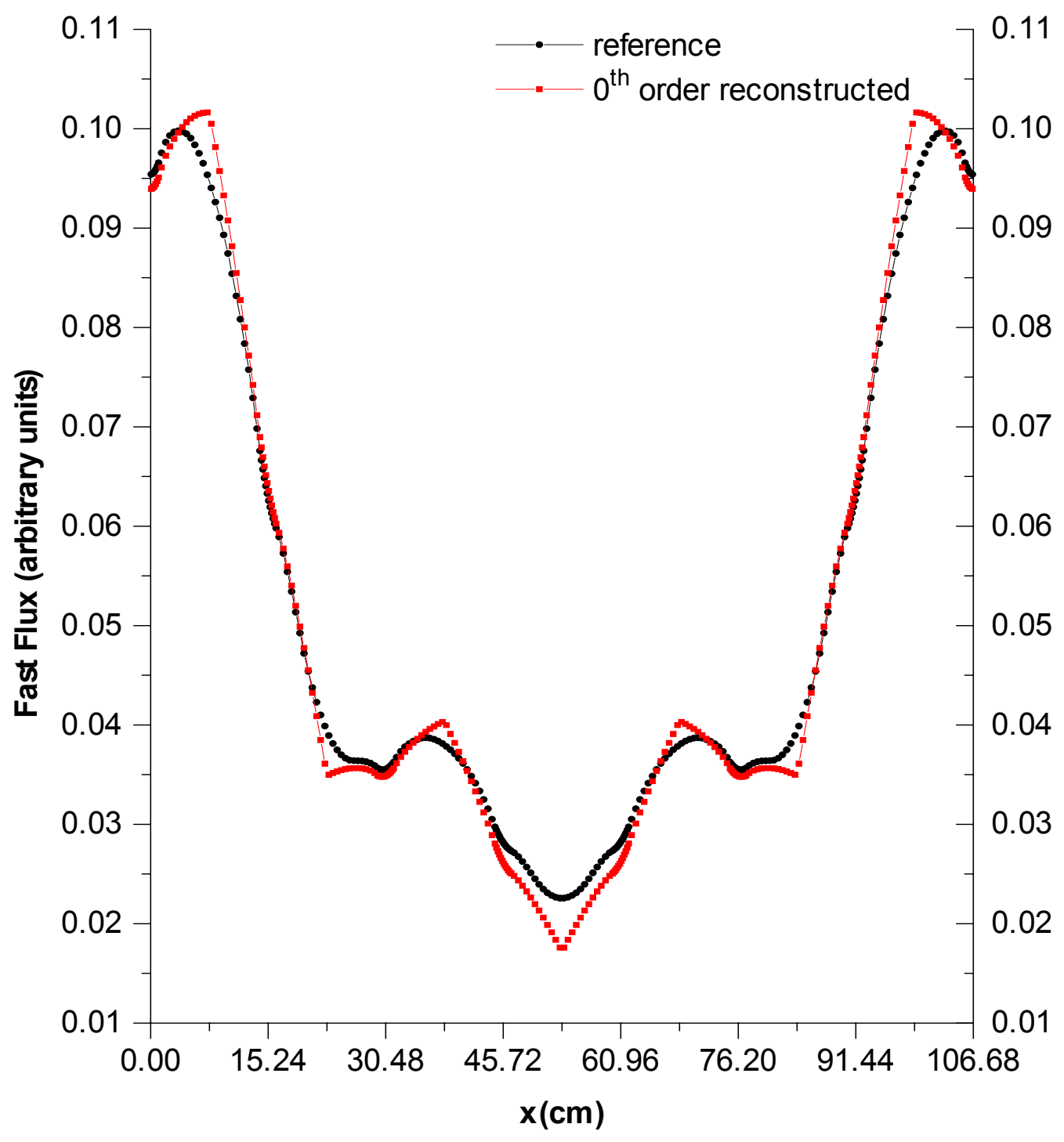

Figure 4-15. Zeroth-order reconstructed flux in group 1 for core 2 


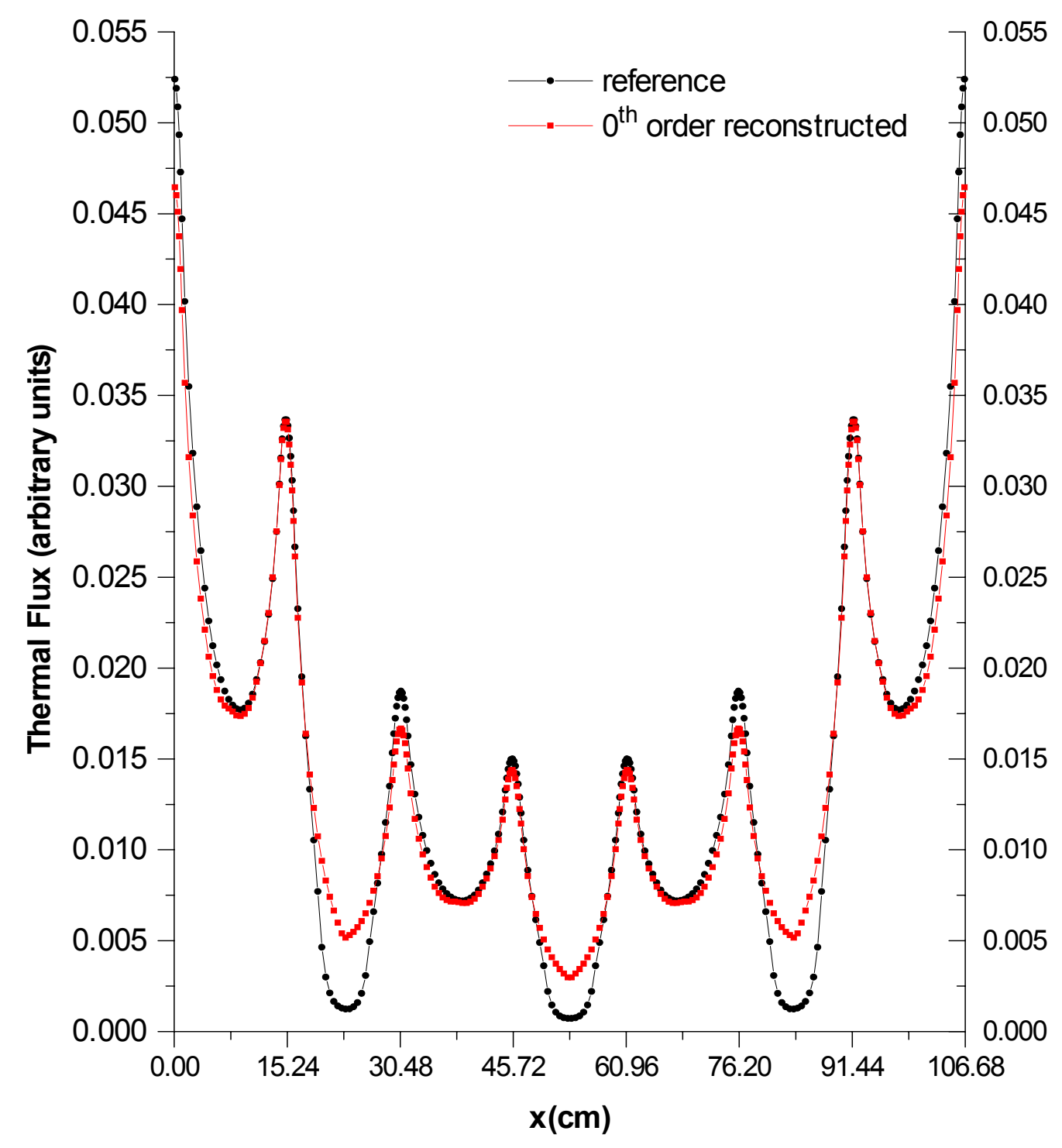

Figure 4-16. Zeroth-order reconstructed flux in group 2 for core 2 
As it was for the two configurations discussed in the previous section, the reference case here is a fine-mesh calculation of the full configuration with a zero current boundary condition. Six meshes are considered for each material region, giving a total of 60 meshes per assembly and 960 meshes per core. Because of the symmetry, only the distribution for the left half of the configuration is shown.

The multiplication constant $\left(\mathrm{k}_{\mathrm{eff}}\right)$ for each core (see Figure 3-5) at different orders of the correction for the nodal cross sections is given in Table 4-18. The distribution of the reconstructed flux, calculated as specified in section 2-3, is shown in Figures 4-17 to 423. Only the first order reconstructed flux is shown, the higher-order distributions being almost identical to the reference distribution for each core. It is interesting to note that, the $0^{\text {th }}$ order (standard GET) $\mathrm{k}_{\mathrm{eff}}$ is the same as the reference value for cores $\mathrm{A}$ and $\mathrm{C}$ (within $10^{-3}$ ) and is also very close in the case of core $\mathrm{B}$ (within $10^{-2}$ ). However, the flux distribution is not approximate well by the $0^{\text {th }}$ order results. The difference is mostly in the fast group, and it is more pronounced in the case of the more heterogeneous core $\mathrm{C}$. The node-integrated flux from the nodal calculation and the assembly-integrated reconstructed flux for each group are compared to the reference results in Tables 4-19 to 4-15. The difference of up to 5\% in the node-integrated flux at the zeroth order is reduced to less than $1 \%$ at the third order.

Table 4-18. $K_{\text {eff }}$ for cores $A, B$ and $C$

\begin{tabular}{|c|c|c|c|c|}
\hline Core & $\mathrm{K}_{\mathrm{ref}}{ }^{*}$ & $\begin{array}{l}\text { Order of } \\
\text { correction }\end{array}$ & $\mathrm{K}_{\text {calc }}$ & $\begin{array}{c}\mathrm{K}_{\text {calc }}-\mathrm{K}_{\text {ref }} \\
\left(\mathrm{mk}^{* *}\right)\end{array}$ \\
\hline \multirow{4}{*}{ A } & \multirow{4}{*}{1.0130} & 0 & 1.0134 & 0.4 \\
\hline & & 1 & 1.0129 & -0.1 \\
\hline & & 2 & 1.0129 & -0.1 \\
\hline & & 3 & 1.0128 & -0.2 \\
\hline \multirow{4}{*}{ B } & \multirow{4}{*}{1.0034} & 0 & 1.0134 & 10.0 \\
\hline & & 1 & 1.0032 & -0.2 \\
\hline & & 2 & 1.0031 & -0.1 \\
\hline & & 3 & 1.0032 & -0.2 \\
\hline \multirow{4}{*}{$\mathrm{C}$} & \multirow{4}{*}{0.9969} & 0 & 0.9979 & 1.0 \\
\hline & & 1 & 0.9964 & -0.5 \\
\hline & & 2 & 0.9963 & -0.6 \\
\hline & & 3 & 0.9963 & -0.6 \\
\hline
\end{tabular}




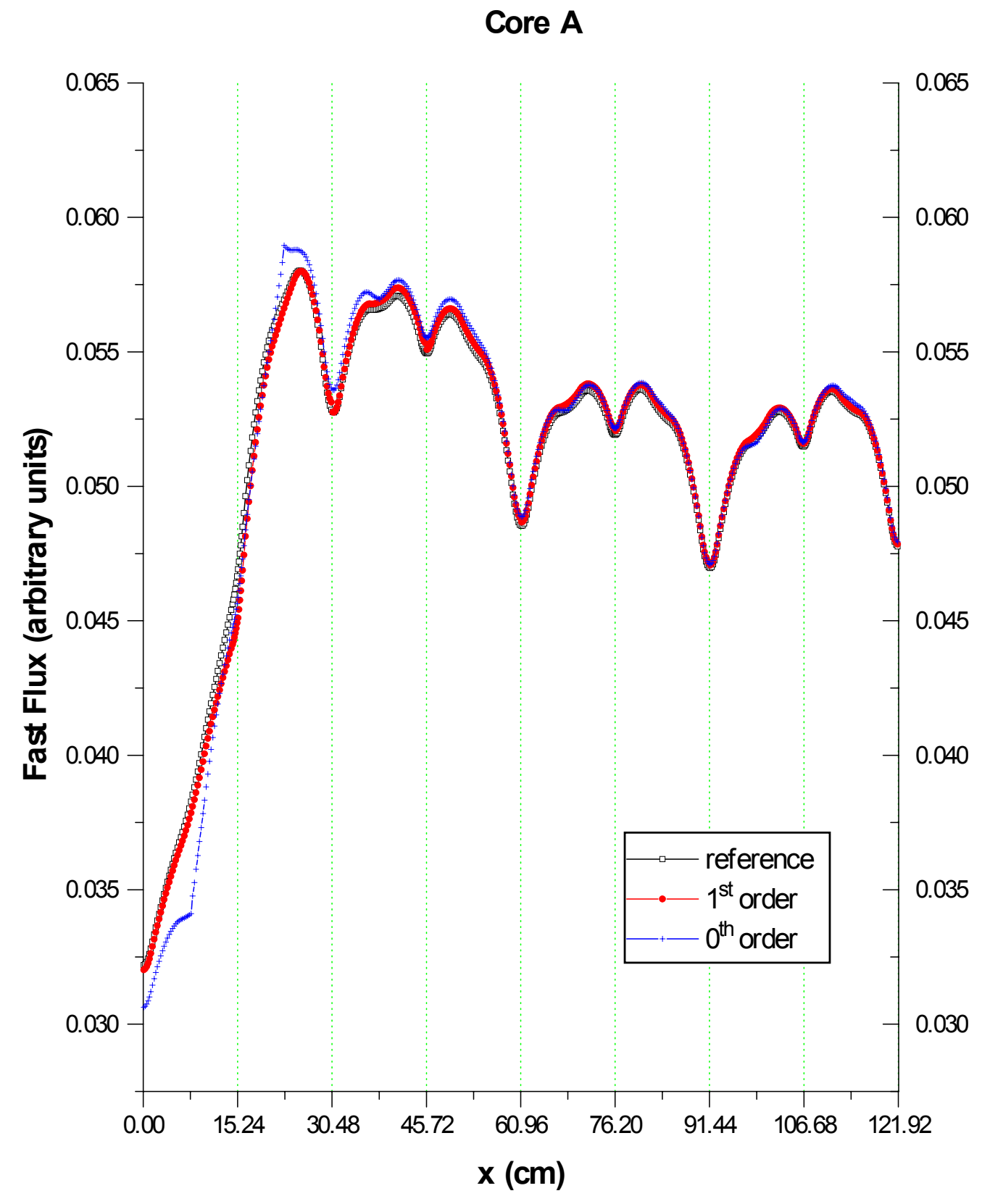

Figure 4-18. Reconstructed fast flux in core A 


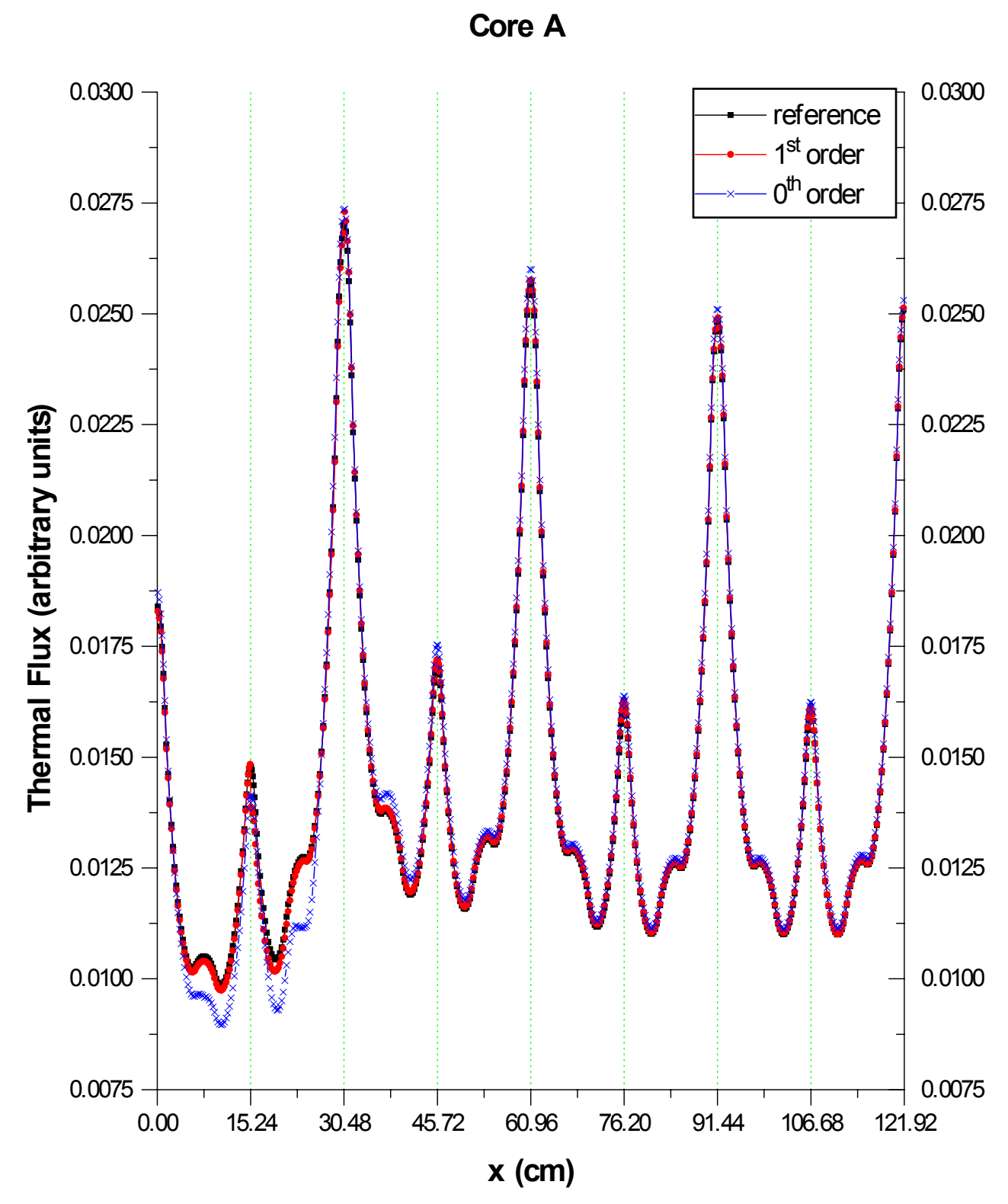

Figure 4-19. Reconstructed thermal flux in core A 


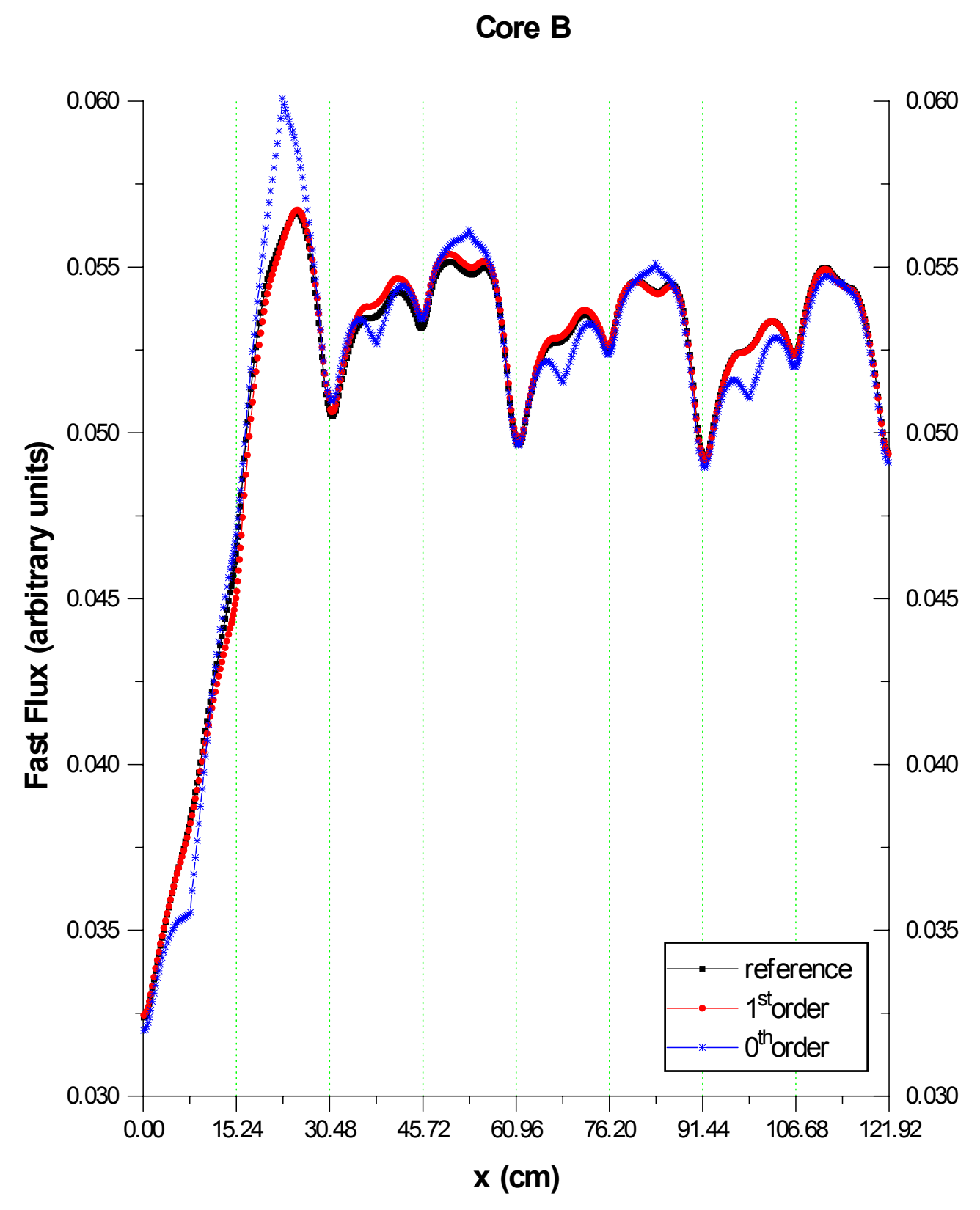

Figure 4-20. Reconstructed fast flux in core B 


\section{Core B}

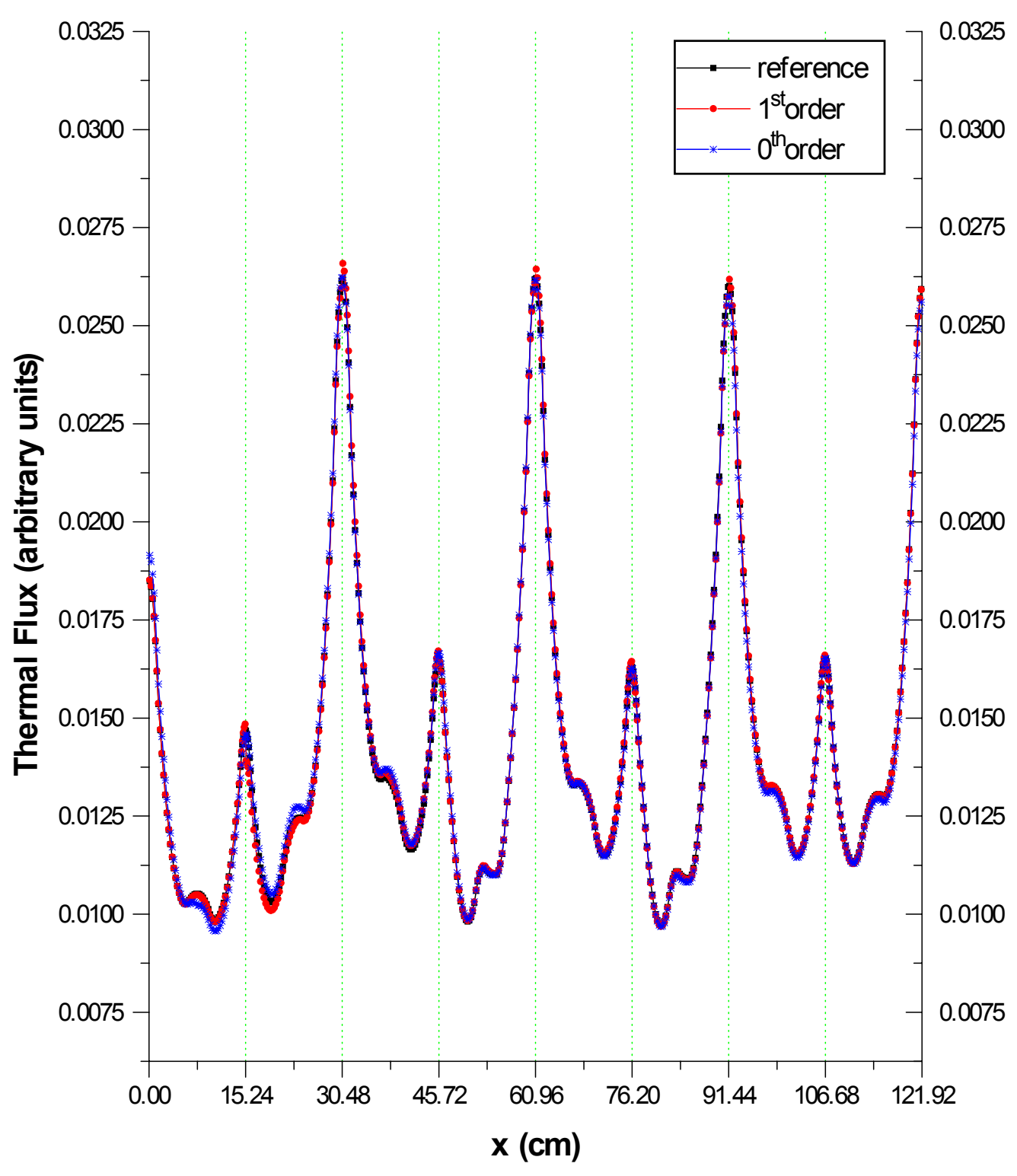

Figure 4-21. Reconstructed thermal flux in core B 


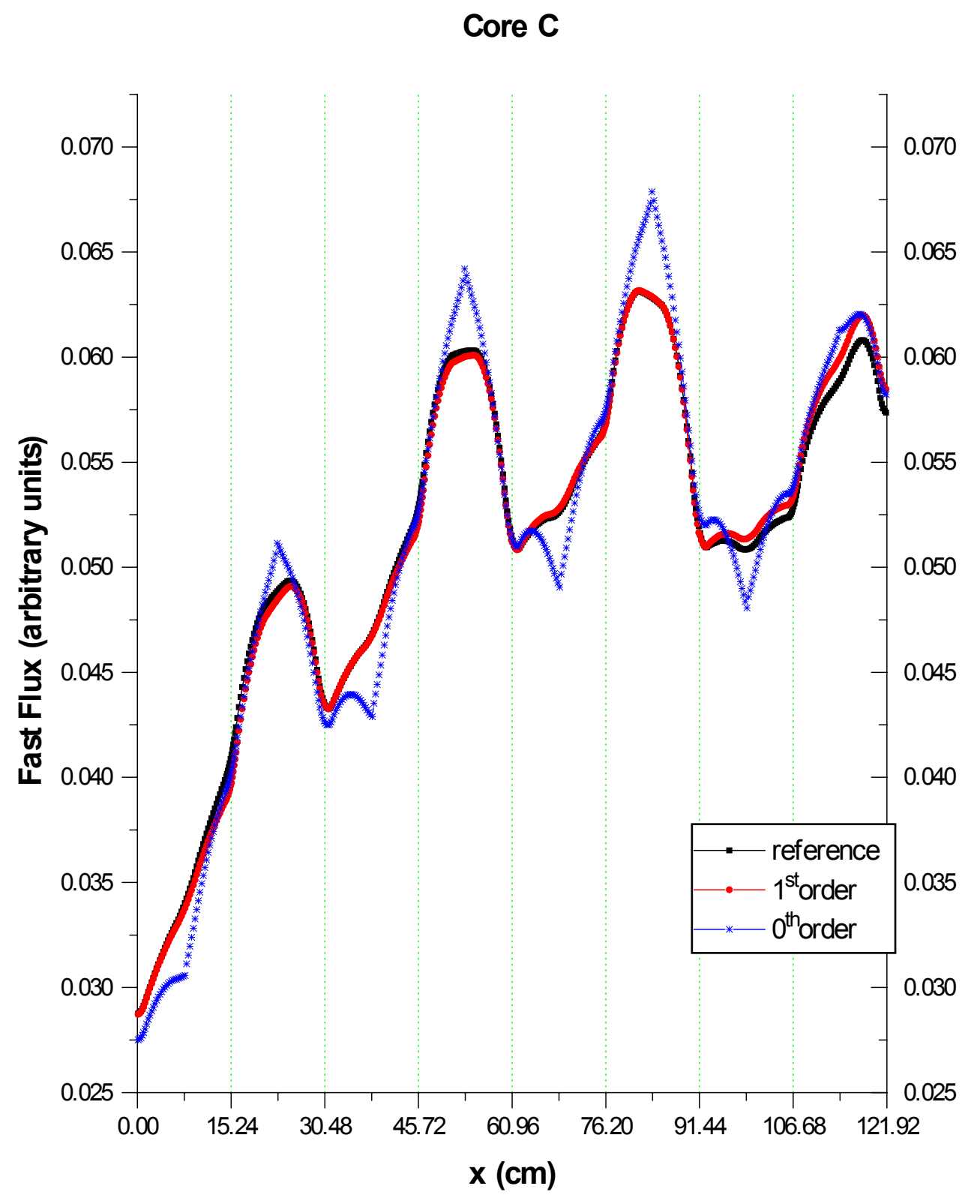

Figure 4-22. Reconstructed fast flux in core $C$ 


\section{Core C}

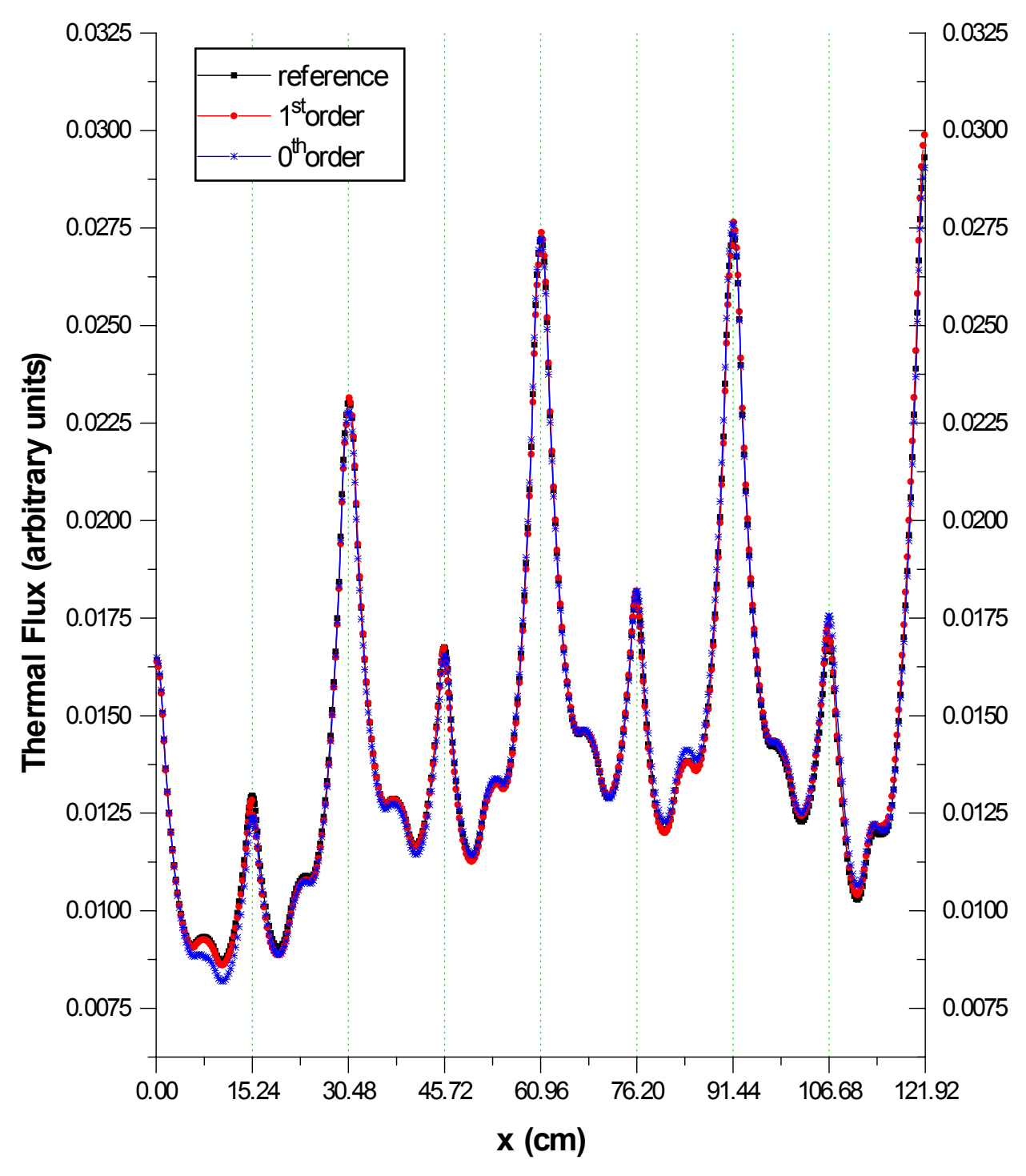

Figure 4-23. Reconstructed thermal flux in core $\mathrm{C}$ 
Table 4-19. Assembly fast flux in core A

\begin{tabular}{|c|c|c|c|c|c|c|}
\hline $\begin{array}{c}\text { Order of } \\
\text { Perturbation }\end{array}$ & $\begin{array}{l}\text { Assembly } \\
\text { Position }\end{array}$ & Reference & Nodal & Error $^{\mathrm{a}}$ & Reconstructed & Error \\
\hline 0 & $\begin{array}{l}1 \\
2 \\
3 \\
4 \\
5 \\
6 \\
7 \\
8\end{array}$ & $\begin{array}{l}0.5903 \\
0.8361 \\
0.8516 \\
0.8258 \\
0.7950 \\
0.7892 \\
0.7792 \\
0.7920\end{array}$ & $\begin{array}{l}0.5774 \\
0.8579 \\
0.8555 \\
0.8267 \\
0.7924 \\
0.7863 \\
0.7743 \\
0.7892\end{array}$ & $\begin{array}{c}-2.19 \\
2.61 \\
0.46 \\
0.11 \\
-0.34 \\
-0.36 \\
-0.63 \\
-0.35\end{array}$ & $\begin{array}{l}0.5586 \\
0.8393 \\
0.8617 \\
0.8335 \\
0.7983 \\
0.7926 \\
0.7803 \\
0.7954\end{array}$ & $\begin{array}{c}-5.37 \\
0.39 \\
1.19 \\
0.93 \\
0.42 \\
0.43 \\
0.14 \\
0.42\end{array}$ \\
\hline 1 & $\begin{array}{l}1 \\
2 \\
3 \\
4 \\
5 \\
6 \\
7 \\
8\end{array}$ & $\begin{array}{l}0.5903 \\
0.8361 \\
0.8516 \\
0.8258 \\
0.7950 \\
0.7892 \\
0.7792 \\
0.7920\end{array}$ & $\begin{array}{l}0.5818 \\
0.8283 \\
0.8552 \\
0.8293 \\
0.7984 \\
0.7916 \\
0.7812 \\
0.7934\end{array}$ & $\begin{array}{l}-1.44 \\
-0.93 \\
0.42 \\
0.41 \\
0.42 \\
0.30 \\
0.25 \\
0.17\end{array}$ & $\begin{array}{l}0.5814 \\
0.8290 \\
0.8550 \\
0.8293 \\
0.7983 \\
0.7916 \\
0.7811 \\
0.7934\end{array}$ & $\begin{array}{c}-1.50 \\
-0.85 \\
0.40 \\
0.42 \\
0.41 \\
0.31 \\
0.24 \\
0.18\end{array}$ \\
\hline 2 & $\begin{array}{l}1 \\
2 \\
3 \\
4 \\
5 \\
6 \\
7 \\
8\end{array}$ & $\begin{array}{l}0.5903 \\
0.8361 \\
0.8516 \\
0.8258 \\
0.7950 \\
0.7892 \\
0.7792 \\
0.7920\end{array}$ & $\begin{array}{l}0.5907 \\
0.8305 \\
0.8496 \\
0.8256 \\
0.7965 \\
0.7909 \\
0.7814 \\
0.7940\end{array}$ & $\begin{array}{c}0.07 \\
-0.67 \\
-0.23 \\
-0.03 \\
0.18 \\
0.22 \\
0.28 \\
0.24\end{array}$ & $\begin{array}{l}0.5902 \\
0.8311 \\
0.8494 \\
0.8257 \\
0.7965 \\
0.7910 \\
0.7813 \\
0.7940\end{array}$ & $\begin{array}{c}-0.02 \\
-0.60 \\
-0.26 \\
-0.02 \\
0.18 \\
0.22 \\
0.27 \\
0.25\end{array}$ \\
\hline 3 & $\begin{array}{l}1 \\
2 \\
3 \\
4 \\
5 \\
6 \\
7 \\
8\end{array}$ & $\begin{array}{l}0.5903 \\
0.8361 \\
0.8516 \\
0.8258 \\
0.7950 \\
0.7892 \\
0.7792 \\
0.7920\end{array}$ & $\begin{array}{l}0.5892 \\
0.8326 \\
0.8513 \\
0.8262 \\
0.7963 \\
0.7902 \\
0.7804 \\
0.7929\end{array}$ & $\begin{array}{l}-0.18 \\
-0.42 \\
-0.04 \\
0.05 \\
0.16 \\
0.13 \\
0.16 \\
0.11\end{array}$ & $\begin{array}{l}0.5888 \\
0.8331 \\
0.8511 \\
0.8263 \\
0.7963 \\
0.7903 \\
0.7804 \\
0.7929\end{array}$ & $\begin{array}{l}-0.26 \\
-0.36 \\
-0.06 \\
0.05 \\
0.15 \\
0.14 \\
0.15 \\
0.11\end{array}$ \\
\hline
\end{tabular}

${ }^{a}$ Defined as $100 *$ (calculated-reference)/reference 
Table 4-20. Assembly thermal flux in core A

\begin{tabular}{|c|c|c|c|c|c|c|}
\hline $\begin{array}{c}\text { Order of } \\
\text { Perturbation }\end{array}$ & $\begin{array}{c}\text { Assembly } \\
\text { Position }\end{array}$ & Reference & Nodal & Error $^{a}$ & Reconstructed & Error \\
\hline 0 & $\begin{array}{l}1 \\
2 \\
3 \\
4 \\
5 \\
6 \\
7 \\
8\end{array}$ & $\begin{array}{l}0.1809 \\
0.2186 \\
0.2370 \\
0.2274 \\
0.2227 \\
0.2177 \\
0.2178 \\
0.2186\end{array}$ & $\begin{array}{l}0.1809 \\
0.2201 \\
0.2385 \\
0.2282 \\
0.2216 \\
0.2169 \\
0.2166 \\
0.2176\end{array}$ & $\begin{array}{c}-0.04 \\
0.68 \\
0.61 \\
0.34 \\
-0.47 \\
-0.36 \\
-0.56 \\
-0.46\end{array}$ & $\begin{array}{l}0.1719 \\
0.2087 \\
0.2419 \\
0.2313 \\
0.2253 \\
0.2202 \\
0.2200 \\
0.2210\end{array}$ & $\begin{array}{l}-5.00 \\
-4.52 \\
2.09 \\
1.71 \\
1.20 \\
1.13 \\
0.98 \\
1.09\end{array}$ \\
\hline 1 & $\begin{array}{l}1 \\
2 \\
3 \\
4 \\
5 \\
6 \\
7 \\
8\end{array}$ & $\begin{array}{l}0.1809 \\
0.2186 \\
0.2370 \\
0.2274 \\
0.2227 \\
0.2177 \\
0.2178 \\
0.2186\end{array}$ & $\begin{array}{l}0.1791 \\
0.2159 \\
0.2381 \\
0.2284 \\
0.2236 \\
0.2183 \\
0.2184 \\
0.2189\end{array}$ & $\begin{array}{c}-0.99 \\
-1.22 \\
0.48 \\
0.44 \\
0.43 \\
0.28 \\
0.29 \\
0.16\end{array}$ & $\begin{array}{l}0.1795 \\
0.2152 \\
0.2383 \\
0.2284 \\
0.2237 \\
0.2183 \\
0.2185 \\
0.2189\end{array}$ & $\begin{array}{c}-0.77 \\
-1.53 \\
0.56 \\
0.42 \\
0.45 \\
0.25 \\
0.32 \\
0.14\end{array}$ \\
\hline 2 & $\begin{array}{l}1 \\
2 \\
3 \\
4 \\
5 \\
6 \\
7 \\
8\end{array}$ & $\begin{array}{l}0.1809 \\
0.2186 \\
0.2370 \\
0.2274 \\
0.2227 \\
0.2177 \\
0.2178 \\
0.2186\end{array}$ & $\begin{array}{l}0.1817 \\
0.2163 \\
0.2366 \\
0.2274 \\
0.2231 \\
0.2181 \\
0.2185 \\
0.2191\end{array}$ & $\begin{array}{c}0.45 \\
-1.04 \\
-0.17 \\
0.01 \\
0.19 \\
0.19 \\
0.31 \\
0.23\end{array}$ & $\begin{array}{l}0.1822 \\
0.2157 \\
0.2368 \\
0.2274 \\
0.2231 \\
0.2181 \\
0.2185 \\
0.2191\end{array}$ & $\begin{array}{c}0.71 \\
-1.30 \\
-0.09 \\
-0.01 \\
0.21 \\
0.17 \\
0.34 \\
0.22\end{array}$ \\
\hline 3 & $\begin{array}{l}1 \\
2 \\
3 \\
4 \\
5 \\
6 \\
7 \\
8\end{array}$ & $\begin{array}{l}0.1809 \\
0.2186 \\
0.2370 \\
0.2274 \\
0.2227 \\
0.2177 \\
0.2178 \\
0.2186\end{array}$ & $\begin{array}{l}0.1813 \\
0.2168 \\
0.2371 \\
0.2276 \\
0.2231 \\
0.2180 \\
0.2182 \\
0.2188\end{array}$ & $\begin{array}{r}0.21 \\
-0.82 \\
0.04 \\
0.08 \\
0.18 \\
0.11 \\
0.19 \\
0.10\end{array}$ & $\begin{array}{l}0.1818 \\
0.2162 \\
0.2373 \\
0.2275 \\
0.2231 \\
0.2179 \\
0.2183 \\
0.2188\end{array}$ & $\begin{array}{r}0.47 \\
-1.08 \\
0.12 \\
0.06 \\
0.20 \\
0.08 \\
0.22 \\
0.08\end{array}$ \\
\hline
\end{tabular}

${ }^{a}$ Defined as $100^{*}$ (calculated-reference)/reference 
Table 4-21. Assembly fast flux in core B

\begin{tabular}{|c|c|c|c|c|c|c|}
\hline $\begin{array}{c}\text { Order of } \\
\text { Perturbation }\end{array}$ & $\begin{array}{c}\text { Assembly } \\
\text { Position }\end{array}$ & Reference & Nodal & Error $^{\mathrm{a}}$ & Reconstructed & Erro1 \\
\hline 0 & $\begin{array}{l}1 \\
2 \\
3 \\
4 \\
5 \\
6 \\
7 \\
8\end{array}$ & $\begin{array}{l}0.5909 \\
0.8189 \\
0.8099 \\
0.8255 \\
0.7987 \\
0.8173 \\
0.7947 \\
0.8151\end{array}$ & $\begin{array}{l}0.5791 \\
0.8414 \\
0.8118 \\
0.8317 \\
0.7934 \\
0.8172 \\
0.7855 \\
0.8114\end{array}$ & $\begin{array}{c}-2.01 \\
2.75 \\
0.24 \\
0.75 \\
-0.67 \\
-0.01 \\
-1.15 \\
-0.45\end{array}$ & $\begin{array}{l}0.5800 \\
0.8414 \\
0.8113 \\
0.8319 \\
0.7929 \\
0.8175 \\
0.7851 \\
0.8113\end{array}$ & $\begin{array}{c}-1.85 \\
2.75 \\
0.18 \\
0.78 \\
-0.72 \\
0.02 \\
-1.20 \\
-0.46\end{array}$ \\
\hline 1 & $\begin{array}{l}1 \\
2 \\
3 \\
4 \\
5 \\
6 \\
7 \\
8\end{array}$ & $\begin{array}{l}0.5909 \\
0.8189 \\
0.8099 \\
0.8255 \\
0.7987 \\
0.8173 \\
0.7947 \\
0.8151\end{array}$ & $\begin{array}{l}0.5870 \\
0.8143 \\
0.8153 \\
0.8283 \\
0.8007 \\
0.8165 \\
0.7944 \\
0.8144\end{array}$ & $\begin{array}{c}-0.67 \\
-0.57 \\
0.67 \\
0.34 \\
0.26 \\
-0.10 \\
-0.03 \\
-0.09\end{array}$ & $\begin{array}{l}0.5814 \\
0.8290 \\
0.8550 \\
0.8293 \\
0.7983 \\
0.7916 \\
0.7811 \\
0.7934\end{array}$ & $\begin{array}{c}-1.50 \\
-0.85 \\
0.40 \\
0.42 \\
0.41 \\
0.31 \\
0.24 \\
0.18\end{array}$ \\
\hline 2 & $\begin{array}{l}1 \\
2 \\
3 \\
4 \\
5 \\
6 \\
7 \\
8\end{array}$ & $\begin{array}{l}0.5909 \\
0.8189 \\
0.8099 \\
0.8255 \\
0.7987 \\
0.8173 \\
0.7947 \\
0.8151\end{array}$ & $\begin{array}{l}0.5949 \\
0.8178 \\
0.8110 \\
0.8252 \\
0.7988 \\
0.8154 \\
0.7940 \\
0.8136\end{array}$ & $\begin{array}{c}0.68 \\
-0.13 \\
0.14 \\
-0.04 \\
0.02 \\
-0.23 \\
-0.09 \\
-0.19\end{array}$ & $\begin{array}{l}0.5945 \\
0.8185 \\
0.8106 \\
0.8254 \\
0.7985 \\
0.8157 \\
0.7937 \\
0.8136\end{array}$ & $\begin{array}{c}0.60 \\
-0.06 \\
0.09 \\
-0.01 \\
-0.02 \\
-0.20 \\
-0.12 \\
-0.18\end{array}$ \\
\hline 3 & $\begin{array}{l}1 \\
2 \\
3 \\
4 \\
5 \\
6 \\
7 \\
8\end{array}$ & $\begin{array}{l}0.5909 \\
0.8189 \\
0.8099 \\
0.8255 \\
0.7987 \\
0.8173 \\
0.7947 \\
0.8151\end{array}$ & $\begin{array}{l}0.5934 \\
0.8193 \\
0.8124 \\
0.8258 \\
0.7988 \\
0.8150 \\
0.7933 \\
0.8127\end{array}$ & $\begin{array}{c}0.43 \\
0.05 \\
0.31 \\
0.03 \\
0.02 \\
-0.28 \\
-0.17 \\
-0.29\end{array}$ & $\begin{array}{l}0.5930 \\
0.8199 \\
0.8120 \\
0.8261 \\
0.7985 \\
0.8153 \\
0.7931 \\
0.8128\end{array}$ & $\begin{array}{l}0.35 \\
0.12 \\
0.26 \\
0.07 \\
-0.02 \\
-0.25 \\
-0.20 \\
-0.28\end{array}$ \\
\hline
\end{tabular}

${ }^{\mathrm{a}}$ Defined as $100 *$ (calculated-reference)/reference 
Table 4-22. Assembly thermal flux in core B

\begin{tabular}{|c|c|c|c|c|c|c|}
\hline $\begin{array}{c}\text { Order of } \\
\text { Perturbation }\end{array}$ & $\begin{array}{c}\text { Assembly } \\
\text { Position }\end{array}$ & Reference & Nodal & Error $^{\mathrm{a}}$ & Reconstructed & Error \\
\hline 0 & $\begin{array}{l}1 \\
2 \\
3 \\
4 \\
5 \\
6 \\
7 \\
8\end{array}$ & $\begin{array}{l}0.1811 \\
0.2138 \\
0.2311 \\
0.2112 \\
0.2290 \\
0.2092 \\
0.2284 \\
0.2254\end{array}$ & $\begin{array}{l}0.1812 \\
0.2159 \\
0.2327 \\
0.2124 \\
0.2279 \\
0.2087 \\
0.2260 \\
0.2238\end{array}$ & $\begin{array}{c}0.06 \\
0.97 \\
0.66 \\
0.61 \\
-0.49 \\
-0.23 \\
-1.03 \\
-0.72\end{array}$ & $\begin{array}{l}0.1807 \\
0.2167 \\
0.2327 \\
0.2119 \\
0.2282 \\
0.2082 \\
0.2263 \\
0.2238\end{array}$ & $\begin{array}{l}-0.24 \\
1.37 \\
0.67 \\
0.37 \\
-0.32 \\
-0.44 \\
-0.94 \\
-0.71\end{array}$ \\
\hline 1 & $\begin{array}{l}1 \\
2 \\
3 \\
4 \\
5 \\
6 \\
7 \\
8\end{array}$ & $\begin{array}{l}0.1811 \\
0.2138 \\
0.2311 \\
0.2112 \\
0.2290 \\
0.2092 \\
0.2284 \\
0.2254\end{array}$ & $\begin{array}{l}0.1806 \\
0.2119 \\
0.2330 \\
0.2115 \\
0.2299 \\
0.2085 \\
0.2287 \\
0.2251\end{array}$ & $\begin{array}{c}-0.24 \\
-0.91 \\
0.82 \\
0.15 \\
0.42 \\
-0.33 \\
0.14 \\
-0.12\end{array}$ & $\begin{array}{l}0.1810 \\
0.2112 \\
0.2334 \\
0.2112 \\
0.2302 \\
0.2082 \\
0.2289 \\
0.2250\end{array}$ & $\begin{array}{c}-0.03 \\
-1.23 \\
0.98 \\
0.02 \\
0.53 \\
-0.47 \\
0.24 \\
-0.16\end{array}$ \\
\hline 2 & $\begin{array}{l}1 \\
2 \\
3 \\
4 \\
5 \\
6 \\
7 \\
8\end{array}$ & $\begin{array}{l}0.1811 \\
0.2138 \\
0.2311 \\
0.2112 \\
0.2290 \\
0.2092 \\
0.2284 \\
0.2254\end{array}$ & $\begin{array}{l}0.1830 \\
0.2126 \\
0.2319 \\
0.2107 \\
0.2294 \\
0.2082 \\
0.2286 \\
0.2249\end{array}$ & $\begin{array}{c}1.04 \\
-0.56 \\
0.31 \\
-0.21 \\
0.19 \\
-0.44 \\
0.09 \\
-0.22\end{array}$ & $\begin{array}{l}0.1834 \\
0.2120 \\
0.2322 \\
0.2105 \\
0.2297 \\
0.2080 \\
0.2288 \\
0.2248\end{array}$ & $\begin{array}{c}1.29 \\
-0.84 \\
0.47 \\
-0.33 \\
0.32 \\
-0.57 \\
0.20 \\
-0.26\end{array}$ \\
\hline 3 & $\begin{array}{l}1 \\
2 \\
3 \\
4 \\
5 \\
6 \\
7 \\
8\end{array}$ & $\begin{array}{l}0.1811 \\
0.2138 \\
0.2311 \\
0.2112 \\
0.2290 \\
0.2092 \\
0.2284 \\
0.2254\end{array}$ & $\begin{array}{l}0.1825 \\
0.2130 \\
0.2323 \\
0.2109 \\
0.2294 \\
0.2081 \\
0.2284 \\
0.2247\end{array}$ & $\begin{array}{c}0.79 \\
-0.39 \\
0.49 \\
-0.14 \\
0.20 \\
-0.50 \\
0.01 \\
-0.31\end{array}$ & $\begin{array}{l}0.1830 \\
0.2123 \\
0.2326 \\
0.2106 \\
0.2297 \\
0.2078 \\
0.2287 \\
0.2246\end{array}$ & $\begin{array}{c}1.04 \\
-0.67 \\
0.65 \\
-0.26 \\
0.32 \\
-0.63 \\
0.11 \\
-0.35\end{array}$ \\
\hline
\end{tabular}

${ }^{\mathrm{a} D e f i n e d ~ a s ~} 100 *$ (calculated-reference)/reference 
Table 4-23. Assembly fast flux in core $C$

\begin{tabular}{|c|c|c|c|c|c|c|}
\hline $\begin{array}{c}\text { Order of } \\
\text { Perturbation }\end{array}$ & $\begin{array}{c}\text { Assembly } \\
\text { Position }\end{array}$ & Reference & Nodal & Error $^{\mathrm{a}}$ & Reconstructed & Error \\
\hline 0 & $\begin{array}{l}1 \\
2 \\
3 \\
4 \\
5 \\
6 \\
7 \\
8\end{array}$ & $\begin{array}{l}0.5235 \\
0.7150 \\
0.7219 \\
0.8821 \\
0.8119 \\
0.9195 \\
0.7841 \\
0.8862\end{array}$ & $\begin{array}{l}0.5181 \\
0.7068 \\
0.7196 \\
0.8763 \\
0.8135 \\
0.9182 \\
0.7910 \\
0.9010\end{array}$ & $\begin{array}{c}-5.01 \\
-0.22 \\
-2.97 \\
1.45 \\
-1.24 \\
2.85 \\
0.22 \\
2.30\end{array}$ & $\begin{array}{l}0.4980 \\
0.7135 \\
0.7005 \\
0.8953 \\
0.8011 \\
0.9464 \\
0.7846 \\
0.9066\end{array}$ & $\begin{array}{c}-4.88 \\
-0.22 \\
-2.97 \\
1.50 \\
-1.32 \\
2.94 \\
0.06 \\
2.30\end{array}$ \\
\hline 1 & $\begin{array}{l}1 \\
2 \\
3 \\
4 \\
5 \\
6 \\
7 \\
8\end{array}$ & $\begin{array}{l}0.5235 \\
0.7150 \\
0.7219 \\
0.8821 \\
0.8119 \\
0.9195 \\
0.7841 \\
0.8862\end{array}$ & $\begin{array}{l}0.5181 \\
0.7068 \\
0.7196 \\
0.8763 \\
0.8135 \\
0.9182 \\
0.7910 \\
0.9010\end{array}$ & $\begin{array}{c}-1.04 \\
-1.14 \\
-0.32 \\
-0.66 \\
0.20 \\
-0.14 \\
0.87 \\
1.66\end{array}$ & $\begin{array}{l}0.5179 \\
0.7073 \\
0.7193 \\
0.8766 \\
0.8131 \\
0.9186 \\
0.7906 \\
0.9011\end{array}$ & $\begin{array}{c}-1.08 \\
-1.09 \\
-0.36 \\
-0.62 \\
0.15 \\
-0.10 \\
0.82 \\
1.68\end{array}$ \\
\hline 2 & $\begin{array}{l}1 \\
2 \\
3 \\
4 \\
5 \\
6 \\
7 \\
8\end{array}$ & $\begin{array}{l}0.5235 \\
0.7150 \\
0.7219 \\
0.8821 \\
0.8119 \\
0.9195 \\
0.7841 \\
0.8862\end{array}$ & $\begin{array}{l}0.5235 \\
0.7099 \\
0.7198 \\
0.8764 \\
0.8120 \\
0.9182 \\
0.7905 \\
0.8936\end{array}$ & $\begin{array}{c}-0.01 \\
-0.72 \\
-0.30 \\
-0.64 \\
0.02 \\
-0.14 \\
0.82 \\
0.83\end{array}$ & $\begin{array}{l}0.5231 \\
0.7105 \\
0.7190 \\
0.8772 \\
0.8112 \\
0.9190 \\
0.7898 \\
0.8939\end{array}$ & $\begin{array}{l}-0.08 \\
-0.63 \\
-0.40 \\
-0.55 \\
-0.08 \\
-0.05 \\
0.72 \\
0.87\end{array}$ \\
\hline 3 & $\begin{array}{l}1 \\
2 \\
3 \\
4 \\
5 \\
6 \\
7 \\
8\end{array}$ & $\begin{array}{l}0.5235 \\
0.7150 \\
0.7219 \\
0.8821 \\
0.8119 \\
0.9195 \\
0.7841 \\
0.8862\end{array}$ & $\begin{array}{l}0.5216 \\
0.7101 \\
0.7203 \\
0.8778 \\
0.8129 \\
0.9188 \\
0.7899 \\
0.8926\end{array}$ & $\begin{array}{c}-0.36 \\
-0.70 \\
-0.23 \\
-0.49 \\
0.12 \\
-0.07 \\
0.74 \\
0.72\end{array}$ & $\begin{array}{l}0.5212 \\
0.7107 \\
0.7195 \\
0.8785 \\
0.8121 \\
0.9196 \\
0.7891 \\
0.8930\end{array}$ & $\begin{array}{c}-0.44 \\
-0.61 \\
-0.33 \\
-0.40 \\
0.02 \\
0.01 \\
0.64 \\
0.76\end{array}$ \\
\hline
\end{tabular}

${ }^{\mathrm{a}}$ Defined as $100 *($ calculated-reference)/reference 
Table 4-24. Assembly thermal flux in core $C$

\begin{tabular}{|c|c|c|c|c|c|c|}
\hline $\begin{array}{c}\text { Order of } \\
\text { Perturbation }\end{array}$ & $\begin{array}{c}\text { Assembly } \\
\text { Position }\end{array}$ & Reference & Nodal & Error $^{\mathrm{a}}$ & Reconstructed & Error \\
\hline 0 & $\begin{array}{l}1 \\
2 \\
3 \\
4 \\
5 \\
6 \\
7 \\
8\end{array}$ & $\begin{array}{l}0.1604 \\
0.1873 \\
0.2200 \\
0.2296 \\
0.2491 \\
0.2382 \\
0.2426 \\
0.2285\end{array}$ & $\begin{array}{l}0.1555 \\
0.1835 \\
0.2172 \\
0.2303 \\
0.2486 \\
0.2434 \\
0.2442 \\
0.2313\end{array}$ & $\begin{array}{c}-3.09 \\
-2.05 \\
-1.25 \\
0.31 \\
-0.20 \\
2.19 \\
0.65 \\
1.21\end{array}$ & $\begin{array}{l}0.1550 \\
0.1846 \\
0.2164 \\
0.2306 \\
0.2486 \\
0.2427 \\
0.2449 \\
0.2312\end{array}$ & $\begin{array}{c}-3.36 \\
-1.45 \\
-1.62 \\
0.42 \\
-0.21 \\
1.89 \\
0.92 \\
1.19\end{array}$ \\
\hline 1 & $\begin{array}{l}1 \\
2 \\
3 \\
4 \\
5 \\
6 \\
7 \\
8\end{array}$ & $\begin{array}{l}0.1604 \\
0.1873 \\
0.2200 \\
0.2296 \\
0.2491 \\
0.2382 \\
0.2426 \\
0.2285\end{array}$ & $\begin{array}{l}0.1591 \\
0.1850 \\
0.2195 \\
0.2278 \\
0.2498 \\
0.2374 \\
0.2449 \\
0.2322\end{array}$ & $\begin{array}{c}-0.82 \\
-1.26 \\
-0.20 \\
-0.78 \\
0.26 \\
-0.34 \\
0.92 \\
1.62\end{array}$ & $\begin{array}{l}0.1593 \\
0.1846 \\
0.2198 \\
0.2274 \\
0.2501 \\
0.2370 \\
0.2452 \\
0.2321\end{array}$ & $\begin{array}{c}-0.70 \\
-1.48 \\
-0.07 \\
-0.94 \\
0.41 \\
-0.51 \\
1.07 \\
1.56\end{array}$ \\
\hline 2 & $\begin{array}{l}1 \\
2 \\
3 \\
4 \\
5 \\
6 \\
7 \\
8\end{array}$ & $\begin{array}{l}0.1604 \\
0.1873 \\
0.2200 \\
0.2296 \\
0.2491 \\
0.2382 \\
0.2426 \\
0.2285\end{array}$ & $\begin{array}{l}0.1609 \\
0.1852 \\
0.2201 \\
0.2273 \\
0.2501 \\
0.2369 \\
0.2456 \\
0.2301\end{array}$ & $\begin{array}{c}0.31 \\
-1.16 \\
0.07 \\
-1.02 \\
0.38 \\
-0.53 \\
1.22 \\
0.68\end{array}$ & $\begin{array}{l}0.1613 \\
0.1845 \\
0.2209 \\
0.2265 \\
0.2509 \\
0.2361 \\
0.2464 \\
0.2297\end{array}$ & $\begin{array}{c}0.55 \\
-1.50 \\
0.40 \\
-1.35 \\
0.70 \\
-0.86 \\
1.54 \\
0.53\end{array}$ \\
\hline 3 & $\begin{array}{l}1 \\
2 \\
3 \\
4 \\
5 \\
6 \\
7 \\
8\end{array}$ & $\begin{array}{l}0.1604 \\
0.1873 \\
0.2200 \\
0.2296 \\
0.2491 \\
0.2382 \\
0.2426 \\
0.2285\end{array}$ & $\begin{array}{l}0.1603 \\
0.1852 \\
0.2203 \\
0.2276 \\
0.2504 \\
0.2370 \\
0.2454 \\
0.2298\end{array}$ & $\begin{array}{c}-0.05 \\
-1.15 \\
0.15 \\
-0.88 \\
0.49 \\
-0.47 \\
1.16 \\
0.58\end{array}$ & $\begin{array}{l}0.1607 \\
0.1846 \\
0.2210 \\
0.2269 \\
0.2512 \\
0.2363 \\
0.2462 \\
0.2295\end{array}$ & $\begin{array}{r}0.19 \\
-1.48 \\
0.47 \\
-1.20 \\
0.81 \\
-0.80 \\
1.47 \\
0.43\end{array}$ \\
\hline
\end{tabular}

${ }^{a}$ Defined as $100^{*}$ (calculated-reference)/reference 


\section{SUMMARY AND CONCLUSION}

The main objective of this project was to develop a new high-order cross section homogenization method based on the boundary condition perturbation theory to improve the accuracy of nodal diffusion methods within the context of the GET. The new homogenization method corrects the homogenized parameters and discontinuity factors for the effect of the core environment (node-to-node leakage), to an arbitrary order of accuracy, by expanding them in terms of the node surface current-to-flux ratios. The method utilizes two adjoint functions to determine the expansion coefficients. Since these adjoint functions are solutions to the infinite medium problem (zero current-to-flux ratio), the expansion coefficients can be precomputed and included with the standard homogenization parameters for use by a nodal code. As a result, the nodal method has the capability of achieving an arbitrarily accurate solution by efficiently updating (correcting) the homogenized parameters, including the discontinuity factor, as it computes the node interface current-to-flux ratio. The level of accuracy for the highorder corrected reactor flux solution is close to that of the fine-mesh calculation, which would be computationally expensive and impractical to determine directly at the core level.

The numerical implementation of the homogenization method required the development of a fine-mesh lattice code capable of providing, along with the standard homogenized parameters, the two adjoint functions (the adjoint flux and an adjoint Green's function) as additional homogenization parameters. When going from one-group to multigroup, the forms of the equations to be solved and of the expressions to be evaluated become more complex, due to energy coupling between groups. The method was first tested and implemented for simple problems (one-group, 1-D geometry). The work was then extended to more complex (two-group 1-D and then 2-D geometry) problems. The main difficulty requiring a substantial effort was the numerical implementation of the solution method for precomputing the Green's function. A fine-mesh lattice code with the capability mentioned above was developed for each of the three sets of problems: onespeed 1-D, two-group 1-D and two-group 2-D.

In this project, it was shown that the perturbation expansion series for the homogenized cross sections and discontinuity factors converge in a multigroup case. This is new in that it has not been shown before in the literature. The benchmark configurations consisted of two types of BWR assemblies in slab geometry for the one-dimensional case and different types of assemblies in the HAFAS core for the two-dimensional case. The benchmark configurations were analyzed for various magnitudes of the perturbation in the boundary condition. It was shown that the perturbation method achieves an excellent accuracy: the reference homogenized cross sections and discontinuity factors are almost exactly reproduced.

The new homogenization method was numerically implemented at the nodal level, in the context of the GET, for one-speed 1-D, as well as for two-group 1-D configurations. For each of these two types of configurations, a finite-difference coarse-mesh code with a bilinear intra-nodal flux shape was developed. As compared to a standard nodal code for 
solving the nodal diffusion equations, which has two levels of calculation (source iteration and flux iteration), this code has an additional level (iteration) in which the the homogenized parameters are corrected. Nodal equations were developed for implementing the homogenization method at the nodal level for two-group 2-D problems, and their numerical implementation is in progress. The code for solving the nodal equations in this case is based on a transverse integrated method with a nodal expansion used for solving the transverse-integrated equations. The associated system of equations is solved by employing a non-linear iterative strategy. For the 2-D case some difficulty might arise in determining a surface-dependent boundary condition (current-to-flux ratio) from node-averaged quantities. Note that the Green's function is not constant at the node interface. As a first approximation, the expansion parameter in the 2-D case would be taken as an average over the node surface, which is consistent with the GET assumption.

The testing of the new homogenization method at the nodal level (for one- and two-group one-dimensional problems) was performed on five benchmark configurations typical of a BWR, from mildly to highly heterogeneous. Three of these five benchmarks, in which each assembly is of the GE-9 bundle design, were newly developed because of the need for more realistic benchmark configurations. It is anticipated that the technical community in reactor physics and math and computations will benefit from the new benchmarks developed in this study. It was shown that the homogenization method provides excellent results. For all of the analyzed configurations, the node-integrated flux is within $1.2 \%$ of the assembly reference (fine-mesh) flux in all nodes for each group. There is a significant improvement from the zeroth order case (standard GET), in which the node-averaged flux has a large error (e.g., up to $8 \%$ in group 1 and up to $14 \%$ in group 2 for some of the analyzed configurations). It was also shown that the reconstructed fine-mesh flux (or equivalently the power distribution) in the core approximates the reference value very well. The reference flux distribution is almost reproduced by the third order correction. 


\section{References}

1. Smith, K. S., "Spatial Homogenization Methods for Light Water Reactor Analysis", Ph.D. Thesis, M. I. T. (1980)

2. Rahnema, F., and Nichita, E.M., "Leakage Corrected Spatial (Assembly) Homogenization Technique", Annals of Nuclear Energy, 24, No.6, 477 (1997)

3. McKinley, M.S., Rahnema, F., " Higher-Order Boundary Condition Perturbation Theory for the Diffusion Approximation ", Nuclear Science and Engineering, 135, $15(2000)$

4. Golub, H.G., Van Loan, C.F., " Matrix Computations ", Third Edition, John Hopkins University Press (1996)

5. IMSL Fortran 90 MP Library v3.0, Lahey Computer Systems (1999)

6. Smith, K. S., "Assembly Homogenization Techniques for Light Water Reactor Analysis", Progress in Nuclear Energy, 17, 303 (1986)

7. Rahnema, F., McKinley, M.S., "High-Order Cross Section Homogenization Method ", Annals of Nuclear Energy, 29, 7, 875 (2002)

8. Lawrence, R.D., "Progress in Nodal Methods for the Solution of the Neutron Diffusion and Transport Equations", Progress in Nuclear Energy, 17, 271 (1986)

9. Sutton, T.M. and Aviles, B.N., "Diffusion Theory Meyhods for Spatial Kinetics Calculations", Progress in Nuclear Energy, 30, 119 (1996)

10. Smith, K.S., "Nodal Method Storage Reduction by Nonlinear Iteration", ANS Transactions, 44, 265 (1983) 


\section{Appendix A}

\section{Discretization of the equations for Green's function}

Let's consider Eqs. (2-21) for the four components of the Green's function $\Psi_{g h}\left(\vec{x}, \vec{x}_{0}\right)$. The discretization in slab geometry of the first of these equations is shown here, the procedure is similar for the other three.

$$
\begin{aligned}
& \left\lfloor-\nabla D_{1}(\vec{x}) \nabla+\sigma_{r 1}(\vec{x})-\lambda_{0} v \sigma_{f 1}(\vec{x}) \chi_{1}(\vec{x})\right] \Psi_{11}\left(\vec{x}, \vec{x}_{0}\right)- \\
& {\left[\sigma_{s 12}(\vec{x})+\lambda_{0} v \sigma_{f 1}(\vec{x}) \chi_{2}(\vec{x})\right] \Psi_{21}\left(\vec{x}, \vec{x}_{0}\right)=\delta\left(\vec{x}-\vec{x}_{0}\right)-\bar{\varphi}_{0,1}\left(\vec{x}_{0}\right)}
\end{aligned}
$$

Let the domain (in the $\mathrm{x}$ direction) where the equation should be solved be divided into $\mathrm{N}$ meshes, such that each mesh has constant material properties over the mesh. Equation (A-1) is integrated over a mesh $\mathrm{i}$ (see figure below), from $\mathrm{x}_{\mathrm{i}-1 / 2}$ to $\mathrm{x}_{\mathrm{i}+1 / 2}$. The functions $\Psi_{11}\left(\vec{x}, \vec{x}_{0}\right)$ and $\Psi_{21}\left(\vec{x}, \vec{x}_{0}\right)$ are considered constant over the mesh:

$$
\begin{aligned}
& \Psi_{11}\left(\vec{x}, \vec{x}_{0}\right) \equiv \Psi_{11}(i, j) \\
& \Psi_{21}\left(\vec{x}, \vec{x}_{0}\right) \equiv \Psi_{21}(i, j)
\end{aligned}
$$

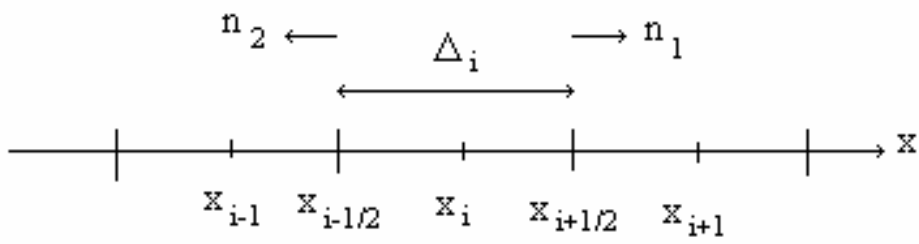

$$
\text { i-1 i } \quad \text { i } 1
$$

Figure A-1. Space Discretization

Let's consider the integration of the "leakage" term first:

$$
L=-\int_{x_{i-1 / 2}}^{x_{i+1 / 2}} \nabla D_{1} \cdot \nabla \Psi_{11} d V=-\sum_{k=1}^{2} \int_{S_{k}} D_{1} \nabla \Psi \cdot{ }_{11} \vec{n}_{S} d S=-D_{i} \frac{\varphi_{i}^{+}-\varphi_{i}}{\Delta_{i} / 2}+D_{i} \frac{\varphi_{i}-\varphi_{i}^{-}}{\Delta_{i} / 2}
$$

with $\varphi_{i}^{+} \equiv \Psi_{11}\left(x_{i+1 / 2}\right), \quad \varphi_{i}^{-} \equiv \Psi_{11}\left(x_{i-1 / 2}\right), \quad \varphi_{i} \equiv \Psi_{11}\left(x_{i}\right), \quad$ and $x_{i}=x_{i-1 / 2}+\Delta_{i} / 2$. The function $\Psi_{11}\left(\vec{x}, \vec{x}_{0}\right)$ has been renamed and the $\mathrm{x}_{0}$ dependence has been dropped for convenience. The following boundary conditions are considered at the interface of mesh $i$ with the adjacent mesh $\mathrm{i}-1$ and $\mathrm{i}+1$, respectively: 


$$
\begin{array}{ll}
x=x_{i-1 / 2} & \varphi_{i-1}^{+}=\varphi_{i}^{-} \\
& -D_{1}^{i-1} \frac{\varphi_{i-1}^{+}-\varphi_{i-1}}{\Delta_{i-1} / 2}=-D_{1}^{i} \frac{\varphi_{i}-\varphi_{i}^{-}}{\Delta_{i} / 2} \\
x=x_{i+1 / 2} & \varphi_{i+1}^{-}=\varphi_{i}^{+} \\
& -D_{1}^{i} \frac{\varphi_{i}^{+}-\varphi_{i}}{\Delta_{i} / 2}=-D_{1}^{i+1} \frac{\varphi_{i+1}-\varphi_{i+1}^{-}}{\Delta_{i+1} / 2}
\end{array}
$$

By solving for $\varphi_{i}^{+}$and $\varphi_{i}^{-}$in (A-3) and (A-4) one gets:

$$
\begin{aligned}
& \varphi_{i}^{-}=\frac{d_{i-1} \varphi_{i-1}+d_{i} \varphi_{i}}{d_{i-1}+d_{i}} \\
& \varphi_{i}^{+}=\frac{d_{i} \varphi_{i}+d_{i+1} \varphi_{i+1}}{d_{i}+d_{i+1}}
\end{aligned}
$$

If expressions (A-6) for the surface fluxes are used in (A-3) it is obtained:

$$
L=-d_{i-1, i} \varphi_{i-1}+\left(d_{i-1, i}+d_{i, i+1}\right) \varphi_{i}-d_{i, i+1} \varphi_{i+1}
$$

where $d_{i, i+1} \equiv 2 d_{i} d_{i+1} /\left(d_{i}+d_{i+1}\right)$. The use of (A-7) when integrating (A-1) over the mesh i leads to:

$$
\begin{array}{r}
-d_{i-1, i} \Psi_{11}(i-1, j)+\left[d_{i-1, i}+d_{i, i+1}+\left(\sigma_{r 1}^{i}-\lambda_{0} v \sigma_{f 1}^{i} \chi_{1}^{i}\right) \Delta_{i}\right] \Psi_{11}(i, j)-d_{i, i+1} \Psi_{11}(i+1, j)= \\
\left(\sigma_{s 12}^{i}+\lambda_{0} v \sigma_{f 1}^{i} \chi_{2}^{i}\right) \Delta_{i} \Psi_{21}(i, j)+\delta_{i j}-\bar{\varphi}_{0,1}(j)
\end{array}
$$

The coupling coefficients $d_{i, i+1}$ and $d_{i-1, i}$ have a particular form for the boundary meshes, depending on the boundary condition. For example, if the boundary condition for the right boundary $(\mathrm{i}=\mathrm{N})$ is:

$$
a J\left(x_{i+1 / 2}\right)+b \varphi_{i}^{+}=0
$$

then

$$
\varphi_{i}^{+}=-\frac{a}{b} J\left(x_{i+1 / 2}\right)
$$

Using this expression for $\varphi_{i}^{+}$to calculate the current at the boundary as expressed in (A3 ), one gets: 


$$
\begin{aligned}
& J\left(x_{i+1 / 2}\right)=-D_{i} \frac{\varphi_{i}^{+}-\varphi_{i}}{\Delta_{i} / 2}=-2 d_{i}\left(\varphi_{i}^{+}-\varphi_{i}\right)=2 d_{i} \frac{a}{b} J\left(x_{i+1 / 2}\right)+2 d_{i} \varphi_{i} \\
& J\left(x_{i+1 / 2}\right)=\frac{2 d_{i}}{1-2 \frac{a}{b} d_{i}} \varphi_{i}
\end{aligned}
$$

The leakage term (A-3) becomes:

$$
\begin{aligned}
L_{r i g h t}=J\left(x_{i+1 / 2}\right)-J\left(x_{i-1 / 2}\right) & =\frac{2 d_{i}}{1-2 \frac{a}{b} d_{i}} \varphi_{i}+d_{i-1, i}\left(\varphi_{i}-\varphi_{i-1}\right)= \\
& -d_{i-1, i} \varphi_{i-1}+\left(\frac{2 d_{i}}{1-2 \frac{a}{b} d_{i}}+d_{i-1, i}\right) \varphi_{i}
\end{aligned}
$$

In this case then $(\mathrm{i}=\mathrm{N})$ we have in the leakage term $d_{i, i+1}=0$ and the coefficient of $\varphi_{i}$ in the leakage term is $\frac{2 d_{i}}{1-2 \frac{a}{b} d_{i}}+d_{i-1, i}$, versus $d_{i-1, i}+d_{i, i+1}$ for an inner mesh. 


\section{Appendix B}

\section{Nodal Equations}

The two-group diffusion equations to be discretized in slab geometry are shown below:

$$
\begin{array}{r}
\left\lfloor-\nabla D_{g}(x) \cdot \nabla+\sigma_{r g}(x)\right\rfloor \varphi_{g}(x)=\sigma_{g^{\prime} g}(x) \varphi_{g^{\prime}}(x)+\lambda \chi_{g}(x)\left[v \sigma_{f g}(x) \varphi_{g}(x)+v \sigma_{f g^{\prime}}(x) \varphi_{g^{\prime}}(x)\right\rfloor \\
g, g^{\prime}=1,2 \quad g \neq g^{\prime}
\end{array}
$$

where $\varphi$ is the scalar flux, $\lambda$ is the eigenvalue, $\mathrm{D}$ is the diffusion coefficient, $\sigma_{r}$ is the removal cross section, $\chi$ is the neutron spectrum, $\sigma_{g^{\prime} g}$ is the scattering cross section from group g' to group g, and $v \sigma_{f}$ is the product of the number of neutrons per fission and the fission cross section, with $g$ as a group index.

The spatial variable $\mathrm{x}$ is discretized according to Figure $\mathrm{B}-1$. Equation (B-1) is integrated over the mesh $i$ from $x_{i-1 / 2}$ to $x_{i+1 / 2}$, with $x_{i}$ the center point. $\varphi_{i}^{-}$and $f_{i}^{-}$are the flux and discontinuity factor on the left boundary of mesh $\mathrm{i}$, whereas $\varphi_{i}^{+}$and $f_{i}^{+}$have the same meaning, but correspond to the right boundary. The length of mesh i is $\Delta_{i}$, and $\varphi_{i}$ is the flux at the center point. The mesh is chosen such that the material properties are constant within the region.

By integrating (B-1) over mesh i one obtaines:

$$
\begin{aligned}
\int_{x_{i-1 / 2}}^{x_{i+1 / 2}}-\nabla D_{g, i} & \nabla \varphi_{g}(x) d x+\sigma_{r g, i} \int_{x_{i-1 / 2}}^{x_{i+1 / 2}} \varphi_{g}(x) d x+\sigma_{g^{\prime} g, i} \int_{x_{i-1 / 2}}^{x_{i+1 / 2}} \varphi_{g^{\prime}}(x) d x= \\
& \lambda \chi_{g, i}\left[v \sigma_{f g, i} \int_{x_{i-1 / 2}}^{x_{i+1 / 2}} \varphi_{g}(x) d x+v \sigma_{f g^{\prime}, i} \int_{x_{i-1 / 2}}^{x_{i+1 / 2}} \varphi_{g^{\prime}}(x) d x\right] \quad g, g^{\prime}=1,2 \quad g \neq g^{\prime}
\end{aligned}
$$

The leakage term in Eq. (B-2) can be written as:

$$
L=-\sum_{k=1}^{2} \int_{S_{k}} D_{g, i} \nabla \varphi_{g}(x) \cdot \vec{n}_{S} d S=J_{g}\left(x_{i+1 / 2}\right)-J_{g}\left(x_{i-1 / 2}\right)=-D_{i} \frac{\varphi_{i}^{+}-\varphi_{i}}{\Delta_{i} / 2}+D_{i} \frac{\varphi_{i}-\varphi_{i}^{-}}{\Delta_{i} / 2}
$$

where $\mathrm{J}$ stands for current. The boundary condition (current continuity and flux discontinuity) is expressed by (with the group index dropped for convenience): 


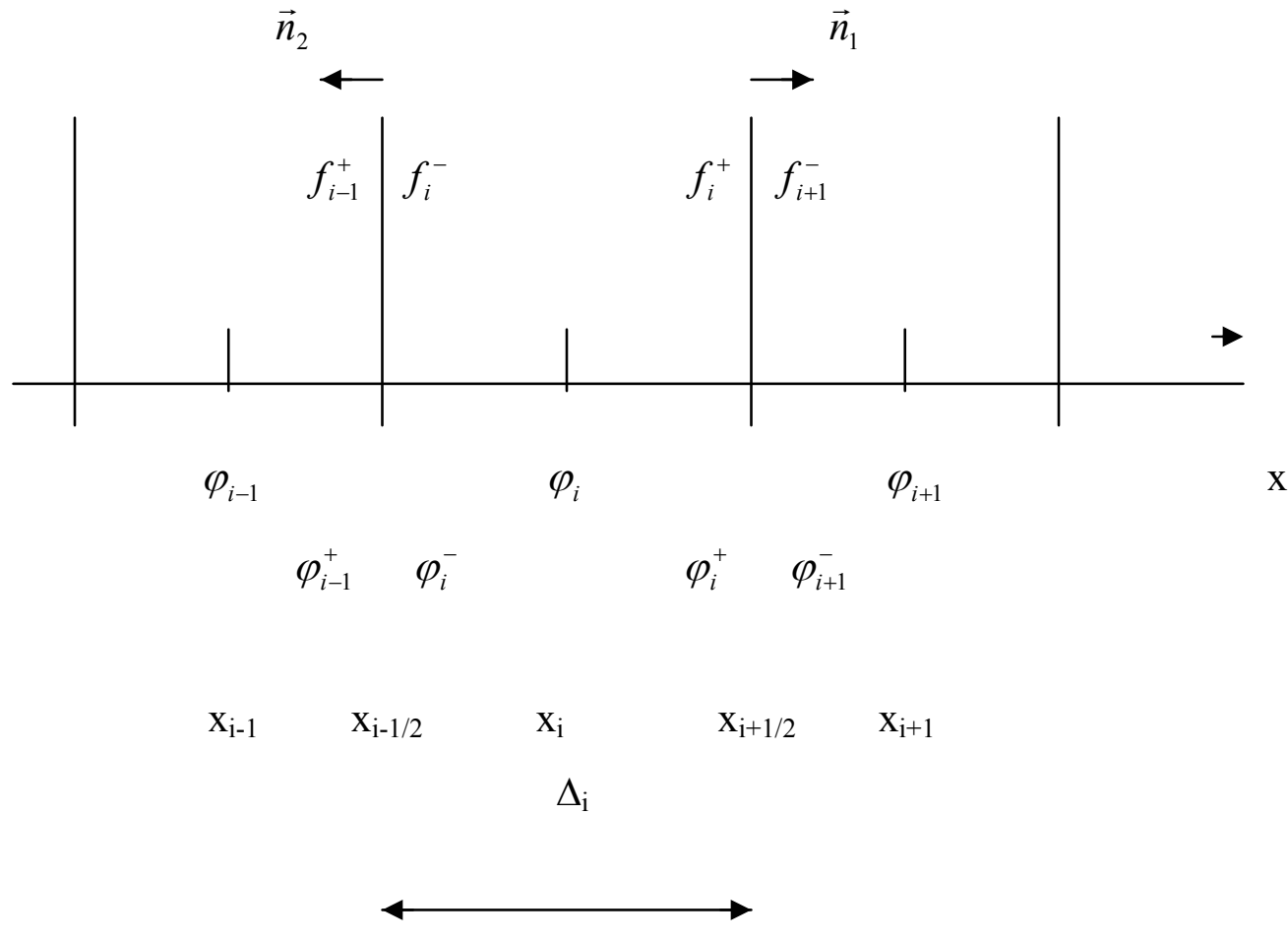

Figure B-1. Discretization of the Spatial Variable

$$
\begin{array}{ll}
x=x_{i+1 / 2} & f_{i}^{+} \varphi_{i}^{+}=f_{i+1}^{-} \varphi_{i+1}^{-} \\
& -D_{i} \frac{\varphi_{i}^{+}-\varphi_{i}}{\Delta_{i} / 2}=-D_{i+1} \frac{\varphi_{i+1}-\varphi_{i+1}^{-}}{\Delta_{i+1} / 2} \\
x=x_{i-1 / 2} & f_{i-1}^{+} \varphi_{i-1}^{+}=\varphi_{i}^{-} f_{i}^{-} \\
& -D_{i-1} \frac{\varphi_{i-1}^{+}-\varphi_{i-1}}{\Delta_{i-1} / 2}=-D_{i} \frac{\varphi_{i}-\varphi_{i}^{-}}{\Delta_{i} / 2}
\end{array}
$$

The surface fluxes corresponding to mesh i are determined from Eqs. (B-4) and (B-5) as:

$$
\begin{aligned}
& \varphi_{i}^{-}=\frac{d_{i-1} f_{i-1}^{+}}{d_{i-1} f_{i}^{-}+d_{i} f_{i-1}^{+}} \varphi_{i-1}+\frac{d_{i} f_{i-1}^{+}}{d_{i-1} f_{i}^{-}+d_{i} f_{i-1}^{+}} \varphi_{i} \\
& \varphi_{i}^{+}=\frac{d_{i+1} f_{i+1}^{-}}{d_{i} f_{i+1}^{-}+d_{i+1} f_{i}^{+}} \varphi_{i+1}+\frac{d_{i} f_{i+1}^{-}}{d_{i} f_{i+1}^{-}+d_{i+1} f_{i}^{+}} \varphi_{i}
\end{aligned}
$$


where $d_{i} \equiv\left(D_{i} / \Delta_{i}\right)$. By using Eqs. (B-6) and (B-7) in Eq. (B-3), the leakage term becomes:

$$
\begin{aligned}
L= & -\frac{2 d_{i} d_{i-1}}{d_{i}+d_{i-1}\left(f_{i}^{-} / f_{i-1}^{+}\right)} \varphi_{i-1}+\left[\frac{2 d_{i} d_{i-1}}{d_{i}+d_{i-1}\left(f_{i}^{-} / f_{i-1}^{+}\right)} \frac{f_{i}^{-}}{f_{i-1}^{+}}+\frac{2 d_{i} d_{i+1}}{d_{i}+d_{i+1}\left(f_{i}^{+} / f_{i+1}^{-}\right)} \frac{f_{i}^{+}}{f_{i+1}^{-}}\right] \varphi_{i} \\
& -\frac{2 d_{i} d_{i+1}}{d_{i}+d_{i+1}\left(f_{i}^{+} / f_{i+1}^{-}\right)} \varphi_{i+1}
\end{aligned}
$$

A bilinear shape is considered for the flux within the node:

$$
\varphi(x)= \begin{cases}a_{1} x+b_{1}, & x_{i-1 / 2} \leq x \leq x_{i} \\ a_{2} x+b_{2}, & x_{i} \leq x \leq x_{i+1 / 2}\end{cases}
$$

with $a_{1}, a_{2}, b_{1}$ and $b_{2}$ constants. The integral of the flux over mesh $\mathrm{i}$ in Eq. (B-2) can be written as:

$$
\begin{aligned}
\int_{x_{i-1 / 2}}^{x_{i+1 / 2}} \varphi(x) d x=\int_{x_{i-1 / 2}}^{x_{i}} \varphi(x) d x+\int_{x_{i}}^{x_{i+1 / 2}} \varphi(x) d x & =a_{1}\left(\Delta_{i} / 4\right)\left(x_{i-1 / 2}+x_{i}\right)+b_{1}\left(\Delta_{i} / 2\right)+ \\
& +a_{2}\left(\Delta_{i} / 4\right)\left(x_{i}+x_{i+1 / 2}\right)+b_{2}\left(\Delta_{i} / 2\right)
\end{aligned}
$$

The coefficients $a_{1}, a_{2}, b_{1}$ and $b_{2}$ are determined from:

$$
\varphi\left(x_{i-1 / 2}\right)=\varphi_{i}^{-}, \quad \varphi\left(x_{i}\right)=\varphi_{i}, \quad \varphi\left(x_{i+1 / 2}\right)=\varphi_{i}^{+}
$$

as:

$$
a_{1}=\frac{\varphi_{i}-\varphi_{i}^{-}}{\Delta_{i} / 2}, \quad a_{2}=\frac{\varphi_{i}^{+}-\varphi_{i}}{\Delta_{i} / 2}, \quad b_{1}=\varphi_{i}-\frac{\varphi_{i}-\varphi_{i}^{-}}{\Delta_{i} / 2} x_{i}, \quad b_{2}=\varphi_{i}-\frac{\varphi_{i}^{+}-\varphi_{i}}{\Delta_{i} / 2} x_{i}
$$

By using Eq. (B-12) in Eq. (B-10) one obtains: 


$$
\int_{x_{i-1 / 2}}^{x_{i+1 / 2}} \varphi(x) d x=\frac{\Delta_{i}}{4}\left(\frac{\varphi_{i-1}}{4}+\frac{\varphi_{i}}{2}+\frac{\varphi_{i+1}}{4}\right)=\frac{1}{4} \Delta_{i} \varphi^{a v g}
$$

where

$\varphi^{a v g} \equiv \frac{\varphi_{i-1}}{4}+\frac{\varphi_{i}}{2}+\frac{\varphi_{i+1}}{4}$

is the average flux in mesh $\mathrm{i}$. Use of (B-8) and (B-13) in (B-2) leads to:

$$
a_{i-1, i}^{g} \varphi_{g, i-1}+a_{i, i}^{g} \varphi_{g, i}+a_{i, i+1}^{g} \varphi_{g, i+1}=S_{g, i}, \quad i=1, \ldots N
$$

where $\mathrm{N}$ is the total number of meshes and $\mathrm{g}$ a group index. The expressions for the coefficients in Eq. (B-15) for the interior meshes are shown below; in the boundary meshes their form depends on the boundary condition imposed.

$$
\begin{aligned}
& a_{i-1, i}^{g}=-\frac{2 d_{g, i} d_{g, i-1} f_{g, i-1}^{+}}{d_{g, i} f_{g, i-1}^{+}+d_{g, i-1} f_{g, i}^{-}}+\frac{d_{g, i-1} f_{g, i-1}^{+}}{d_{g, i} f_{g, i-1}^{+}+d_{g, i-1} f_{g, i}^{-}} \frac{\Delta_{i}}{4} \sigma_{r g, i} \\
& a_{i, i+1}^{g}=-\frac{2 d_{g, i} d_{g, i+1} f_{g, i+1}^{-}}{d_{g, i} f_{g, i+1}^{-}+d_{g, i+1} f_{g, i}^{+}}+\frac{d_{g, i+1} f_{g, i+1}^{-}}{d_{g, i} f_{g, i+1}^{-}+d_{g, i+1} f_{g, i}^{+}} \frac{\Delta_{i}}{4} \sigma_{r g, i}
\end{aligned}
$$

$$
\begin{aligned}
& a_{i, i}^{g}=\frac{2 d_{g, i} d_{g, i-1} f_{g, i}^{-}}{d_{g, i} f_{g, i-1}^{+}+d_{g, i-1} f_{g, i}^{-}}+\frac{2 d_{g, i} d_{g, i+1} f_{g, i}^{+}}{d_{g, i} f_{g, i+1}^{-}+d_{g, i+1} f_{g, i}^{+}}+\frac{\Delta_{i}}{2} \sigma_{r g, i}+ \\
& \left(\frac{d_{g, i} f_{g, i-1}^{+}}{d_{g, i} f_{g, i-1}^{+}+d_{g, i-1} f_{g, i}^{-}}+\frac{d_{g, i} f_{g, i+1}^{-}}{d_{g, i} f_{g, i+1}^{-}+d_{g, i+1} f_{g, i}^{+}}\right) \frac{\Delta_{i}}{4} \sigma_{r g, i}
\end{aligned}
$$

$$
S_{g, i}=\chi_{g, i}\left\lfloor v \sigma_{f g, i} \varphi_{g, i}^{a v g}+v \sigma_{f g^{\prime}, i} \varphi_{g^{\prime}, i}^{a v g}\right\rfloor+\sigma_{g^{\prime}, i} \varphi_{g^{\prime}, i}^{a v g}
$$

